\title{
2nd Canadian Respiratory Conference: A Breath of Fresh Air
}

\author{
April 23-25, 2009 \\ Toronto, Ontario
}

\author{
2nd Canadian Respiratory Conference: A Breath of Fresh Air. Can \\ Respir J 2010;17(Suppl A):5A-43A
}

The present supplement is a synopsis of presentations from the second Canadian Respiratory Conference, April 23-25, 2009, in Toronto, Ontario. I would like to acknowledge the tremendous amount of work done by Dr Robert Varadi who contacted so many of the authors to bring this summary to you in an abbreviated format, as well as Dr Scott Butcher who provided valuable support. The Journal welcomes your feedback to enable us to plan future conference supplements. The meeting was a great success, with more than 500 attendees.

Once again, a key plus has been the co-location of our affiliated respiratory clinical, academic, teaching and research societies, which greatly added to the strength of the conference. My thanks to the four founding partners (The Canadian Lung Association, The Canadian Thoracic Society, The Canadian Respiratory Health Professionals and the Canadian COPD Alliance) as well as the conference organizing committee, the scientific program committee, the university division directors across the country, all health care professional participants, the organizing staff and our industry partners, for enabling this conference to achieve such success.

The material included from the plenary and concurrent sessions, as well as the poster session abstracts, reflects the depth and breadth of the meeting. Many members of our clinical faculty are internationally recognized for their expertise in respiratory health. They and all others involved in the presentations have given freely of their time and expertise, reflecting their meaningful commitment to the goals of the conference.

For respiratory physicians, this is the only made-in-Canada national academic-clinical respiratory conference; we are indebted to our colleagues from the respiratory societies for making every effort to enable it to reach this level of excellence. Our next meeting will be held in Halifax, Nova Scotia, April 30-May 1, 2010. We look forward to seeing you there.

Roger Goldstein, Chair, Scientific Program Committee (2009)

\section{$2^{\mathrm{e}}$ Congrès canadien sur la santé respiratoire : Une bouffée d'air frais}

Le présent supplément contient un synopsis des présentations au $2^{\mathrm{e}}$ Congrès canadien sur la santé respiratoire, qui avait lieu du 23 au 25 avril 2009, à Toronto, en Ontario. Je tiens à souligner le travail colossal effectué par le docteur Robert Varadi, qui a communiqué avec énormément d'auteurs pour que vous receviez ce sommaire sous forme abrégée, de même que le soutien précieux du docteur Scott Butcher. La Revue sera heureuse de recevoir vos commentaires pour l'aider à planifier les prochains suppléments du congrès. Le congrès a obtenu un franc succès, avec 500 participants.

Encore une fois, la présence conjointe des sociétés affiliées de santé respiratoire clinique, universitaire, d'enseignement et de recherche a contribué énormément au dynamisme du congrès. Je tiens à remercier les quatre associés fondateurs (l'Association pulmonaire canadienne, la Société canadienne de thoracologie, Les Professionnels canadiens en santé respiratoire et L'Alliance canadienne sur la MPOC), de même que le comité organisateur du congrès, le comité du programme scientifique, les directeurs des divisions universitaires du pays, tous les professionnels de la santé participants, le personnel organisateur et les partenaires de l'industrie d'avoir permis au congrès d'obtenir un tel succès.

La documentation provenant des séances plénières et concomitantes et les résumés des séances d'affiches reflètent la profondeur et l'étendue du congrès. Bon nombre des conférenciers cliniques sont réputés sur la scène internationale pour leurs compétences en santé respiratoire. Ces conférenciers et toutes les autres personnes qui ont participé aux présentations ont donné leur temps et leurs compétences gratuitement, démontrant ainsi leur engagement significatif envers les objectifs du congrès.

Pour les médecins en santé respiratoire, il s'agit du seul congrès clinique et universitaire national en santé respiratoire à émerger du Canada. Nous sommes redevables à nos collègues des sociétés de respirologie d'avoir pris toutes les mesures nécessaires pour que le congrès atteigne ce niveau d'excellence. Le prochain congrès aura lieu à Halifax, en Nouvelle-Écosse, les 30 avril et $1^{\text {er }}$ mai 2010 . Nous avons hâte de vous y rencontrer.

Roger Goldstein, Président, Comité scientifique (2009)

\section{Overdiagnosis of asthma in obese and nonobese Canadian adults}

\author{
Shawn Aaron MD \\ Ottawa Health Research Institute, Ottawa, Ontario \\ saaron@ohri.ca
}

\section{BACKGROUND}

It is unclear whether asthma is potentially overdiagnosed in Western countries, particularly among obese subjects who may experience more dyspnea.

\section{METHODS}

A longitudinal study of nonobese (body mass index $20 \mathrm{~kg} / \mathrm{m}^{2}$ to $25 \mathrm{~kg} / \mathrm{m}^{2}$ ) and obese subjects (body mass index $30 \mathrm{~kg} / \mathrm{m}^{2}$ or greater) with physician-diagnosed asthma was conducted (1). Subjects were recruited via random-digit dialing from eight Canadian communities; they were assessed with asthma symptom questionnaires, spirometry and serial bronchial challenge tests while being tapered off asthma medications. A diagnosis of current asthma was excluded in subjects who did not have evidence of acute worsening of asthma symptoms, reversible airflow obstruction or bronchial hyper-responsiveness, despite being weaned off asthma medications. Asthma medications were stopped in those in whom a diagnosis of asthma was excluded and clinical outcomes were assessed.

\section{RESULTS}

Of 540 subjects with physician-diagnosed asthma who entered into the study, 496 (242 obese and 254 nonobese) could be conclusively assessed for a diagnosis of asthma. Obese patients were first diagnosed with asthma at an older age compared with nonobese subjects (27.9 versus 23.5 years, $\mathrm{P}=0.007$ ). Obese subjects who self-identified as having physician-diagnosed asthma were also slightly older than nonobese subjects and were more likely to report wheeze and/or dyspnea within the past 12 months. Obese subjects had a higher prevalence of associated comorbidities including gastroesophageal reflux, diabetes and hypertension. Total Scores and Activity subscores on the Asthma Quality of Life Questionnaire were statistically lower in the obese cohort, but the differences in mean scores did not reach the clinically important threshold of 0.5 .

The diagnosis of asthma was ultimately excluded in $31.8 \%(95 \%$ CI $26.3 \%$ to $37.9 \%$ ) of subjects in the obese group and in $28.7 \%$ (95\% CI $23.5 \%$ to $34.6 \%$ ) of subjects in the nonobese group. Obese subjects were not more likely to be overdiagnosed with asthma. Sixty-six per cent of subjects in whom asthma was excluded did not restart asthma medications or require health care services for asthma symptoms during a 7.5 month follow-up period.

\section{CONCLUSION}

Approximately $30 \%$ of obese and nonobese Canadians with physiciandiagnosed asthma did not have asthma when objectively assessed. 
Asthma is likely overdiagnosed in Canadians; however, obese subjects are not at greater risk of overdiagnosis of asthma compared with nonobese subjects.

ACKNOWLEDGEMENTS: Dr Aaron is supported by funding from the Canadian Institutes of Health Research.

\section{REFERENCES}

1. Aaron SD, Vandemheen KL, Boulet LP, et al. Overdiagnosis of asthma in obese and nonobese adults. CMAJ 2008;179:1121-31.

\section{Understanding the possible inflammatory pathophysiology of the fall asthma epidemic}

Darryl J Adamko MD FRCPC, Ramses Illaraza PhD, Yingqi Wu

Pediatric Pulmonology, Pulmonary Research Group,

University of Alberta, Edmonton, Alberta dadamko@ualberta.ca

A sthma exacerbation is a life-threatening event in which a person cannot breathe (1). Common cold viruses are the leading cause of asthma exacerbation $(2,3)$. While most healthy adults are exposed to the same common viruses each year and have relatively mild symptoms, many asthma patients react with decreased lung function and severe shortness of breath. Why asthma patients respond so poorly to common colds is unclear. Understanding how airway virus infections can trigger such severe attacks in patients with asthma is an important but poorly understood area.

Prevention of asthma exacerbation has largely relied on inhaled corticosteroid therapy $(4,5)$. While effective in most patients, the cellular target for inhaled corticosteroid therapy in the prevention of virus-induced exacerbations remains unclear. Being atopic is the major risk factor for hospitalization during virus infection (6,7). Experimental rhinovirus (RV) infection increases the recruitment of eosinophils to the airways after antigen challenge (8) and causes increased airway reactivity compared with nonallergic individuals (9). After intranasal infection with RV, biopsies of the lower airways of asthmatic adults contain increased levels of eosinophils that persist even into convalescence (10). During naturally acquired viral infection, children with asthma show significant increases in eosinophil major basic protein (MBP) in their nasal secretions (11). While experimental RV infection of the nose causes lower airway eosinophilia and airway hyper-reactivity in atopic asthmatics, it causes only mild lower airway narrowing and neutrophilia in nonatopic healthy subjects (12). In patients with asthma, the presence of airway eosinophils and their release products during periods of exacerbations is established (13-16). Patients with asthma have a baseline level of eosinophils in the airways before virus infection. Unlike neutrophils, the presence of eosinophil activity in the airways during virus-induced asthma exacerbation becomes a unique feature, which could explain why asthma patients do so poorly. Whether eosinophils are responsible for the asthma attacks and how they could be activated is unknown. Our laboratory believes that eosinophils are key effector cells that are activated by viruses to induce airway damage. The overall objective of our laboratory has been to determine the mechanisms by which airway viruses induce eosinophils to release their mediators both in vitro and in vivo.

There are major differences in the frequency of association between different airway viruses and the induction of asthma exacerbation. RV is by far most common (2). Whether this is due to intrinsic properties of RV and/or the frequency with which RV induces a host response is unknown. Given its importance, our laboratory focuses on RV compared with another airway virus, respiratory syncytial virus. We have published that eosinophils are activated by airway viruses in vitro, but only if the eosinophils are incubated with CD4+ T cells proliferating in response to antigen presenting cells (dendritic cells) (17). There remain many important questions for this model. We are determining whether there are differences in the immune responses induced by RV compared with RSV because these differences could affect their ability to induce eosinophil mediator release and asthma attacks. We are investigating the factors created by virus-stimulated $\mathrm{T}$ cells and/or dendritic cells which induce eosinophil mediator release.

Finally, the question remains whether this in vitro model reflects the in vivo experience. Current animal models of allergy and virus infection use animals that are naïve to the virus (ie, without immune memory). This does not reflect the human experience, where most people have immune memory to most common cold viruses. Our in vitro data suggest that viruses induce eosinophil activation through CD4+ memory T cells. We believe that if a sensitized and challenged animal with immune memory to a virus is subjected to the virus antigen a second time, this could trigger a CD4 memory $\mathrm{T}$ cell response leading to eosinophil activation and airway dysfunction. Understanding the allergic response to common colds is a critical area of lung research. The data will define differences at the cellular level, leading to better directed therapy and prevention of this serious clinical entity.

ACKNOWLEDGEMENTS: This work is supported by funding from the Canadian Institutes of Health Research and Merck-Frosst Canada.

\section{REFERENCES}

1. Murray JF, Nadel JA (eds). Textbook of Respiratory Medicine, 3rd edn. Philadelphia: WB Saunders Co, 2000.

2. Johnston SL, Pattemore PK, Sanderson G, et al. Community study of role of viral infections in exacerbations of asthma in 9-11 year old children. BMJ 1995;310:1225-9.

3. Nicholson KG, Kent J, Ireland DC. Respiratory viruses and exacerbations of asthma in adults. BMJ 1993;307:982-6.

4. Barnes PJ. Efficacy of inhaled corticosteroids in asthma. J Allergy Clin Immunol 1998;102:531-8.

5. Barnes PJ, Pedersen S. Efficacy and safety of inhaled corticosteroids in asthma. Report of a workshop held in Eze, France, October 1992. Am Rev Respir Dis 1993;148:S1-26.

6. Heymann PW, Carper HT, Murphy DD, et al. Viral infections in relation to age, atopy, and season of admission among children hospitalized for wheezing. J Allergy Clin Immunol 2004;114:239-47.

7. Korppi M, Kotaniemi-Syrjanen A, Waris M, Vainionpaa R, Reijonen TM. Rhinovirus-associated wheezing in infancy: Comparison with respiratory syncytial virus bronchiolitis. Pediatr Infect Dis J 2004;23:995-9.

8. Calhoun WJ, Dick EC, Schwartz LB, Busse WW. A common cold virus, rhinovirus 16 , potentiates airway inflammation after segmental antigen bronchoprovocation in allergic subjects. J Clin Invest 1994;94:2200-8.

9. Grunberg K, Smits HH, Timmers MC, et al. Experimental rhinovirus 16 infection. Effects on cell differentials and soluble markers in sputum in asthmatic subjects. Am J Respir Crit Care Med 1997;156:609-16.

10. Fraenkel DJ, Bardin PG, Sanderson G, Lampe F, Johnston SL, Holgate ST. Lower airways inflammation during rhinovirus colds in normal and in asthmatic subjects. Am J Respir Crit Care Med. 1995; 151:879-86.

11. Teran LM, Seminario MC, Shute JK, et al. RANTES, macrophageinhibitory protein 1alpha, and the eosinophil product major basic protein are released into upper respiratory secretions during virusinduced asthma exacerbations in children. J Infect Dis 1999;179:677-81.

12. de Kluijver J, Grunberg K, Sont JK, et al. Rhinovirus infection in nonasthmatic subjects: Effects on intrapulmonary airways. Eur Respir J 2002;20:274-9.

13. Frigas E, Gleich GJ. The eosinophil and the pathophysiology of asthma. J Allergy Clin Immunol 1986;77:527-37.

14. Bousquet J, Chanez P, Lacoste JY, et al. Eosinophilic inflammation in asthma. N Engl J Med 1990;323:1033-9.

15. Kim CK, Kim SW, Park CS, Kim BI, Kang H, Koh YY. Bronchoalveolar lavage cytokine profiles in acute asthma and acute bronchiolitis. J Allergy Clin Immunol 2003;112:64-71.

16. Gibson PG, Dolovich J, Denburg JA, Girgis-Gabardo A, Hargreave FE. Sputum cell counts in airway disease: A useful sampling technique. Agents Actions Suppl 1990;30:161-72.

17. Davoine F, Cao M, Wu Y, et al. Virus-induced eosinophil mediator release requires antigen-presenting and CD4+ T cells. J Allergy Clin Immunol 2008; 22:69-77, e1-2 


\section{Complicated parapneumonic effusions in children}

\author{
Mark Anselmo MD \\ Department of Respiratory Medicine, Montreal Children's Hospital, \\ McGill University, Montreal, Quebec \\ mark.anselmo@muhc.mcgill.ca
}

A lthough there has been a trend downward in the number of cases of pneumonia in children needing hospitalization in parts of Canada, there has been an increase in the percentage of complicated pleural effusions in children, especially the younger ones $(1,2)$. While mortality in Canada is nonexistent for this problem, controversy exists as to the best care pathway for children with complicated parapneumonic effusions. Presently, we are faced with many options. Primary medical interventions include intravenous antibiotics alone, closed chest-tube drainage (CTD) and closed chest-tube drainage with intrapleural fibrinolytic therapy (IFT). Primary operative interventions include open thoracotomy (OT) and video-assisted thoracoscopic surgery (VATS). Until recently, there had been much controversy as to which interventional approach is superior in children due to many factors. First, there have been no large randomized controlled trials (RCTs) of one therapy against another in children. Second, small studies had not demonstrated a survival difference between the different approaches, and all approaches seem to achieve the same goals, resolution of symptoms and return to normal function. Third, the approach to many disorders seen in both adults and children tend to rely on patterns of practice established for adult patients, and this has held true for pediatric parapneumonic effusions. Initial expert panels such as the 2003 expert opinion on complicated parapneumonic effusions indicated that VATS was the definitive treatment for effusions in adults (3).

This opinion was echoed in an early meta-analysis of pediatric empyema. Avansino et al (4) systematically reviewed publications of primary operative approach (VATS/OT) versus medical therapy (CTD/IFT). While declaring operative therapy superior, the review acknowledged that the included studies were quite dissimilar and that no well-designed RCTs were available, diminishing the impact of this systematic review. A cohort review by $\mathrm{Li}$ and Gates (5) examined a large number of patients retrospectively and found primary operative therapy to be superior to medical therapy in terms of length of stay (LOS). However, on subgroup analysis in patients with empyema, there was no statistically significant difference between those treated with VATS versus IFT.

Sonnappa et al (6) performed the first RCT of VATS versus IFT in children. This important study, although small, found no difference between the two approaches, save cost. In the United States, Kurt et al (7) also performed a RCT comparing VATS and CTD. This study allowed fibrinolytics, but only after a $24 \mathrm{~h}$ persistence of effusion despite CTD. Kurt et al found VATS superior; however, the results did not compare primary IFT and VATS. Most recently, St Peter et al (8) performed a small RCT comparing primary VATS versus OT, and similar to the Sonnappa et al study, found no difference in the two approaches, except in cost (Table 1).

Table 1: Treatment options in pediatric parapneumonic effusions

\begin{tabular}{|c|c|c|c|}
\hline Study & Type of study & Results & Comments \\
\hline $\begin{array}{r}\text { Avansino } \\
\text { et al (4) }\end{array}$ & Meta-analysis & $\begin{array}{l}\text { Primary operative approach } \\
\text { (VATS/OT) lowered mortal- } \\
\text { ity, need for reintervention, } \\
\text { LOS, duration of chest tube } \\
\text { and antibiotics versus pri- } \\
\text { mary medical therapy }\end{array}$ & $\begin{array}{l}\text { Meta-analysis of } \\
\text { small studies; } \\
\text { Mortality only } \\
\text { seen years ago; } \\
\text { IFT not well } \\
\text { represented }\end{array}$ \\
\hline
\end{tabular}

Continued in next column
Table 1 (continued): Treatment options in pediatric parapneumonic effusions

\begin{tabular}{|c|c|c|c|}
\hline Study & Type of study & Results & Comments \\
\hline $\begin{array}{l}\text { Li and } \\
\text { Gates (5) }\end{array}$ & $\begin{array}{l}\text { Retrospective } \\
\text { cohort } \\
\text { review }\end{array}$ & $\begin{array}{l}\text { Primary operative approach } \\
\text { lowered LOS and cost and } \\
\text { risk of transfer }\end{array}$ & $\begin{array}{l}\text { Significant in } \\
\text { terms of OT/ } \\
\text { VATS versus } \\
\text { CTD; IFT vs } \\
\text { VATS/OT trend } \\
\text { toward VATS }\end{array}$ \\
\hline $\begin{array}{l}\text { Kurt et al } \\
\text { (7) }\end{array}$ & RCT & $\begin{array}{l}\text { Primary VATS lowered LOS, } \\
\text { procedure number, and } \\
\text { days of tube drainage } \\
\text { versus CTD }\end{array}$ & $\begin{array}{l}\text { IFT only used } \\
\text { after } 24 \mathrm{~h} ; \text { small } \\
\text { study size }\end{array}$ \\
\hline $\begin{array}{l}\text { Sonnappa } \\
\text { et al (6) }\end{array}$ & $\mathrm{RCT}$ & $\begin{array}{l}\text { No difference between VATS } \\
\text { and IFT in terms of LOS, } \\
\text { days of CTD and procedure } \\
\text { number. IFT less expensive }\end{array}$ & $\begin{array}{l}\text { First VATS versus } \\
\text { IFT RCT in } \\
\text { children }\end{array}$ \\
\hline $\begin{array}{l}\text { St Peter } \\
\text { et al (8) }\end{array}$ & RCT & $\begin{array}{l}\text { No difference between VATS } \\
\text { and IFT in terms of LOS, } \\
\text { febrile days and oxygen need }\end{array}$ & $\begin{array}{l}\text { Smaller study } \\
\text { than Sonnappa } \\
\text { et al }\end{array}$ \\
\hline
\end{tabular}

CTD Chest-tube drainage; IFT Intrapleural fibrinolytic therapy; LOS Length of stay; OT Open thoracotomy; RCT Randomized controlled trial; VATS Videoassisted thoracoscopic surgery; vs Versus

After initial retrospective studies and small nonrandomized trials seemed to point toward VATS as being the primary choice for treatment of empyema in children, the most recent RCTs directly comparing IFT and VATS have only found VATS to be more costly, but no more effective. Currently, in cases of pediatric empyema, initial treatment with IFT seems reasonable and appropriate. Caveats must be kept in mind. First, a thorough initial assessment with proper history, examination, imaging and, if needed, diagnostic thoracentesis are necessary to establish the diagnosis before intervention. Second, in certain patients, VATS may be a reasonable initial choice. Finally, there are very little data regarding the third medical option - antibiotics alone without intervention - and we are presently left with patterns of practice from our adult colleagues suggesting that intervention in these children is necessary.

\section{REFERENCES}

1. De WP, Robin E, Fortin E, Thibeault R, Ouakki M, Douville-Fradet M. Pneumonia after implementation of the pneumococcal conjugate vaccine program in the province of Quebec, Canada. Pediatr Infect Dis J 2008;27:963-8.

2. Langley JM, Kellner JD, Solomon N, et al. Empyema associated with community-acquired pneumonia: A Pediatric Investigator's Collaborative Network on Infections in Canada (PICNIC) study. BMC Infect Dis 2008;8:129.

3. Colice GL, Curtis A, Deslauriers J, et al. Medical and surgical treatment of parapneumonic effusions: An evidence-based guideline. Chest 2000;118:1158-71.

4. Avansino JR, Goldman B, Sawin RS, Flum DR. Primary operative versus nonoperative therapy for pediatric empyema: A meta-analysis. Pediatrics 2005;115:1652-9.

5. Li ST, Gates RL. Primary operative management for pediatric empyema: Decreases in hospital length of stay and charges in a national sample. Arch Pediatr Adolesc Med 2008;162:44-8.

6. Sonnappa S, Cohen G, Owens CM, et al. Comparison of urokinase and video-assisted thoracoscopic surgery for treatment of childhood empyema. Am J Respir Crit Care Med 2006;174:221-7.

7. Kurt BA, Winterhalter KM, Connors RH, Betz BW, Winters JW. Therapy of parapneumonic effusions in children: Video-assisted thoracoscopic surgery versus conventional thoracostomy drainage. Pediatrics 2006;118:e547-e553.

8. St Peter SD, Tsao K, Harrison C, et al. Thoracoscopic decortication vs tube thoracostomy with fibrinolysis for empyema in children: A prospective, randomized trial. J Pediatr Surg 2009;44:106-11. 


\section{Molecular mechanisms regulating ICU- acquired muscle dysfunction}

\author{
Jane Batt MD PhD \\ Division of Respirology, University of Toronto, Toronto, Ontario \\ Jane.Batt@utoronto.ca
}

$\mathrm{T}^{\mathrm{s}}$ he molecular mechanisms underlying the development of intensive care unit (ICU)-acquired muscle dysfunction are being delineated through studies on rodent models of disease and humans. This presentation highlights three key phenomena now recognized to underpin the development of acute and persistent muscle dysfunction in the ICU survivor.

Skeletal muscle atrophy is a well-recognized phenomenon that occurs in multiple disease states including ICU-acquired muscle dysfunction. Loss of skeletal muscle mass results from an imbalance between protein synthesis and degradation, with increased muscle proteolysis relative to protein synthesis. Degradation of muscle protein is mediated via several intracellular signalling networks, but ubiquitin-dependent proteolysis is the predominant mechanism responsible for the development of muscle atrophy. Protein ubiquitination is a process whereby proteins to be degraded are tagged with chains of ubiquitin moieties, which serve as recognition markers, targeting proteins for cleavage by the $26 \mathrm{~S}$ proteasome. Ubiquitin ligases are the critical enzymes that both link ubiquitin moieties to the target protein and confer specificity to the system by interacting directly with the target protein through welldefined protein-protein interaction domains. The ubiquitin ligases atrogin-1 and MuRF1 are key regulators of muscle atrophy.

Atrogin-1 and MuRF1 are increased in the muscle of multiple rodent models of skeletal muscle atrophy including the steroiddenervation (SD) and paralysis-ventilation models of ICU-acquired muscle dysfunction. Atrogin-1 and MuRF1 knockout mice are partially protected from skeletal muscle atrophy. Recently, we have identified a third ubiquitin ligase, Nedd4, that also appears to induce the development of muscle atrophy. It has been recently recognized that there is reciprocal signalling between pathways mediating muscle hypertrophy and atrophy, via regulation of expression of atrogin-1 and MuRF1, reiterating the important role these ligases play in the loss of muscle mass. Activation of the IGF1 receptor results in activation of $\mathrm{AKT}$ and subsequent downstream signalling, which induces protein synthesis/muscle hypertrophy and simultaneously inhibits transcription of atrogin-1 and MuRF1, thus shutting down muscle proteolysis.

Ubiquitin proteasome-mediated proteolysis is relevant to human disease. Increased $26 \mathrm{~S}$ proteasome activity and increased atrogin-1, MuRF1 expression are evident in the atrophying skeletal muscle of individuals with diabetes mellitus, uremia, sepsis and chronic obstructive pulmonary disease. We have identified increased expression of Nedd4 in the atrophied muscle of chronic obstructive pulmonary disease patients. Increased $26 \mathrm{~S}$ proteasome activity is evident in the muscle of individuals with ICU-acquired muscle dysfunction. The expression of MuRF-1 and atrogin-1, beyond the context of gene expression array analysis, which requires validation, has not yet been assessed in ICU patients.

What is the relevance clinically? Currently, there are no drugs that inhibit specific ubiquitin ligases. However, a 26S proteasome inhibitor, bortezomib, has recently become available and approved for the treatment of some cancers. In rodent models of denervation-induced, and congestive heart failure- or burn-associated skeletal muscle atrophy, bortezomib reduced the loss of muscle mass by a minimum of $50 \%$. Bortezomib has not been assessed in rodent models of ICU-acquired muscle dysfunction, but this drug, and others like it, hold potential for treatment of this condition.

Muscle membrane inexcitability is a second phenomenon that contributes to the development of ICU-acquired muscle dysfunction. Investigations, conducted predominantly in the SD rodent model, reveal a 'sodium channelopathy' that leads to the loss of muscle excitability. There is an approximately twofold decrease in the density of sodium channels in SD muscle compared with control, which diminishes muscle excitability by reducing the number of sodium channels available to generate an action potential. The resting membrane potential of SD muscle is more depolarized than muscle from control rats. Depolarization of the resting membrane potential inactivates sodium channels so that they are unable to open and participate in generating muscle action potentials. Modulation of the voltage dependence of channel activity is also evident in SD muscle such that the sodium channels activate and inactivate at hyperpolarized membrane potentials in SD muscle. This alteration in sodium channel function is the primary failure that results in membrane inexcitability in the SD muscle. Ongoing investigation is necessary to determine whether the alterations in sodium channel function are relevant to the patient with ICU-acquired muscle dysfunction.

Hyperglycemia has been consistently associated with ICU-acquired muscle dysfunction, and normalization of blood sugars achieved with intensive insulin treatment is the only intervention shown to date to decrease neuromuscular dysfunction. The molecular mechanisms underlying this observation remain poorly understood. Current consensus is that hyperglycemia induces, in part, muscle mitochondrial dysfunction. Mitochondria are the main ATP-generating organelles, and it is speculated that a lower muscle mitochondrial content, and thus cellular energy status, results in increased muscle fatigability. Treatment with insulin is effective because of the normalization of 'toxic' glucose levels. In addition, in rodent models, a neuroprotective effect is seen and insulin increases muscle mass by inhibiting atrogin-1/ MuRF1 expression and muscle proteolysis, and increases muscle protein synthesis. These effects of insulin in patients with ICU-acquired muscle dysfunction have not been directly assessed.

\section{REFERENCES}

1. Khan J, Harrison TB, Rich MM. Mechanisms of neuromuscular dysfunction in critical illness. Crit Care Clin 2008;24:165-77.

2. Herridge MS, Batt J, Hopkins RO. The pathophysiology of long term neuromuscular and cognitive outcomes following critical illness. Crit Care Clin 2008;24:179-99.

3. Plant PJ, Correa J, Goldenberg N, Bain J, Batt J. The inositol phosphatase MTMR4 is a novel target of the ubiquitin ligase Nedd4. Biochem J 2009;419:57-63.

4. Plant PJ, Brooks D, Faughnan M, et al. Cellular markers of muscle atrophy in chronic obstructive pulmonary disease (COPD). Am J Resp Cell Molec Bio 2009 Jun 11. [Epub ahead of print].

5. van den Berghe $G$, Wouters $P$, Weekers $F$, et al. Intensive insulin therapy in critically ill patients. N Engl J Med 2001;345:1359-67.

6. Lang $\mathrm{CH}$, Huber D, Frost RA. Burn-induced increase in atrogin-1 and MuRF-1 in skeletal muscle is glucocorticoid independent but downregulated by IGF-I. Am J Physiol Regul Integr Comp Physiol 2007;292:R328-R336.

7. Beehler BC, Sleph PG, Benmassaoud L, Grover GJ. Reduction of skeletal muscle atrophy by a proteasome inhibitor in a rat model of denervation. Exp Biol Med 2006;231:335-41.

\section{Using a chronic disease management model to improve patient care outcomes}

\author{
Donna Bleakney \\ Chronic Disease Management and Renal Services, Saskatoon Health \\ Region, Saskatoon, Saskatchewan \\ donna.bleakney@saskatoonhealthregion.ca
}

The disease burden of chronic obstructive pulmonary disease 1 (COPD) and the impact on health care delivery is substantive and growing. The literature supports the concept that a comprehensive, interprofessional, patient-centred approach to managing chronic diseases is effective. Saskatoon Health Region (SHR) has established a COPD program (LiveWell COPD Program) that has proven to keep people out of the hospital and out of the intensive care unit, reduce 
re-admission rates, and manage costs effectively. The components of the program: exercise, disease-specific management and self-management are integral to establishing positive outcomes for the patient with COPD.

The LiveWell COPD program was established using a chronic disease management (CDM) model for care delivery. SHR adopted Wagner's Chronic Illness Care model as the CDM model to follow (1). The $\mathrm{BC}$ expanded chronic care model is an enhancement of the Chronic Illness Care model and is currently used in the SHR CDM programs (2). The global burden of chronic disease is significant because patients with chronic diseases account for a large proportion of the health care costs (more than 60\%). Using a chronic disease management approach helps to target the population who traditionally have several admissions to the health care system each year, with many admissions having predictable and preventable complications. Scientific research has demonstrated that targeting COPD patients with optimal care leads to less shortness of breath, increased exercise capacity, better quality of life and reduced health care use (3).

\section{PROGRAM DESIGN}

An inter-professional team, including many community and health region partners, was developed to optimize the care provided to patients with a primary diagnosis of COPD. The program is centrally coordinated, with both urban and rural delivery. The LiveWell COPD program was designed from published, evidence-based research and the experience of others. Interventions used are guideline recommended or evidence-based. The program design and delivery is applicable to and appropriate for most chronic medical conditions - the greatest benefit would be realized for diseases with the highest burden. The program is designed with three pillars of care: exercise, diseasespecific management and self-management (Figure 1).

\begin{tabular}{|c|c|c|}
\hline $\begin{array}{l}\text { Group Exercise and } \\
\text { Rehabilitation }\end{array}$ & $\begin{array}{c}\text { Disease-Specific } \\
\text { Management }\end{array}$ & $\begin{array}{c}\text { Patient Self- } \\
\text { Management Skills }\end{array}$ \\
\hline $\begin{array}{l}\text { Community-based } \\
\text { exercise and } \\
\text { rehabilitation } \\
\text { programming } \\
\text { - Group education } \\
\text { - Group and social } \\
\text { support }\end{array}$ & $\begin{array}{l}\text { Inter-professional } \\
\text { team working } \\
\text { closely with the } \\
\text { patient, family, } \\
\text { family physicians } \\
\text { and specialists } \\
\text { Evidence-based } \\
\text { optimal care } \\
\text { delivery }\end{array}$ & $\begin{array}{l}\text { - Individualized plan } \\
\text { of action } \\
\text { - Peer-led support } \\
\text { "LiveWell with } \\
\text { Chronic } \\
\text { Conditions" } \\
\text { - Enhanced self- } \\
\text { management skills }\end{array}$ \\
\hline
\end{tabular}

Figure 1) The LiveWell Chronic Disease Management Program

\section{PROGRAM DELIVERY}

Patients are referred to the LiveWell COPD program through inpatient identification during hospitalization or through outside referrals (eg, patient, physician, health care professional). All patients are assessed for eligibility in the program by using a standard eligibility criteria assessment form. The LiveWell COPD nurse clinician is the case manager and facilitates an appropriate plan of action in collaboration with the patient and their family physician. The LiveWell COPD health professional team are certified respiratory educators and have completed the Lung Association COPDTrec course. Patients receive education about their chronic disease as assessed in their individualized plan of action. The benefits of self-management and exercise for COPD patients are innumerable and well documented. Effective selfmanagement skills are discussed, and patients are also referred to their local LiveWell with Chronic Conditions program, peer-led classes based on the Stanford self-management program. All patients in the LiveWell COPD program are referred to a pulmonary rehabilitation program. Patients receive regular follow-up telephone calls. Program and patient outcomes are evaluated on a regular basis.

\section{OUTCOMES}

SHR LiveWell COPD program outcomes are evaluated on a regular basis (4). Significant improvements have been demonstrated by using a CDM approach for COPD management. Since 2005, system-wide COPD hospital readmission rates have decreased by $23 \%$, hospital days by $22 \%$ and ICU days by $44 \%$. Average length of stay days decreased from 11.0 to 7.9 days for patients with COPD.

Outcome measurement was also analyzed on the specific patients attending the comprehensive LiveWell COPD program. After one year of enrollment in the program, patient readmissions were reduced by $71 \%$, hospital days by $62 \%$ and emergency department visits by $44 \%$. After three years of enrollment in the comprehensive program, COPD readmissions were reduced by $64 \%$, hospital days by $29 \%$ and $\mathrm{ED}$ visits by $30 \%$.

Patient quality of life has also been measured, using St George's Respiratory Questionnaire. After one year of program enrollment, St George's Respiratory Questionnaire scores were reduced (improved) by an average of 8.3 points ( 52.9 to 44.6 ). Patients also reported that they felt more in control of their chronic disease and were better able to manage their own care.

\section{CONCLUSION}

The SHR LiveWell COPD program outcomes demonstrate that a comprehensive, interprofessional, patient-centred approach to managing chronic diseases is effective. Improved quality of life, reduced exacerbations and hospitalizations and reduced health care costs are possible when patients attend a COPD program that uses a chronic disease management model for care delivery.

\section{REFERENCES}

1. Wagner EH. Chronic disease management: What will it take to improve care for chronic illness? Eff Clin Pract 1998;1:2-4.

2. Barr VJ, Robinson S, Marin-Link B, et al. The expanded Chronic Care Model: An integration of concepts and strategies from population health promotion and the Chronic Care Model. Hosp Q 2003;7:73-82.

3. O'Donnell DE, Aaron S, Bourbeau J, et al. State of the Art Compendium: Canadian Thoracic Society recommendations for management of chronic obstructive pulmonary disease. Can Respir J 2004;11(Suppl B):7B-59B.

4. Strategic Health Information and Planning Services (SHIPS). Saskatoon Health Region, Saskatoon, 2009.

\section{How obesity might predispose to the development of asthma}

Louis-Philippe Boulet MD FCCP FRCPC

Institut universitaire de cardiologie et de pneumologie de Québec, Québec City, Québec

Ipboulet@med.ulaval.ca

$\Delta$ sthma and obesity are two frequently associated health problems A $(1,2)$. Although asthma may promote weight gain through increased sedentary lifestyle and/or systemic corticosteroids usage, this does not explain the association of asthma and obesity. Various mechanisms have been proposed to explain how obesity could promote the development of asthma (3-5) (Table 1). This article summarizes these possible etiological factors.

\section{Table 1: How can obesity influence the development of} asthma?

Influence on lung mechanics/function
Reduced functional residual capacity and tidal volume
Breathing at lower lung volumes
Influence of obesity-associated systemic inflammation
Increased production of:
Proinflammatory cytokines (eg, tumour necrosis factor-alpha, interleukin 6)
Chemokines (eg, eotaxin)
Increased oxidative stress
Increased leptin levels
Reduced adiponectin levels

Continued on next page 


\begin{tabular}{l} 
Table 1 (continued): How can obesity influence the \\
development of asthma? \\
\hline Increased prevalence of asthma-related comorbid conditions \\
Gastroesophageal reflux \\
Obstructive sleep apnea \\
Diabetes, dyslipidemia, hypertension, etc \\
Common developmental/etiological factors \\
Common genetic/in utero developmental influences \\
Dietary factors \\
Environmental influences/lifestyle/habits
\end{tabular}

\section{MECHANICAL CHANGES}

Obesity induces numerous changes in lung mechanics and function (6). The most obvious change is a reduction of the expiratory reserve volume, the elastic properties of the chest wall being modified. Obese subjects breathe at lower lung volumes, near the airways closing volume. A restrictive pattern with a mild reduction in total lung capacity is occasionally observed, but only in some morbidly obese subjects. Furthermore, obese subjects show an altered pattern of breathing, with higher breathing frequencies and reduced tidal volumes, even when exercising. Obesity is associated with a reduction in respiratory system compliance, increased work of breathing and increased exertional dyspnea $(6,7)$.

Breathing at low lung volumes may unload airway smooth muscle. Furthermore, a reduced airway distension during breathing can increase airway responsiveness, possibly from a change in airway smooth muscle plasticity (increased stiffness). Our observation that obese nonasthmatic subjects have lost the protective effect of a deep inspiration, as can be observed in nonobese nonasthmatic subjects, supports this hypothesis (8). However other mechanisms related to small airway closure may prevail to explain this observation, such as an influence of hypoxemia, particularly in the supine position, and airway edema. These changes may promote the development of airway hyperresponsiveness (AHR), although in human studies, increases in the prevalence of AHR in obese subjects have not been universally reported $(9,10)$.

\section{SYSTEMIC/AIRWAY INFLAMMATION}

Adipocytes may store and release a variety of inflammatory agents, and obesity is considered to be a low-grade systemic inflammatory condition. Increased levels of various inflammatory cytokines and mediators such as tumour necrosis factor-alpha, interleukin-6, eotaxin, vascular endothelial growth factor, monocyte chemotactic protein, and markers of systemic inflammation such as $\mathrm{C}$-reactive protein and serum fibrinogen have been observed in obese subjects $(5,11)$. Furthermore, levels of markers of oxidative stress such as 8-isoprostane, are increased in the blood and the lungs of obese compared with nonobese subjects (12). Furthermore, the proinflammatory hormone leptin is found in increased quantities in obese subjects' serum while the anti-inflammatory hormone adiponectin is lower than in nonobese subjects (5). Our group (13) and Todd et al (14) have, however, not found a significant difference in induced sputum differential cell counts in the obese compared to non-obese subjects globally although we and Van Veen et al (15) have found an inverse relationship between body mass index and sputum eosinophils.

\section{ROLE OF COMORBIDITIES}

Comorbid conditions such as gastroesophageal reflux, obstructive sleep apnea, diabetes, dyslipidemia and cardiovascular diseases are more prevalent in the obese and may possibly influence asthma expression, although a possible role in the development of the disease is less obvious (5). While obesity could theoretically be a risk factor for atopy, such a relationship has not been found convincingly.

\section{DEVELOPMENTAL/GENETIC INFLUENCES AND OTHER FACTORS}

The genes involved with asthma and obesity are closely related and it is possible that both conditions share a similar genetic predisposition $(5,16)$. Finally, it is possible that common environmental, dietary or health-style influences act as common factors for both asthma and obesity, but this requires further evaluation.

\section{ASTHMA CONTROL AND RESPONSE TO ASTHMA THERAPY}

Asthma is usually more difficult to control in the obese patient (17). The first reason could be that it is not asthma and, as in the nonobese, respiratory symptoms may be due to another condition. In the case of obesity, weight gain can itself induce respiratory symptoms, but an increase in airway obstruction in the obese remains to be documented. Therefore, confirmation by objective measures showing reversible airway obstruction or AHR is absolutely needed. In a recent study, Aaron et al (18) showed that close to one-third of patients with or without obesity have an incorrect diagnosis of asthma.

Otherwise, poorer asthma control may be related to obesity-related comorbid conditions, or to an altered response to treatment. We and others have shown that obesity is associated with a reduced response to asthma medications such as inhaled corticosteroids, as well as, particularly in presence of morbid obesity, to the association of an inhaled corticosteroid and a long-acting bronchodilator $(19,20)$. Leukotriene receptor antagonists may be less affected by obesity but this remains to be confirmed (20).

\section{EFFECTS OF WEIGHT LOSS ON ASTHMA}

In the obese subject, even a modest weight loss is associated with a significant improvement of asthma and reduced medication needs (21). Weight reduction from diet and exercise can improve asthma symptoms, reduce peak expiratory flow variation and improve spirometric values, while bariatric surgery in the most severe forms of obesity brings the most remarkable results.

\section{CONCLUSIONS - FUTURE RESEARCH}

The recognition of the marked influences of obesity on asthma has led to an increasing number of studies on the relationships between these two entities. It has become obvious that obesity makes asthma more difficult to control, but how obesity contributes to the development of asthma remains to be studied. In most patients, this influence is probably multifactorial. Asthma in the obese is increasingly recognized as a specific phenotype but the clinical implications with respect to asthma management should be explored. Furthermore, the pattern of body fat distribution and its influence on airway function and responsiveness should be studied. Asthma diagnosis and control require objective measures of airway function in the obese particularly, and the effects of therapy should be carefully examined. In these patients, weight loss should be a priority and the patients should be supported in their efforts to achieve to their ideal weight.

\section{REFERENCES}

1. Boulet LP, DesCormiers A. Obesity and asthma: A Canadian perspective. Can Resp J 2007;14:217-20.

2. Beuther DA, Sutherland ER. Overweight, obesity, and incident asthma: A meta-analysis of prospective epidemiologic studies. Am J Respir Crit Care Med 2007;175:661-6.

3. Schaub B, von ME. Obesity and asthma, what are the links? Curr Opin Allergy Clin Immunol 2005;5:185-93.

4. Weiss ST, Shore S. Obesity and asthma: Directions for research. Am J Respir Crit Care Med 2004;169:963-8.

5. Shore AS. Obesity and asthma: Possible mechanisms. J Allergy Clin Immunol 2008;121:1087-93.

6. Parameswaran K, Todd DC, Soth M. Altered respiratory physiology in obesity. Can Respir J 2006;13:203-10.

7. Rubinstein I, Zamel N, DuBarry L, Hoffstein V. Airflow limitation in morbidly obese, nonsmoking men. Ann Intern Med 1990;112:828-32.

8. Boulet LP, Turcotte H, Boulet G, Simard B, Robichaud P. Deep inspiration avoidance and airway response to methacholine: Influence of body mass index. Can Respir J 2005;12:371-6.

9. Chinn S, Jarvis D, Burney P. Relation of bronchial responsiveness to body mass index in the ECRHS. European Community Respiratory Health Survey. Thorax 2002:57:1028-33.

10. Schachter LM, Salome CM, Peat JK, Woolcock AJ. Obesity is a risk for asthma and wheeze but not airway hyperresponsiveness. Thorax 2001;56:4-8.

11. Juge-Aubry CE, Henrichot E, Meier CA. Adipose tissue: A regulator of inflammation. Best Pract Res Clin Endocrinol Metab 2005;19:547-66. 
12. Komakula S, Khatri S, Mermis J, et al. Body mass index is associated with reduced exhaled nitric oxide and higher exhaled 8-isoprostanes in asthmatics. Respir Res 2007;8:32.

13. Lessard A, Turcotte H, Cormier Y, Boulet LP. Obesity and asthma: A specific phenotype? Chest 2008;134:317-23.

14. Todd DC, Armstrong S, D'Silva L, Allen CJ, Hargreave FE, Parameswaran K. Effect of obesity on airway inflammation: A crosssectional analysis of body mass index and sputum cell counts. Clin Exp Allergy 2007;37:1049-54.

15. van Veen IH, Ten Brinke A, Sterk PJ, Rabe KF, Bel EH. Airway inflammation in obese and nonobese patients with difficult-to-treat asthma. Allergy 2008;63:570-4.

16. Hallstrand TS, Fischer ME, Wurfel MM, Afari N, Buchwald D, Goldberg J. Genetic pleiotropy between asthma and obesity in a community-based sample of twins. J Allergy Clin Immunol 2005;116:1235-41.

17. Saint-Pierre P, Bourdin A, Chanez P, Daures JP, Godard P. Are overweight asthmatics more difficult to control? Allergy 2006;61:79-84.

18. Aaron SD, Vandemheen KL, Boulet LP, et al; Canadian Respiratory Clinical Research Consortium. Overdiagnosis of asthma in obese and nonobese adults. CMAJ 2008;179:1121-31.

19. Boulet LP, Franssen E. Influence of obesity on response to fluticasone with or without salmeterol in moderate asthma. Respir Med 2007;101:2240-7.

10. Peters-Golden M, Swern A, Bird SS, Hustad CM, Grant E, Edelman JM. Influence of body mass index on the response to asthma controller agents. Eur Respir J 2006;27:495-503.

21. Eneli IU, Skybo T, Camargo CA Jr. Weight loss and asthma: A systematic review. Thorax 2008;63:671-6.

\section{Fluid redistribution: A unifying hypothesis for sleep apnea and cardiovascular disease}

\author{
T Douglas Bradley MD \\ Toronto Rehabilitation Institute and Toronto General Hospital, \\ Toronto, Ontario \\ douglas.bradley@utoronto.ca
}

$\mathrm{O}^{\mathrm{b}}$ bstructive sleep apnea (OSA) is common and has significant morbidity. OSA is caused by repetitive collapse of the upper airway (UA) during sleep, but the cause of UA collapse is not completely understood. Although obesity is a risk factor for OSA, body weight and neck circumference only account for $30 \%$ of the variability in the frequency of apneas and hypopneas per hour of sleep (apnea-hypopnea index [AHI]) $(1,2)$, and approximately $60 \%$ of patients with OSA in the community are not obese (3). Hence, factors other than obesity must contribute to UA obstruction in such patients. The observation that OSA is more prevalent in patients with edematous states, such as heart failure, than in the general population (4), suggests that fluid retention may increase the risk for OSA.

The upright posture of humans predisposes to dependent fluid accumulation in the legs. This is counteracted by contraction of the calf muscles during walking. However, modern living has increased the number of jobs requiring prolonged sitting, during which absence of contraction of the calf muscles leads to dependent fluid accumulation in the legs. Upon lying down at bedtime, the fluid retained in the legs is redistributed to the upper body (5). Therefore, some of this displaced fluid might reach the neck and peripharyngeal tissues, and predispose to UA obstruction. To test this general hypothesis, we embarked on a series of experiments to examine relationships between rostral fluid displacement from the legs, UA properties and severity of OSA.

In healthy nonobese adults, we displaced fluid from the legs by applying lower body positive pressure via inflatable trousers. This increased neck circumference, reduced UA calibre and increased UA resistance $(6,7)$. We also examined UA collapsibility by determining the critical collapsing pressure in response to application of negative pressure to the UA during wakefulness. Critical collapsing pressure increased during lower body positive pressure in men but not in women $(8,9)$. These findings suggested that the UA of young men becomes more susceptible to collapse in response to rostral fluid distribution than that of young women, and may be one factor accounting for the higher prevalence of OSA in men.
In 23 nonobese healthy men referred for sleep studies, we assessed the changes in leg fluid volume and in neck circumference before and after sleep, and the amount of time spent sitting the day of the sleep study (10). The overnight increase in neck circumference and the AHI correlated strongly with overnight reduction in leg fluid volume $(\mathrm{r}=-0.792, \mathrm{P}<0.001$ and $\mathrm{r}=-0.802, \mathrm{P}<0.001$, respectively). The overnight reduction in leg fluid volume was, in turn, related to the time spent sitting during the day $(r=-0.588, P=0.003)$, suggesting that greater fluid accumulation in the legs during the day led to greater movement of fluid out of the legs at night. Multivariate analysis revealed that the only independent correlates of the AHI were the overnight changes in leg fluid volume and neck circumference which, together, explained $68 \%$ of the variability in the AHI among subjects. These findings suggest that overnight rostral fluid displacement from the legs, related to prolonged sitting, may play a previously unrecognized role in the pathogenesis of OSA in nonobese men.

Out data imply that sedentary living and dependent fluid accumulation could be therapeutic targets for the management of some patients with OSA. Testing this hypothesis will require further studies to determine whether preventing leg fluid accumulation during the day, or rostral fluid shift overnight, reduces severity of OSA.

ACKNOWLEDGEMENTS: Dr Bradley is supported by funding from the Canadian Institutes of Health Research.

\section{REFERENCES}

1. Hoffstein V, Mateika S. Differences in abdominal and neck circumferences in patients with and without obstructive sleep apnoea. Eur Respir J 1992;5:377-81.

2. Dempsey JA, Skatrud JB, Jacques AJ, et al. Anatomic determinants of sleep-disordered breathing across the spectrum of clinical and nonclinical male subjects. Chest 2002;122:840-51.

3. Young T, Shahar E, Nieto FJ, et al; Sleep Heart Health Study Research Group. Predictors of sleep-disordered breathing in community-dwelling adults: The Sleep Heart Health Study. Arch Intern Med 2002;162:893-900.

4. Arzt M, Young T, Finn L, et al. Sleepiness and sleep in patients with both systolic heart failure and obstructive sleep apnea. Arch Intern Med 2006;166:1716-22.

5. Linnarsson D, Tedner B, Eiken O. Effects of gravity on the fluid balance and distribution in man. Physiologist 1985;28:S28-9.

6. Shiota S, Ryan CM, Chiu KL, et al. Alterations in upper airway cross-sectional area in response to lower body positive pressure in healthy subjects. Thorax 2007;62:868-72.

7. Chiu KL, Ryan CM, Shiota S, et al. Fluid shift by lower body positive pressure increases pharyngeal resistance in healthy subjects. Am J Respir Crit Care Med 2006;174:1378-83.

8. Su MC, Chiu KL, Ruttanaumpawan P, et al. Lower body positive pressure increases upper airway collapsibility in healthy subjects. Respir Physiol Neurobiol 2008;161:306-12.

9. Su MC, Chiu KL, Ruttanaumpawan P, et al. Difference in upper airway collapsibility during wakefulness between men and women in response to lower body positive pressure. Clin Sci 2009;116:713-20.

10. Redolfi S, Yumino D, Ruttanaumpawan P, et al. Relationship between overnight rostral fluid displacement and obstructive sleep apnea in non-obese men. Am J Respir Crit Care Med 2009;179:241-6.

\section{Gender and asthma: An evolving understanding of the importance of sex}

\author{
Anna Day MD FRCPC
}

Division of Respirology, University of Toronto, Toronto, Ontario a.day@utoronto.ca

$T_{\mathrm{g}-\mathrm{m}}^{\mathrm{h}}$ here is an increasing body of evidence that suggests there are gender differences in both the prevalence and natural history of asthma. These gender differences are responsible for differences in asthma morbidity and outcome, and may have an impact on outcomes for other airway conditions including smoking-related pulmonary disease. 


\section{NATURAL HISTORY OF ASTHMA}

The overall prevalence of asthma in childhood (16\%) decreases by almost one-half in the adult Canadian population (8.5\%) (1). However, when the data are disaggregated by gender, we find that boys have a significantly higher prevalence of asthma than girls (18\% versus $12 \%$ ). Following adolescence there is a marked decrease in the prevalence of asthma in adult men (7\%) but only a small decrease in adult women $(10 \%)$ and the prevalence of asthma is now greater in women than in men. These data and recent longitudinal studies following children to adulthood suggest that, while most boys outgrow their asthma by the end of their teenage years, women tend to have the onset of their asthma after puberty.

\section{IMPACT OF ASTHMA BY GENDER}

Mortality differences according to gender are small and unlikely to be significant because there are so few asthma-related deaths in Canada (1). However, there are differences in morbidity. Boys are hospitalized for asthma almost twice as often as girls. Adult women visit the emergency room and are hospitalized for asthma twice as often as men and have poorer outcomes in the community, despite better knowledge, greater reported use of inhaled steroids and satisfactory access to physicians (2). This suggests that gender differences in morbidity may be due to biological and environmental differences, rather than psychosocial etiologies.

\section{AIRWAY RESPONSIVENESS AND GENDER}

Increased airway responsiveness (AHR) is a hallmark of asthma and might be expected to parallel the gender differences in the natural history of asthma. However, despite the gender differences in morbidity for asthma in childhood, AHR is similar for asthmatic boys and girls (3). Following puberty, AHR improves only for boys and there is an increasing body of evidence that AHR is more prevalent in adult women than in men (4). In a recent study of athletes, males had close correlation of asthma symptoms, AHR and a diagnosis of asthma but females had twice the symptoms and three times the prevalence of AHR as the diagnosis of asthma (5). This suggests that AHR may not be the only factor in determining asthma morbidity.

\section{BIOLOGICAL FACTORS IMPACTING ASTHMA MORBIDITY}

Gender differences in asthma can be considered to be a result of biological determinants (physiological, immunological and hormonal) and psychosocial differences (environmental, social and psychological). We will address the biological factors in the present paper.

Morphometric and physiological studies of pulmonary structure and function have established the principle of dysanapsis, the variable relationship between airway size and lung size (6). Although males have larger lungs for size throughout life, boys have smaller airways in relation to lung size than girls, which may explain the increased morbidity for boys with asthma. At puberty, girls have proportional growth of airways in relation to parenchyma but boys have a disproportional increase in airway size relative to lung volume. The airways of men are $17 \%$ larger in diameter than the airways of women. The smaller size of women's lungs and airways may contribute to increased breathlessness in women (7).

Immunological gender differences exist for allergy and atopy, and likely have an impact on the natural history of asthma. Boys are more likely than girls to have skin prick reactivity to common allergies, whereas women are more atopic than men. Serum immunoglobulin E is consistently lower in women. There is some suggestion that women with asthma have more immunological conditions and that women may handle inflammation differently than men (8).

Hormonal gender differences have an impact at multiple levels. Variation in hormones related to the menstrual cycle is clearly associated with asthma exacerbations. Some asthmatic women may have abnormalities in sex hormone regulation of the beta-adrenergic system. Other studies suggest that gender can affect the impact of genetic changes of the beta 2 adrenoreceptors (9).

\section{WHY A GENDER APPROACH TO ASTHMA?}

Biological gender differences may make women with or at risk for asthma more susceptible to the impact of environmental exposures including biomass fuels, air pollution, moulds and cigarette smoke, and result in greater asthma morbidity. Biological differences could impact the response to anti-inflammatory medications, particularly corticosteroids and bronchodilators. Increased AHR may result in a worse outcome for women who smoke, and may contribute to the increasing prevalence of chronic obstructive pulmonary disease we are seeing in women. The Lung Health Study demonstrated that women who smoke have a higher rate of AHR than men and that increased AHR is associated with faster decline in lung function for women but not for men (10). Airway size and increased AHR may in some way be related to the increasing incidence of lung cancer we are seeing in women who smoke. The significantly higher morbidity for boys with asthma and adult women with asthma requires investigation and appropriate intervention. It might even help Canada in the 2010 Olympics!

\section{REFERENCES}

1. Public Health Agency of Canada. Asthma facts and figures. <www. phac-aspc.gc.ca/cd-mc/crd-mrc/asthma_figures-asthme_figures-eng. php> (Version current at December 16, 2009).

2. Day A, Ernst P, Glick L, Zimmerman S, Chapman Z. Women and asthma: Lessons from a gender analysis of the asthma in Canada survey. J Asthma 2006;43:169-73.

3. Tantisira KG, Colvin R, Tonascia J, Strunk RC, Weiss ST, Fuhlbrigge AL. Airway responsiveness in mild to moderate childhood asthma: Sex influences on the natural history. Am J Respir Crit Care Med 2008;178:325-31.

4. Manfreda J, Sears MR, Becklake MR, et al. Geographic and gender variability in the prevalence of bronchial responsiveness in Canada. Chest 2004;125:1657-64.

5. Langdeau JB, Day A, Turcotte H, Boulet LP. Gender differences in the prevalence of airway hyperresponsiveness and asthma in athletes. Respir Med 2009;103:401-6.

6. Becklake MR, Kauffmann F. Gender differences in airway behaviour over the human life span. Thorax 1999;54:1119-38.

7. Ofir D, Laveneziana P, Webb KA, Lam YM, O’Donnell DE. Sex differences in the perceived intensity of breathlessness during exercise with advancing age. J Appl Physiol 2008;104:1583-93.

8. Sin DD, Cohen SB, Day A, Coxson H, Paré PD. Understanding the biological differences in susceptibility to chronic obstructive pulmonary disease between men and women. Proc Am Thorac Soc 2007;4:671-4.

9. Stefano Guerra S, Graves PE, Morgan WJ, et al. Relation of $\beta_{2}$-adrenoceptor polymorphisms at codons 16 and 27 to persistence of asthma symptoms after the onset of puberty. Chest 2005;128:609-17.

10. Connett JE, Murray RP, Buist AS, et al, for the Lung Health Study Research Group. Changes in smoking status affect women more than men: Results of the Lung Health Study. Am J Epidemiol 2003;157:973-9.

\section{Improving exercise function in patients with COPD: How do we get nonresponders to respond?}

\author{
Neil D Eves PhD \\ Faculties of Kinesiology and of Medicine, University of Calgary, \\ Calgary, Alberta \\ neves@ucalgary.ca
}

$P$ ulmonary rehabilitation to improve exercise tolerance and quality of life in patients with chronic obstructive pulmonary disease (COPD) is well established (1). However, closer inspection of individual responses to rehabilitation identifies that a number of patients often fail to obtain clinically meaningful improvements in these important outcomes $(2,3)$. Recently, Decramer (2) reported that in response to six months of pulmonary rehabilitation, only $47 \%$ of patients obtained a minimal clinically important improvement in 6 min walk distance of $50 \mathrm{~m}$ after both three and six months; $15 \%$ 
were nonresponders after three months but became responders at six months, while $34 \%$ of patients were still unable to obtain a clinically meaningful improvement in $6 \mathrm{~min}$ walk distance even after six months. These findings highlight the heterogeneous responses to rehabilitation in patients with COPD and clearly identify a subgroup of patients who struggle to benefit from a traditional pulmonary rehabilitation program.

Few studies have addressed why some patients may not respond to pulmonary rehabilitation. Eves et al (4) demonstrated a strong association between improvements in exercise tolerance and the volume $(r=0.71, P<0.001)$ and intensity $(r=0.70, P<0.001)$ of exercise performed by patients during pulmonary rehabilitation. Consequently, any factor that limits a patient's capacity to perform exercise may reduce the benefits that can be obtained from a rehabilitation program. Figure 1 highlights a number of factors that affect exercise tolerance and may influence how a patient responds to rehabilitation. These include the severity of exertional symptoms, respiratory and skeletal muscle dysfunction, impaired cardiovascular function and the presence of comorbidities. Hypoxemia and the severity of systemic and skeletal muscle inflammation may also interfere with the normal adaptive processes in response to exercise. A further consideration is that a number of patients adhere poorly to pulmonary rehabilitation. Smoking status, lack of disease-specific social support, depression and social isolation have all been identified as factors associated with poor exercise adherence (5), and patients dealing with these issues present a unique challenge for rehabilitation programs.

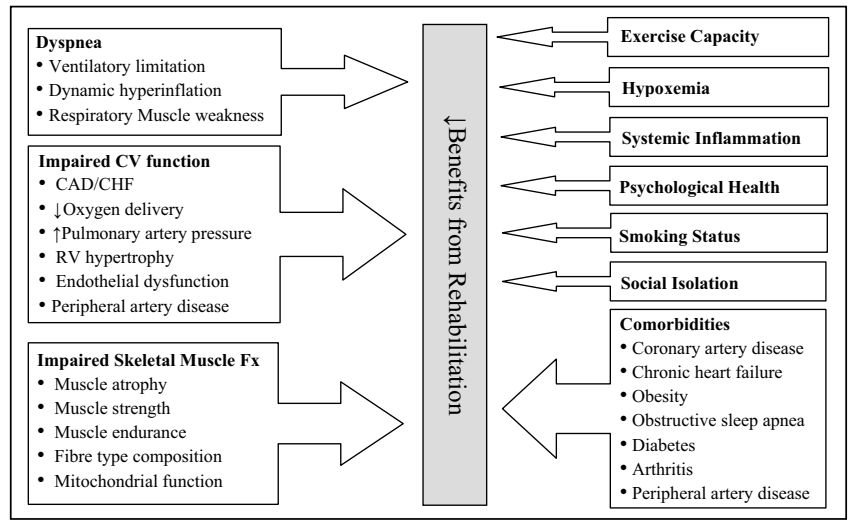

Figure 1) Factors that may reduce the benefits that can be obtained from pulmonary rehabilitation. CAD Coronary artery disease; CHF Congestive heart failure; Fx Function; RV Right ventricular

The type and severity of exercise limitation may be a key factor in determining who responds to rehabilitation. Plankeel et al (6) reported that ventilatory-limited patients achieved smaller increases in peak oxygen consumption $\left(\mathrm{VO}_{2 \text { peak }}\right)$ following four weeks of pulmonary rehabilitation compared with those who demonstrated cardiovascular, mixed (cardiovascular and ventilatory) or no obvious cardiopulmonary limitation. Ventilatory limitation is commonly associated with dynamic hyperinflation, which has been closely linked with dyspnea severity and exercise intolerance in patients with COPD (7). As such, adjunct therapies that can reduce ventilatory limitation and/or respiratory muscle work and alleviate dyspnea may allow ventilatory limited patients to perform more exercise and gain greater benefits from pulmonary rehabilitation. Support for this postulate can be obtained from work performed in our laboratory, where patients were randomly assigned to six weeks of exercise breathing either air or helium-hyperoxia. Helium-hyperoxia attenuates dynamic hyperinflation by reducing ventilatory demand with hyperoxia, while additionally reducing expiratory flow limitation with helium (8). Patients who received helium-hyperoxia were able to exercise at a greater intensity on all days of rehabilitation, which resulted in a greater volume of exercise performed during rehabilitation. Following rehabilitation, those in the helium-hyperoxia group had significantly greater improvements in constant load exercise time (when breathing air) compared with those in the air group. Assessing individual responses in each of these groups, $53 \%$ of patients achieved a minimally clinically important improvement in exercise tolerance (9) with air, compared with $94 \%$ of patients with helium-hyperoxia. These findings highlight that if we can find ways to increase the volume of exercise that patients with COPD can perform during rehabilitation, we can potentially turn non-responders into responders and allow more patients to receive the known benefits of pulmonary rehabilitation.

\section{REFERENCES}

1. Ries AL, Bauldoff GS, Carlin BW, et al. Pulmonary rehabilitation: Joint ACCP/AACVPR evidence-based clinical practice guidelines. Chest 2007;131:4S-42S.

2. Decramer M. Pulmonary rehabilitation 2007: From bench to practice and back. Clin Invest Med 2008;31:E312-8.

3. Vagaggini B, Costa F, Antonelli S, et al. Clinical predictors of the efficacy of a pulmonary rehabilitation programme in patients with COPD. Respir Med 2009;103:1224-30.

4. Eves ND, Sandmeyer LC, Wong EY, et al. Helium-hyperoxia: A novel intervention to improve the benefits of pulmonary rehabilitation for patients with COPD. Chest 2009;135:609-18.

5. Young P, Dewse M, Fergusson W, Kolbe J. Respiratory rehabilitation in chronic obstructive pulmonary disease: Predictors of nonadherence. Eur Respir J 1999;13:855-9.

6. Plankeel JF, McMullen B, MacIntyre NR. Exercise outcomes after pulmonary rehabilitation depend on the initial mechanism of exercise limitation among non-oxygen-dependent COPD patients. Chest 2005;127:110-6.

7. O'Donnell DE, Revill SM, Webb KA. Dynamic hyperinflation and exercise intolerance in chronic obstructive pulmonary disease. Am J Respir Crit Care Med 2001;164:770-7.

8. Eves ND, Petersen SR, Haykowsky MJ, Wong EY, Jones RL. Helium-hyperoxia, exercise, and respiratory mechanics in chronic obstructive pulmonary disease. Am J Respir Crit Care Med 2006;174:763-71.

9. Casaburi R. Factors determining constant work rate exercise tolerance in COPD and their role in dictating the minimal clinically important difference in response to interventions. COPD 2005;2:131-6.

\section{Alternatives to CPAP therapy}

Kathleen A Ferguson BSc MD FRCPC

Division of Respirology, Schulich School of Medicine, University of Western Ontario, London, Ontario kafergus@uwo.ca

Continuous positive airway pressure (CPAP) is the mainstay of

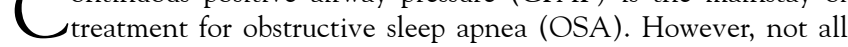
patients want or tolerate CPAP, so alternative therapies are required. The present paper briefly reviews the evidence for oral appliance therapy (OA) and upper airway surgery.

A systematic review of the evidence for OA was published in 2006 (1). Fifteen randomized controlled trials (RCTs) were reviewed. The authors concluded that $\mathrm{OA}$ reduced the apnea-hypopnea index (AHI) to less than five per hour in $40 \%$ of patients, to less than 10 per hour in $52 \%$, and by at least $50 \%$ in $69 \%$ of patients. Many studies reported improvements in snoring, sleepiness and oxygenation.

A recent RCT evaluated CPAP, conservative therapy and OA in 101 subjects with mild to moderate OSA (2). CPAP improved the AHI and sleepiness better than OA but both methods were more effective than conservative treatment (no benefit). Morning diastolic blood pressure decreased in both the OA and CPAP groups. CPAP was better at improving general health-related quality of life but was equal to OA in improving disease-specific quality of life.

Many RCTs have compared OA with CPAP (1). CPAP reduced the AHI to normal levels in all patients, whereas OA failed to do so in one-third or more. In patients with mild to moderate OSA (3), CPAP and OA improved sleepiness and other neurobehavioural outcomes 
more than placebo, but there was no difference between the two therapies. In a study of sleepier patients (4), CPAP produced a better effect on subjective but not objective sleepiness.

There are numerous types of upper airway surgery performed for the treatment of OSA. One of the more common procedures is uvulopalatopharyngoplasty. A Cochrane review of uvulopalatopharyngoplasty concluded that approximately $50 \%$ of patients have a $50 \%$ improvement in apnea severity (5). A 2005 update reached a similar conclusion (6). However, clinical staging may improve success (7). In a study of consecutively treated patients, approximately one-third were successfully treated $(50 \%$ reduction in respiratory disturbance index to less than 20 per hour). Thinner patients with larger tonsils and a high palate had the best outcomes while patients with low-lying palates and/or morbid obesity did poorly.

A systematic review and meta-analysis of the literature evaluated the efficacy of multilevel upper airway surgery in 49 studies that included almost 2000 patients (8). Surgery had to include procedures on at least two levels of airway obstruction. Surgery was successful in $66 \%$ of patients (AHI reduced by at least $50 \%$ to less than 20 per hour). Nasal obstruction is common in OSA but there are no RCTs of nasal surgery. Studies of nasal surgery have found minimal effects on AHI but one study found that CPAP pressures were lower postoperatively (9). Maxillofacial surgery may be performed in patients who have maxillary and/or mandibular insufficiency, or in patients with a normal facial skeleton if there is significant OSA and other treatments have failed. The surgery generally consists of a combined advancement of maxilla, mandible and chin. There are no published RCTs of maxillofacial surgery for OSA but there are many published case series using different combinations of surgical techniques, sometimes including nasal or palatal surgery. Case series in highly selected patients have found that most patients have a significant and often curative improvement in AHI (10).

\section{CONCLUSIONS}

CPAP remains the standard of care for patients with OSA. OAs are an effective option in some patients and represent an alternative to CPAP that is supported by evidence from well done RCTs. Upper airway surgery may play a role in the treatment of patients with OSA, particularly when noninvasive treatment options have failed. There are few controlled trials that support the use of most of the available procedures in unselected patients.

\section{REFERENCES}

1. Ferguson KA, Cartwright R, Rogers R, et al. Oral appliances for snoring and obstructive sleep apnea: A review. Sleep 2006;29:244-62.

2. Lam B, Sam K, Mok WY, et al. Randomised study of three nonsurgical treatments in mild to moderate obstructive sleep apnoea. Thorax 2007;62:354-59.

3. Barnes M, McEvoy RD, Banks S, et al. Efficacy of positive airway pressure and oral appliance in mild to moderate obstructive sleep apnea. Am J Respir Crit Care Med 2004;170:656-64.

4. Engleman HM, McDonald JP, Graham D, et al. Randomized crossover trial of two treatments for sleep apnea/hypopnea syndrome: Continuous positive airway pressure and mandibular repositioning splint. Am J Respir Crit Care Med 2002;166:855-9.

5. Bridgman SA, Dunn KM, Ducharme F. Surgery for obstructive sleep apnoea. Cochrane Database Syst Rev 2002 2000;(2):CD00100.

6. Sundaram S, Bridgman S, Lim J, et al. Surgery for obstructive sleep apnoea. Cochrane Database Syst Rev 2005;(4):CD00100.

7. Friedman M, Ibrahim H, Bass L. Clinical staging for sleep-disordered breathing. Otolaryngol Head Neck Surg 2002;127:13-21.

8. Lin HC, Friedman M, Chang HW, et al. The efficacy of multilevel surgery of the upper airway in adults with obstructive sleep apnea/ hypopnea syndrome. Laryngoscope 2008;118:902-8.

9. Friedman M, Tanyeri H, Lim JW, et al. Effect of improved nasal breathing on obstructive sleep apnea. Otolaryngol Head Neck Surg 2000;122:71-4.

10. Prinsell JR. Maxillomandibular advancement surgery in a sitespecific treatment approach for obstructive sleep apnea in 50 consecutive patients. Chest 1999;116:1519-29.

\section{The impact of technology on the diagnosis and treatment of lung cancer}

\author{
Richard J Finley MD FRCSC FACS \\ Division of Thoracic Surgery, Vancouver General Hospital, \\ University of British Columbia, Vancouver, British Columbia \\ Richard.Finley@vch.org
}

In 2008, an estimated 23,900 Canadians will have been diagnosed with lung cancer, while 20,200 will die because of it. Lung cancer incidence and death rates continue to climb among women while decreasing among men. Lung cancer remains the leading cause of cancer death for both men and women, with 270,000 potential years of life lost. The purpose of the present abstract is to review the impact of the new technologies: low-dose computed tomography (CT) scanning for lung cancer screening, staging with CT/positron emission tomography (PET) fusion imaging, and video-assisted thoracoscopic (VATS) lobectomy on the diagnosis, staging, treatment and survival of lung cancer.

The $15 \%$ decrease in mortality for colorectal, breast and prostate cancer seen in the past 20 years associated with early detection screening programs has stimulated new lung cancer screening programs, with the hope of improving survival by detecting and treating early stage disease. CT detection of small growing lung nodules can suggest early lung cancer. Unfortunately, confident distinction of benign from malignant small lung nodules (less than $15 \mathrm{~mm}$ ) cannot be reliably achieved using only CT criteria, CT/PET scans or pathological diagnosis using CT-guided needle biopsy (1). VATS excision biopsy removes the entire nodule in one sitting and eliminates the sampling error associated with needle biopsy, making it appealing to physicians and patients. Suzuki et al (2), however, reported that failure to visualize or palpate the nodule at VATS, requiring conversion to thoracotomy, occurred in $63 \%$ of patients when the nodule was $10 \mathrm{~mm}$ or less in diameter and greater than $5 \mathrm{~mm}$ from the pleural surface. To reduce the incidence of open thoracotomy in our centre (3), 75 small nodules were marked preoperatively in the CT suite, where one end of an $80 \mathrm{~mm}$ long, 0.018 in diameter, fibrecoated microcoil was placed deep to small peripheral lung nodules, with the other end coiled in the pleural space. In the operating room, VATS excision of lung tissue, lesion and microcoil was performed successfully in 73 of 75 patients (97\%) under fluoroscopic guidance. The preoperative treatment plan based on bronchoscope, needle biopsy and PET scan was changed in 19 of 69 patients (28\%) following VATS excision.

The staging of lung cancer is continuously evolving, as technological advances combine with clinical advances to better stratify patients into treatment and prognostic categories and alter preoperative investigation algorithms. The increasing use of CT/PET is increasingly identifying patients with additional lesions that could contraindicate surgical treatment, but which require pathological confirmation to exclude a false-positive result (4). Preoperative staging with PET/CT and cranial imaging of patients with early stage non-small cell lung cancer identifies more precisely those patients with mediastinal and extrathoracic disease, thereby sparing some patients from stage-inappropriate surgery when compared with conventional preoperative staging. CT/PET is not cost-effective if other investigations such as chest CT scans or brain imaging show nonresectable disease.

Over the past decade, VATS surgery has improved with better fibre optic light transmission, better image processing techniques that magnify the image and share it with the operative team on a video screen, refinement of instruments and endostaplers, and the development of expertise in VATS pulmonary resections by thoracic surgeons. Compared with open thoracotomy, patients with VATS pulmonary resection experienced less pain and lower analgesic requirements up to postoperative day 7 , but there was no significant difference in pain thereafter. In randomized controlled trials $(5,6)$, 
there were no significant differences in staging, complete resections, length of stay, costs, postoperative impairment of pulmonary function, operative morbidity and mortality, or in long-term survival.

Although new technology has improved the diagnosis, staging and treatment of lung cancer, the cost of care has increased and mortality has not significantly changed.

ACKNOWLEDGEMENTS: Dr Finley is supported by funding from the British Columbia Lung Association.

\section{REFERENCES}

1. McWilliams A, Mayo JR, Ahn MI, MacDonald SL, Lam SC. Lung cancer screening using multi-slice thin-section computed tomography and autofluorescence bronchoscopy. J Thorac Oncol 2006;1:61-8.

2. Suzuki K, Nagai K, Yoshida J, et al. Video-assisted thoracoscopic surgery for small indeterminate pulmonary nodules: Indications for preoperative marking. Chest 1999;115:563-8.

3. Mayo JR, Clifton JC, Powell TI, et al. Lung nodules: CT-guided placement of microcoils to direct video-assisted thoracoscopic surgical resection. Radiology 2009;250:576-85.

4. Maziak D, Darling G, Inculet R, et al. A randomized controlled trial (RCT) of 18 F-fluorodeoxyglucose (FDG) positron emission tomography (PET) versus conventional imaging (CI) in staging potentially resectable non-small cell lung cancer (NSCLC). J Clin Oncol 2008;26:7502. (Abst)

5. Watanabe A, Koyanagi T, Obama T, et al. Assessment of node dissection for clinical stage I primary lung cancer by VATS. Eur J Cardiothorac Surg 2005;27:745-52.

6. Van Schil P. Cost analysis of video-assisted thoracic surgery versus thoracotomy: Critical review. Eur Resp J 2003;22:735-9.

\section{Knowledge translation: Moving knowledge to action in respiratory care}

\author{
Ian D Graham $\mathrm{PhD}^{1,2}$, Jacqueline $M$ Tetroe $M A^{1}$ \\ ${ }^{1}$ Knowledge Translation Portfolio, Canadian Institutes of Health \\ Research; ${ }^{2}$ School of Nursing, University of Ottawa, Ottawa, Ontario \\ lan.graham@cihr-irsc.gc.ca
}

$\mathrm{K}$ nowledge translation (KT) is about making users aware of knowledge or innovations and facilitating their use of it to improve health and health care systems. It is about moving knowledge into action. There are other terms in use to describe this concept, many of which are not operationally defined $(1,2)$. The Canadian Institutes of Health Research has developed the following working definition: $\mathrm{KT}$ is a dynamic and iterative process that includes synthesis, dissemination, exchange and ethically sound application of knowledge to improve the health of Canadians, provide more effective health services and products and strengthen the health care system. This process takes place within a complex system of interactions between researchers and knowledge users that may vary in intensity, complexity and level of engagement depending on the nature of the research and the findings as well as the needs of the particular knowledge user. An examination of the meaning of the specific concepts in this definition allows a more in-depth understanding of what we mean by KT.

Synthesis means the contextualization and integration of research findings of individual research studies within the larger body of knowledge on the topic. A synthesis must be reproducible and transparent in its methods and can review qualitative or quantitative findings. Dissemination involves identifying the appropriate audience, and tailoring the message and medium to that audience. The exchange of knowledge refers to the interaction between the knowledge user and the researcher resulting in mutual learning through the process of planning, producing, disseminating, and applying existing or new knowledge. Ethically sound KT activities are those that are consistent with ethical principles and norms, social values as well as legal and other regulatory frameworks. The term application refers to the iterative process by which knowledge is put into practice or policy and has been illustrated in the action cycle of the knowledge to action process (Figure 1). Implicit in the Canadian Institutes of Health Research definition is the notion that evaluation and monitoring of KT initiatives, processes and activities are key components of $\mathrm{KT}$.

Given the complexity of behaviour change and the multiple factors that can influence, there is growing recognition that application efforts should be guided by conceptual models or frameworks $(3,4)$. The usefulness of conceptual models comes from the organization they provide for thinking, observation and interpreting what is seen. The Knowledge to Action Process was derived from a concept analysis of 31 planned action theories and models $(5,6)$.

KT can be divided into three broad categories: KT Science - studying the determinants of knowledge use and effective methods of promoting the uptake of knowledge; end-of-grant KT - initiatives undertaken once the grant/research has been completed; and integrated KT - engaging users of research throughout the research process. End of grant KT refers to the standard KT activities of most researchers: KT to their peers and, when appropriate, tailoring the message and medium to audiences beyond the scientific community. Integrated KT represents a different approach and involves collaboration between researchers and research users in the research process starting with shaping of the research questions. This category of KT is similar to participatory research (7) or Gibbons' Mode 2 knowledge production (8). Not every researcher should be involved in integrated KT. For many researchers, disseminating research findings to the appropriate audience (this includes other researchers) is usually sufficient. The intensity of knowledge translation should depend on factors such as the potential impact of using the findings; the strength of the evidence supporting the findings; the target audience(s); what is known about effective strategies to reach the audience(s); what is practical and feasible to do under the circumstances and considerations of who else should be involved in KT efforts.

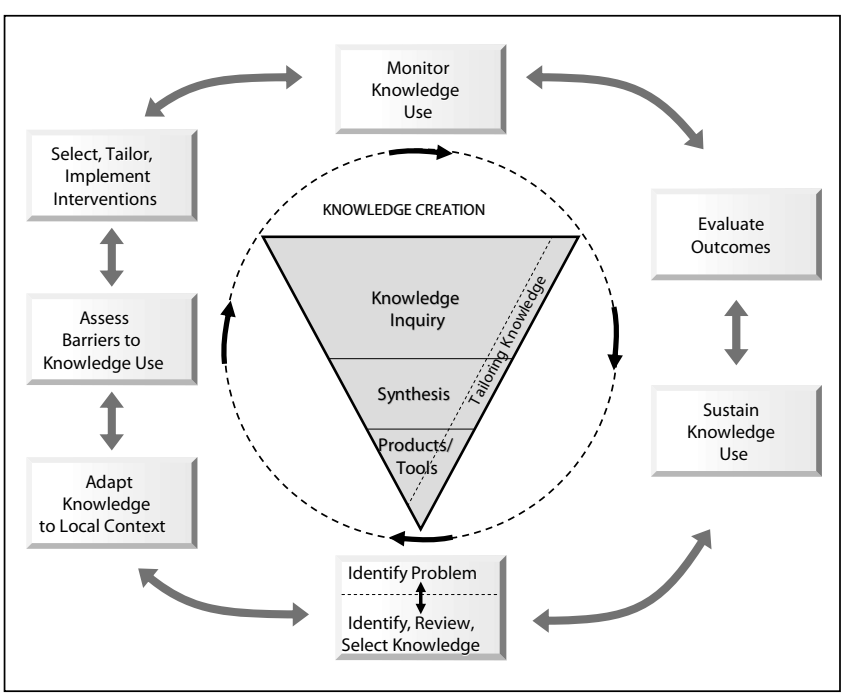

Figure 1) The Knowledge to Action Process. Reproduced with permission with modifications from ref 2 , page 19 , figure 1

\section{REFERENCES}

1. Tetroe J M, Graham ID, Foy R, et al. Health research funding agencies' support and promotion of knowledge translation: An international study. Milbank Q 2008;86:125-55.

2. Graham ID, Logan J, Harrison MB, et al. Lost in knowledge translation: Time for a map? J Contin Educ Health Prof 2006;26:13-24

3. McDonald K, Graham I, Grimshaw J. Toward a theoretic basis for quality improvement interventions. In: Shojania KG, McDonald K, Wachter R, Owens D, eds. Closing the Quality Gap: A Critical 
Analysis of Quality Improvement Practices, Vol 1 (diabetes mellitus and hypertension). (Technical review \#9 ed.) Washington, DC: Agency for Healthcare Research and Quality, 2004.

4. The Improved Clinical Effectiveness through Behavioural Research Group (ICEBeRG). Designing theoretically-informed implementation interventions. Implementation Sci 2006;1:4.

5. Graham ID, Tetroe JM. Theories of knowledge to action: Planned action theories. In: Straus S, Tetroe JM, Graham ID, eds. Knowledge Translation in Health Care Moving from Evidence to Practice. London: Wiley-Blackwell, 2009.

6. Graham ID, Tetroe J. Some theoretical underpinnings of knowledge translation. Acad Emerg Med 2007;14:936-94.

7. Macaulay AC, Commanda LE, Freeman WL, Gibson N, McCabe ML, Robbins CM. Participatory research maximises community and lay involvement. North American Primary Care Research Group. BMJ 1999;319:774-8.

8. Gibbons M, Limoges C, Nowotny H, Schwartzmann S, Scott P, Trow M. The New Production of Knowledge: The dynamics of science and research in contemporary societies. London: Sage, 1994.

\section{Nitric oxide}

\author{
Hartmut Grasemann MD PhD \\ Division of Respiratory Medicine, The Hospital for Sick Children, \\ Toronto, Ontario \\ hartmut.grasemann@sickkids.ca
}

$\mathrm{N}$ itric oxide (NO) is enzymatically produced by $\mathrm{NO}$ synthases (NOSs). There are three isoforms of NOS of which two, namely NOS1 (neuronal NOS) and NOS3 (endothelial NOS), are constitutively expressed and regulated predominantly by the calcium/calmodulin system, while the expression of NOS2 (inducible NOS) can be induced by certain proinflammatory cytokines. The NOS isoforms are expressed by a number of different cell types within the lung and NO is produced in the airways and can be measured in exhaled air. NO concentrations are highest in the nose and paranasal sinus and lowest in the peripheral airways.

\section{TECHNICAL ASPECTS OF EXHALED NO MEASUREMENTS}

When measuring exhaled NO, published standardized techniques should be applied $(1,2)$. In general, exhaled $\mathrm{NO}$ can be measured with on-line or off-line techniques, depending on availability of an $\mathrm{NO}$ analyzer in the patient area. The most commonly used technique is a single exhalation against a resistor. The pressure in the mouth will result in soft palate closure that allows for separation of the nasal and paranasal cavities from the lower airways. Single exhalations will typically be performed at a constant exhalation flow rate of $50 \mathrm{~mL} / \mathrm{s}$. Exhaled air obtained at higher flows, however, will represent more peripheral airways. Based on a two-compartment model (3), the exhaled NO concentration will depend on three flow-independent parameters: the maximum total volumetric flux of $\mathrm{NO}$ from the airway wall $\left(\mathrm{J}_{\mathrm{NO}}\right)$, the diffusing capacity of $\mathrm{NO}$ in the airways, and the steadystate alveolar NO concentration. Using multiple constant flow exhalations at each expiratory flow, the $\mathrm{NO}$ output $\left(\mathrm{J}_{\mathrm{NO}}\right)$ can be calculated as $\mathrm{J}_{\mathrm{NO}}=$ expiratory flow $\times$ the fraction of exhaled $\mathrm{NO}\left(\mathrm{FE}_{\mathrm{NO}}\right)$. The slope of this regression line is the alveolar $\mathrm{NO}$ concentration and the intercept is the bronchial NO output $\left(\mathrm{J}_{\mathrm{NO}}\right)$. Flow-independent NO parameters may help delineate diseases with involvement of different areas of the lung or airways (3).

Different techniques are required to measure lower airway $\mathrm{NO}$ in children. While children five to 17 years of age will generally be able to follow the instructions to perform single-breath flow-controlled manoeuvres, the recommended techniques for preschool (two to five years of age) children are flow-controlled spontaneous breathing, where the operator changes resistance and thereby flow within a certain range while the child is breathing spontaneously, or uncontrolled flow methods. Uncontrolled tidal breathing techniques have also been described for children younger than two years of age, where singlebreath forced exhalation manoeuvres are also used (2).

\section{NASAL NO}

The concentrations of $\mathrm{NO}$ in the nose are flow dependent, similar to $\mathrm{FE}_{\mathrm{NO}}$ from the lower airways. One technical difference is, however, that the flow through the nasal cavities is typically generated by the $\mathrm{NO}$ analyzer and equals the aspiration flow of the sample line. This flow needs to be held constant to make results comparable between different set-ups. At a constant aspiration flow rate, nasal NO concentrations will gradually increase during the measurement and eventually plateau. These plateaus are recorded and used for analyses.

\section{CLINICAL INDICATIONS FOR NO MEASUREMENTS}

The concentration of $\mathrm{NO}$ in the upper and lower airways has been found to be decreased in a number of diseases including primary ciliary dyskinesia (PCD) and cystic fibrosis. In contrast, eosinophilic airways inflammation has been shown to be associated with increased $\mathrm{NO}$ in exhaled air and increased $\mathrm{FE}_{\mathrm{NO}}$ is frequently found in asthma patients. The diagnosis of asthma is typically based on clinical history, reversible airway obstruction and presence of airways hyperresponsiveness. Direct assessment of airway inflammation is not part of conventional approaches used to diagnose or monitor control of asthma. Airway inflammation in asthma patients results in activation of NOS3 increased $\mathrm{FE}_{\mathrm{NO}}$ and decreases in response to antiinflammatory treatment. Therefore, measurement of exhaled NO has been advertised as a noninvasive tool in the assessment of asthma airway inflammation.

Discussions about the usefulness of NO measurements in asthma management to date are controversial and studies in severe asthmatic patients are still lacking. In a recent randomized, double-blind, parallelgroup, multicentre, 46-week treatment trial, the management of asthma based on $\mathrm{FE}_{\mathrm{NO}}$ in addition to guideline-based treatment showed no additional effect of NO measurements on asthma symptom control (4).

PCD is a disease that is characterized by chronic and recurrent respiratory symptoms including chronic cough, sinusitis, bronchitis, pneumonia and otitis media. Despite early onset of symptoms, the diagnosis of PCD is often missed early in life. Nasal NO is significantly decreased in patients with PCD and has been found to be diagnostic even in newborns with PCD and situs inversus (5). Nasal NO is therefore recommended as a noninvasive tool in the diagnosis of PCD (6).

\section{SUMMARY}

Airway NO can be measured by commercially available NO analyzers and published recommendations as to how to measure exhaled NO should be applied to make results comparable. Nasal NO can be used as a simple noninvasive screening tool for PCD. Repeated measurements of $\mathrm{FE}_{\mathrm{NO}}$ may be useful in guiding asthma therapy in individual patients. The usefulness of airway $\mathrm{NO}$ measurements for other clinical indications is, at this point in time, not clearly established.

\section{REFERENCES}

1. American Thoracic Society, European Respiratory Society. ATS/ ERS recommendations for standardized procedures for the online and offline measurement of exhaled lower respiratory nitric oxide and nasal nitric oxide, 2005. Am J Respir Crit Care Med 2005;171:912-30.

2. Baraldi E, de Jongste JC; European Respiratory Society; American Thoracic Society. Measurement of exhaled nitric oxide in children, 2001. Eur Respir J 2002;20:223-37.

3. Tsoukias NM, Shin HW, Wilson AF, George SC. A single-breath technique with variable flow rate to characterize nitric oxide exchange dynamics in the lungs. J Appl Physiol 2001;91:477-87.

4. Szefler SJ, Mitchell H, Sorkness CA, et al. Management of asthma based on exhaled nitric oxide in addition to guideline-based treatment for inner-city adolescents and young adults: A randomised controlled trial. Lancet 2008;372:1065-72.

5. Stehling F, Roll C, Ratjen F, Grasemann H. Nasal nitric oxide to diagnose primary ciliary dyskinesia in newborns. Arch Dis Child Fetal Neonatal Ed 2006;91:F233.

6. Bush A, Chodhari R, Collins N, et al. Primary ciliary dyskinesia: Current state of the art. Arch Dis Child 2007;92:1136-40. 


\section{Knowledge translation: Breathing life into the knowledge-to-action cycle}

\author{
Samir Gupta MD MSC \\ Li Ka Shing Knowledge Institute of St Michael's Hospital, \\ University of Toronto, Toronto, Ontario \\ Guptas@smh.toronto.on.ca
}

$\mathrm{N}_{\mathrm{pos}}^{\mathrm{en}}$ ew medical knowledge and breakthroughs are the continuous product of an extensive global health research enterprise. However, evaluations of quality of care have consistently demonstrated gaps between existing knowledge and practice, across jurisdictions and disciplines. A growing recognition of both lost potential health gains and harms resulting from these gaps has spurred the science of knowledge translation (KT). Graham et al (1) termed the process of systematically bridging these gaps the "knowledge to action" (KTA) process and developed a framework describing its key elements, based on a review of planned-action theories and models. The resulting "action cycle" provides a step-by-step guide for would-be knowledge implementers. In this paper, I will operationalize the KTA process using a smoking cessation intervention as an example.

\section{IDENTIFY THE PROBLEM}

The process begins with identification of a problem that needs addressing. Smoking was the primary risk factor for the top three causes of death and was estimated to be responsible for $22 \%$ of all deaths in Canada (2). In chronic obstructive pulmonary disease (COPD), it accelerates lung function decline, leading to earlier morbidity and mortality (3). Despite this, $19 \%$ of Canadians aged 15 years and older (2) and $45.4 \%$ of Canadians with COPD smoke (4).

\section{IDENTIFY, REVIEW AND SELECT KNOWLEDGE}

We now turn to the knowledge creation funnel for existing knowledge on smoking cessation interventions. Randomized controlled trials have demonstrated that a brief physician smoking cessation intervention improves quit rates in all smokers and reduces all-cause mortality in COPD (3). A Cochrane review confirms that a brief intervention significantly increases the likelihood of quitting (5). The 2007 Canadian Thoracic Society COPD Guideline, a tailored knowledge product, states: "Minimal interventions, lasting less than 3 minutes, should systematically be offered to every smoker... (1A)." (6). Despite this, only $51 \%$ of Canadian smokers visiting a health care provider in the preceding 12 months were advised to reduce or quit smoking (7). This constitutes the KTA gap.

\section{ADAPT THE KNOWLEDGE TO THE LOCAL CONTEXT}

The highest-volume setting for a successful Canadian smoking cessation intervention is primary care, so the knowledge should be customized to this context. A simple and directed message for target practitioners would be: "A less than 3 min physician smoking cessation intervention significantly decreases smoking rates and improves health outcomes."

\section{ASSESS THE BARRIERS TO KNOWLEDGE USE}

Identifying the barriers to local knowledge uptake is a prerequisite for designing successful interventions. Barriers to delivery of a smoking cessation intervention in primary care include attitudinal barriers such as concern about harming the doctor-patient relationship, a perceived lack of skills, and frustration owing to perceived low success rates; and external barriers, such as a lack of time $(8,9)$.

\section{SELECT, TAILOR AND IMPLEMENT INTERVENTIONS}

Once barriers are identified, specific interventions should be developed accordingly. Literature reviews may provide a suite of previously applied KT interventions for consideration. Also, any previously studied KT interventions addressing the gap of interest, whether successful or not, should be studied for their applicability. Qualitative data on the effect of each intervention on recognized barriers may also be available. In this case, a literature review concluded that strategies combining physician education and training with practice-based approaches such as prompts and reminders were effective in increasing physician delivery of smoking cessation advice (9). In a unique study (10), an inexpensive chart stamp indicating the patient's current smoking status was also effective. One might emulate some or all aspects of previous interventions, and/or may choose novel approaches.

\section{MONITOR KNOWLEDGE USE}

Knowledge use is a necessary but insufficient condition for achievement of the desired health outcome (in this case smoking cessation and resulting morbidity and mortality). Knowledge use should be measured at two levels: conceptual knowledge use, or changes in physician knowledge, attitudes, and beliefs regarding the benefits of smoking cessation advice delivery (which may or may not successfully change behaviour); and instrumental knowledge use, or the concrete application of this knowledge such that it actually increases the frequency of smoking cessation advice delivery (behaviour change). Although knowledge use is in itself an intermediate end point, when an intervention targets a behaviour for which there is strong evidence of health benefit, it may be appropriate to limit measurement to instrumental knowledge use alone.

\section{EVALUATE THE OUTCOMES OF KNOWLEDGE USE}

It is the impact of knowledge use that determines the ultimate success of a KT intervention. Generally, these outcomes may be measured at a patient, provider and/or a system level. In this case, relevant patientlevel outcomes would include smoking cessation rates, rates and complications of smoking-related diseases, and mortality.

\section{SUSTAIN KNOWLEDGE USE}

Health systems are complex and ever-changing. As a result, while some barriers fall, others are erected, and previously designed interventions may become less effective. Barriers to sustainability may in themselves be distinct from barriers to initial adoption and behaviour change. Sustainability strategies are developed in the same way as initial interventions were, by cycling back through the steps in the KTA cycle, as such initiating a feedback loop.

Passive dissemination of research findings is an inadequate means to effect the behaviour change required to reap the health outcome benefits of new knowledge. Through the KTA cycle, Graham et al (1) have systematized the process of KT and provided a much-needed structured approach to implementation. As the respiratory community turns its attention to the science of implementation, areas of future inquiry may include exploration of certain cycle stages within the context of a particular problem, such as the magnitude of a particular care gap, or particular barriers to adoption. Ultimately, the action cycle can be used to address the many prevalent care gaps in respirology.

ACKNOWLEDGEMENTS: Dr Gupta is supported by funding from the Li Ka Shing Knowledge Institute of St Michael's Hospital, Toronto, Ontario.

\section{REFERENCES}

1. Graham ID, Logan J, Harrison MB, et al. Lost in knowledge translation: Time for a map? J Contin Educ Health Prof 2006;26:13-24.

2. Health Canada. Canadian Tobacco Use Monitoring Survey (CTUMS) 2006. <www.hc-sc.gc.ca/hc-ps/tobac-tabac/researchrecherche/stat/_ctums-esutc_2006/ann_summary-sommaire-eng. php $>$ (Version current at May 29, 2009).

3. Anthonisen NR, Connett JE, Kiley JP, et al. Effects of smoking intervention and the use of an inhaled anticholinergic bronchodilator on the rate of decline of $\mathrm{FEV}_{1}$. Lung Health Study. JAMA 1994:272:1497-505.

4. Chapman KR, Bourbeau J, Rance L. The burden of COPD in Canada: Results from the Confronting COPD survey. Respir Med 2003;97(Suppl C):S23-S31. 
5. Lancaster T, Stead LF. Physician advice for smoking cessation. Cochrane Database of Systematic Reviews 2004(4): CD000165. DOI: $10.1002 / 14651858$.CD000165.pub2.

6. O'Donnell DE, Aaron S, Bourbeau J, et al. Canadian Thoracic Society recommendations for management of chronic obstructive pulmonary disease - 2007 update. Can Resp J 2007;14(Suppl B):5B-32B.

7. Centers for Disease Control. MMWR Weekly. Smoking-cessation advice from health-care providers - Canada, 2005. 2007;56:708-12. $<$ http://www.cdc.gov/mmwr/preview/mmwrhtml/mm5628a3.htm>

8. McEwen A, West R, Preston A. Triggering anti-smoking advice by GPs: Mode of action of an intervention stimulating smoking cessation advice by GPs. Patient Educ Couns 2006;62:89-94.

9. Anderson E, Jané-Llopis E. How can we increase the involvement of primary healthcare in the treatment of tobacco dependence? A meta-analysis. Addiction 2004;98:299-312.

10. Ahluwalia JS, Gibson CA, Kenney E, Wallace DD, Resnicow K. Smoking status as a vital sign. J Gen Int Med 1999;14:402-8.

\section{A practical approach to formulating an exercise program for patients with COPD}

Kylie Hill PhD

Department of Respiratory Medicine, West Park Healthcare Centre, and Department of Physical Therapy, University of Toronto, Toronto, Ontario kyliehill73@hotmail.com

\section{CURRENT RECOMMENDATIONS}

Aerobic exercise that aims to condition the muscles of locomotion is a mandatory component of pulmonary rehabilitation (PR) $(1,2)$. These exercises commonly involve walking and cycling, performed for $30 \mathrm{~min}$, between three and five days a week, for six to 12 weeks. Although exercise training programs performed at low intensities are likely to yield benefits in clinical outcomes such as health-related quality of life, high-intensity training confers greater physiological benefit and should be encouraged to optimize gains in exercise capacity (2). The recommended initial training intensity is $60 \%$ to $80 \%$ of an individual's maximum exercise capacity (3).

\section{MEASUREMENT OF EXERCISE CAPACITY}

In Canada, the 6 min walk test (6MWT) is used by approximately $90 \%$ of PR programs offered in the outpatient setting, making it a popular assessment protocol (4). In contrast, the incremental cycle ergometry test (ICET) is routinely performed by than less than $50 \%$ of PR programs (4). Therefore, clinicians are likely only to have the results of a 6MWT on which to prescribe initial training intensities. An encouraged 6MWT and ICET elicit similar peak heart rates and rates of oxygen uptake in people with chronic obstructive pulmonary disease (5). This suggests that the 6MWT elicits maximum (or nearmaximum) cardiac and oxidative demands in this population and its results can therefore be used to prescribe training intensities.

\section{PRESCRIBING A HIGH-INTENSITY EXERCISE TRAINING PROGRAM}

Walking

Previous studies have demonstrated that walking-based training at a speed equivalent to $80 \%$ of the average walking speed achieved during an encouraged 6MWT is feasible and effective (6). Table 1 provides an example of how to establish a high-intensity walking-based training program using the results of a $6 \mathrm{MWT}$.

\section{TABLE 1}

\begin{tabular}{llll}
\hline Measurement & Modality & Calculation & Prescription \\
\hline $6 \mathrm{MWD}=450 \mathrm{~m} \begin{array}{c}20 \text { min corridor } \\
\text { walk }\end{array}$ & $(4.5 \mathrm{~km} / \mathrm{h} \times 0.8) / 3$ & $1.2 \mathrm{~km}$ in $20 \mathrm{~min}$ \\
$\mathrm{GMWD}=450 \mathrm{~m} \begin{array}{c}\text { Treadmill walking } \\
\text { speed }\end{array}$ & $4.5 \mathrm{~km} / \mathrm{h} \times 0.8$ & $3.6 \mathrm{~km} / \mathrm{h}(2.24 \mathrm{miles} / \mathrm{h})$ \\
\hline
\end{tabular}

Suggestions for prescribing a high-intensity walking program. 6MWD $6 \mathrm{~min}$ walk distance
Cycling

Training intensities equivalent to $60 \%$ of an individual's peak work rate achieved during an ICET has been demonstrated to be effective (7). Because cycle-based training imposes a greater specific muscle load on the quadriceps, individuals with chronic obstructive pulmonary disease are often limited from tolerating higher initial loads due to local muscle fatigue and leg discomfort. The peak work rate achieved during an ICET can be estimated using the 6MWD (8). This enables clinicians to estimate cycle-based training work rates using the results of this field-based walking test.

\section{Progression}

Training volume should be increased in accordance with symptoms. Aiming for a score on the Borg category ratio scale of 4 is appropriate (1).

\section{STRATEGIES TO OPTIMIZE TRAINING LOAD}

Rollators may assist individuals who experience difficulty during walking-based exercise. Those with a baseline 6MWD of less than $300 \mathrm{~m}$ are most likely to benefit from this strategy (9). Interval-based training approaches, that intersperse work periods with regular rest periods, allow relief from intolerable symptoms and may also optimize the training load that can be tolerated (10).

\section{REFERENCES}

1. Nici L, Donner C, Wouters E, et al. American Thoracic Society/ European Respiratory Society statement on pulmonary rehabilitation. Am J Respir Crit Care Med 2006;173:1390-413.

2. Ries AL, Bauldoff GS, Carlin BW, et al. Pulmonary rehabilitation: Joint ACCP/AACVPR evidence-based clinical practice guidelines. Chest 2007;131(5 Suppl):4S-42S

3. Troosters T, Casaburi R, Gosselink R, et al. Pulmonary rehabilitation in chronic obstructive pulmonary disease. Am J Respir Crit Care Med 2005;172:19-38.

4. Brooks D, Sottana R, Bell B, et al. Characterization of pulmonary rehabilitation programs in Canada in 2005. Can Respir J 2007;14:87-92.

5. Troosters T, Vilaro J, Rabinovich R, et al. Physiological responses to the 6 -min walk test in patients with chronic obstructive pulmonary disease. Eur Respir J 2002;20:564-9.

6. Jenkins SC. 6-minute walk test in patients with COPD: Clinical applications in pulmonary rehabilitation. Physiother 2007;93:175-82.

7. Maltais F, LeBlanc P, Jobin J, et al. Intensity of training and physiologic adaptation in patients with chronic obstructive pulmonary disease. Am J Respir Crit Care Med 1997;155:555-61.

8. Hill K, Jenkins SC, Cecins N, et al. Estimating maximum work rate during incremental cycle ergometry testing from six-minute walk distance in patients with chronic obstructive pulmonary disease. Arch Phys Med Rehabil 2008;89:1782-7.

9. Solway S, Brooks D, Lau L, et al. The short-term effect of a rollator on functional exercise capacity among individuals with severe COPD. Chest 2002;122:56-65.

10. Vogiatzis I, Nanas S, Roussos C. Interval training as an alternative modality to continuous exercise in patients with COPD. Eur Respir J 2002;20:12-9.

\section{Rapid response teams: A successful type of ICU outreach}

Rick Hodder MSc MD FRCPC

Divisions of Pulmonary and Critical Care, the Ottawa Hospital,

University of Ottawa, Ottawa, Ontario

rhodder@ottawahospital.on.ca

$A$ s our population ages, the demand for acute care hospital beds is rapidly rising and many hospitals regularly face overcrowding dilemmas, so that bed management issues have become a daily priority. Intensive care units (ICUs) are frequently full, and expanding patient numbers and strained resources have challenged us to find more effective ways of identifying deteriorating patients earlier so that we can institute pre-emptive rescue therapy to avert catastrophe and either prevent the need for ICU admission, or shorten the length of stay if 
ICU admission is appropriate. One review (1) observed that before ICU admission, $54 \%$ of patients had suboptimal care with a mortality rate of $48 \%$, and estimated that earlier identification and management of deteriorating ward patients could prevent up to $41 \%$ of ICU admissions.

Hospitals have traditionally provided a cardiac arrest team to care for patients on the brink of death, but survival statistics are disheartening. In one recent American study, survival with good neurological outcome was seen in $15.2 \%$ of patients if the arrest occurred during the daytime and only $11 \%$ of those experiencing a cardiac arrest at night (2). Many in-hospital arrests are potentially preventable, as it is repeatedly observed that several hours of clinical deterioration occur before an arrest, suggesting a missed opportunity for early intervention (3-5). Failure to attend to the deteriorating patient promptly can have devastating consequences. In one observational study, the need for cardiopulmonary resuscitation was 3.6\% if the patient had been seen by the primary team before ICU admission, compared with $30.4 \%$ when the patient was not seen (6). Even when deterioration is noted, hospital ward staff often experience frustrating delays in getting physicians to the bedside in a timely fashion. This can result in a sense of helplessness for nurses and, in the extreme, lead to a culture of hopelessness in which calls are not made.

There are many potential causes for suboptimal acute care including lack of knowledge, failure to appreciate clinical urgency, failure to seek advice in a timely fashion, lack of supervision and a failure of organization. In Ontario, the recent severe acute respiratory syndrome experience revealed deficiencies in the organization and delivery of acute care in the province, which led the Ministry of Health and Long-Term Care to create a Critical Care Expert Advisory Panel to address these issues. The panel recommended seven strategy components to enhance the delivery of critical care by improving access and quality of care. In addition to improving ICU capacity, human resources, critical care information systems, and education/training, the panel recommended the creation of Critical Care Response Teams (CCRT).

The concept of critical care outreach or rapid response teams originated in Australia several years ago, and today many hospitals have created rapid response programs, referred to by such names as Medical Emergency Teams, Critical Care Outreach Teams, Critical Care Response Teams, etc. These teams usually provide on site, 'on call' service $24 \mathrm{~h}$ a day, seven days a week and generally consist of a nurse (often an ICU practitioner), a physician (ICU physician or other) and often another allied health care professional (usually a respiratory therapist). Depending on local personnel resources, rapid response teams follow two models of care delivery. In the Medical Emergency Teams model, the entire team, including the physician, goes immediately to the patient's bedside when called. In the CCRT model, the nurse, with or without a respiratory therapist, is the first responder and after assessing the patient, calls the physician for advice and to attend if necessary. Rapid response teams function best if allied with the ICU so that requests for admission will be facilitated. Most teams also make routine follow-up visits on patients they have been called to assess and on patients who have recently been discharged from the ICU. The latter is important because studies have documented that $24 \%$ of readmissions to the ICU occur within $24 \mathrm{~h}$ of ICU discharge (7), and $47 \%$ of patients requiring readmission do so within $72 \mathrm{~h}$ of discharge (8).

Calling criteria for the rapid response team are generally explicitly defined and include a threatened airway, tachypnea, low oxyhemoglobin saturation, tachycardia, hypotension, altered level of consciousness, as well as the nonspecific 'concern for the patient'. The latter calling criterion is perhaps the most valuable, because it empowers nurses (or junior house staff in teaching hospitals) to act when they are concerned about their patients. To facilitate care, most rapid response teams have a well-equipped mobile cart with resuscitation fluids, drugs, vascular access tools and a monitor. In some centres, particularly those following the CCRT model, immediate care is also facilitated by the use of a predetermined set of delegated acts, which the team nurse can initiate according to specific protocols without a physician's order. Depending on the centre, such delegated acts might include starting an intravenous line and administering a fluid bolus or even a vasopressor for hypotension, or intravenous beta-blocker for extreme hypertension or certain dysrrhythmias. In Ontario, many rapid response personnel have taken a CCRT course offered by the Canadian Resuscitation Institute and Critical Care Education Network (www.criedunet.ca) (9). Participants receive training in the skills of crisis resource and concurrent management, and become adept at communication, organized rapid patient assessment and institution of immediate therapy, followed by rapid reassessment and additional action if required.

Evaluation of rapid response teams has been limited in part because the models of critical care outreach and the systems to provide them vary nationally and internationally. However, in general, the evidence supporting their value has been positive. Most studies have used historical control data, but have consistently shown reductions in cardiac arrests (10-14), and some have shown increased hospital survival $(11,12)$. The effect on ICU admissions has been variable, with some studies showing a decrease in number, while others have noted an increase in ICU admission rate but reduced ICU length of stay, suggesting benefits for earlier intervention. The results from the first two years' experience with a rapid response team at The Ottawa Hospital are shown in Figure 1. Not only was there a reduction in the number of hospital cardiac arrests and a slight reduction in the need for ICU admissions from the wards, there was a significant reduction in the severity of patients requiring ICU admission based on the multiple organ dysfunction score, and a significant reduction in the number of readmissions to ICU within $48 \mathrm{~h}$ of ICU discharge (14). Similar data have been observed at the University Health Network in Toronto ( $S$ Reynolds, personal communication).

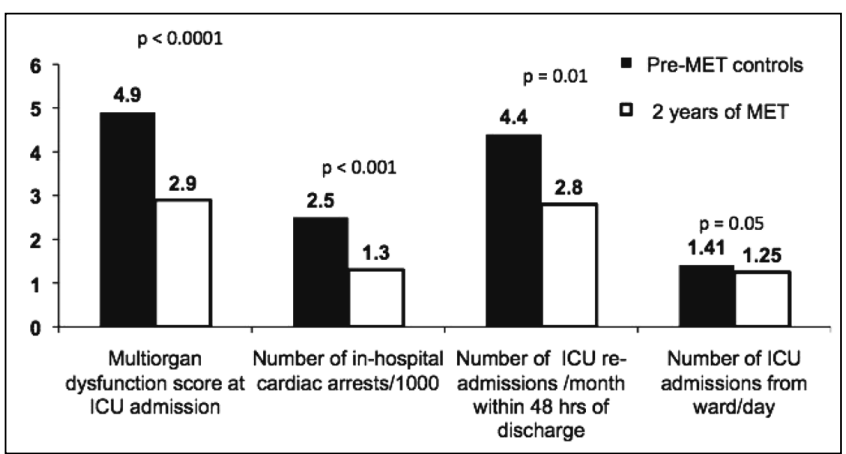

Figure 1) Effect of institution of a rapid response team at The Ottawa Hospital, Ottawa, Canada (14). ICU Intensive care unit; MET Medical Emergency Team

As a member of the Rapid Assessment of Critical Events team in Ottawa, I have observed another significant positive impact of the rapid response teams, namely, an improved sense of confidence in critical care assessment in the team members themselves and in the ward nurses of our hospital. I believe that this reflects the positive impact that rapid response teams can have on the education of health care professionals. During rapid response training, ICU nurses learn to be effective communicators and are given the opportunity to relearn the skills necessary for assessing patients who are not already fully trussed up with ICU technology such as indwelling arterial lines, mechanical ventilation and sophisticated monitoring equipment. Ward nurses also benefit from rapid response team calls by observing and participating in the acute assessment and therapy of their patients alongside their colleagues from the rapid response team. One of the most important empowering benefits of this experience is learning to recognize the patient who is on a downward spiral and gaining the 
confidence to act on that concern by taking the initiative to call the physician or rapid response team when necessary. Although difficult to evaluate quantitatively, I believe that this educational benefit is real and will in the end prove to be the most important legacy of the rapid response team initiative.

\section{REFERENCES}

1. McQuillan P, Pilkington S, Allan A, et al. Confidential inquiry into quality of care before admission to intensive care. BMJ 1998;316:1853-8.

2. Peberdy MA, Ornato JP, Larkin GL, et al. Survival from in-hospital cardiac arrest during nights and weekends. JAMA 2008;299:785-92.

3. Buist M, Jarmolowski E, Burton P, et al. Recognising clinical instability in hospital patients before cardiac arrest or unplanned admission to intensive care: A pilot study in a tertiary-care hospital. Med J Australia 1999;171:22-5.

4. Schein R, Hazday N, Pena M, et al. Clinical antecedents to in-hospital cardiopulmonary arrest. Chest 1990;98:1388-92.

5. Franklin C, Mathew J. Developing strategies to prevent inhospital cardiac arrest: Analyzing responses of physicians and nurses in the hours before the event. Crit Care Med 1994;22:244.

6. Goldhill D, Worthington L, Mulcahy A, et al. The patient-at-risk team: Identifying and managing seriously ill ward patients. Anaesthesia 1999;54:853.

7. Chen L, Martin C, Keenan S, et al. Patients readmitted to the intensive care unit during the same hospitalization: Clinical features and outcomes. Crit Care Med 1998;26:1834.

8. Rosenberg A, Hofer T, Hayward R, et al. Who bounces back? Physiologic and other predictors of intensive care unit readmission. Crit Care Med 2001;29:511.

9. R Hodder, ed. Critical Care Response Team Provider Manual, 1st edn. Ottawa: Canadian Resuscitation Institute, 2006.

10. Buist MD, Moore GE, Bernard SA, et al. Effects of a medical emergency team on reduction of incidence of and mortality from unexpected cardiac arrests in hospital: Preliminary study. BMJ 2002;324:387-90.

11. Ball C, Kirkby M, Williams S. Effect of the critical care outreach team on patient survival to discharge from hospital and readmission to critical care: Non-randomised population based study. BMJ 2003;327:1014.

12. Bellomo R, Goldsmith D, Uchino S, et al. Prospective controlled trial of effect of medical emergency team on postoperative morbidity and mortality rates. Crit Care Med 2004;32:916.

13. Dacey M, Mirza E, Wilcox V, et al. The effect of a rapid response team on major clinical outcome measures in a community hospital. Crit Care Med 2007;35:2076.

14. Baxter AD, Cardinal P, Hooper J, Patel R. Medical emergency teams at The Ottawa Hospital: The first two years. Can J Anesth 2008;55:223-31.

\section{Biologic agents in rheumatoid arthritis and pulmonary disease}

\author{
Nader Khalidi MD FRCPC \\ Division of Rheumatology, McMaster University, Hamilton, Ontario \\ naderkhalidi@sympatico.ca
}

$\mathrm{B}$ iologics are genetically engineered proteins derived from human genes. They are designed to inhibit specific components of the immune system that play pivotal roles in fueling inflammation, which is a central feature of several forms of arthritis. Biologics differ significantly from traditional drugs used to treat rheumatoid arthritis in that they target specific components of the immune system instead of broadly affecting many areas of the immune system. The biologic agents currently available include the anti-tumour necrosis factor agents infliximab, etanercept and adalimumab, the T-cell modulator abatacept, and B-cell modulator rituximab. There are many potential rare pulmonary side effects of these agents. Of the three anti-tumour necrosis factor agents, infliximab and etanercept have the greatest number reported in the literature, including acute diffuse interstitial lung disease, subacute diffuse interstitial pneumonia, pulmonary infiltrates with eosinophilia, irreversible pulmonary fibrosis and opportunistic infectious pneumonia. Abatacept use in chronic obstructive pulmonary disease has been associated with an increased risk of developing an acute exacerbation, and use of abatacept should be undertaken with caution. Interstitial lung disease or pulmonary fibrosis occurred in less than $0.5 \%$ of patients. There are rare descriptions of rituximab causing acute diffuse interstitial lung disease, subacute diffuse interstitial pneumonia, desquamative interstitial pneumonia, irreversible pulmonary fibrosis and diffuse alveolar hemorrhage. Strategies to reduce pulmonary toxicity include having knowledge of the drugs now being used by rheumatologists and working closely with them, and referring patients to a multidisciplinary rheumatology/respirology clinic with colleagues familiar with the use of these drugs (McMaster, McGill, Calgary and Vancouver have formal clinics, and Ottawa and Winnipeg have strong, close relationships).

\section{AZATHIOPRINE AND TPMT}

Azathioprine (AZA) is a drug that is commonly used as an immunosuppressant by respirologists and rheumatologists (1). Thiopurine S-methyltransferase (TPMT) is the rate-limiting step in the conversion of thiopurine drugs including AZA to inactive metabolites. Heritable deficiency of TPMT activity increases risk of adverse events, most notably myelosuppression leading to leukopenia and neutropenic sepsis. In a series of 739 patients treated over a 27-year period (1964 to 1991) with $2 \mathrm{mg} / \mathrm{kg}$ per day of AZA, there was drug-attributable myelosuppression in 5\%, including severe leukopenia in $1.2 \%$ of patients (2). Of these leukopenic patients, three had pancytopenia and two died. Thus, although rare, severe hematological toxicity can occur and can be fatal in approximately $0.3 \%$ (two of 739 ) patients. A recent Spanish study (3) detected abnormal liver enzyme levels in $15 \%$ and hepatotoxicity in 5\% among 786 adult patients with inflammatory bowel disease who were prescribed AZA. Unlike myelosuppression, hepatotoxicity in AZA-prescribed patients was not correlated with TPMT deficiency in this and another United States study $(3,4)$.

To date, at least 23 TPMT alleles have been classified, including TPMT*1 (wild-type allele), which encodes the enzyme with normal activity. Three variant alleles, TPMT*2, TPMT*3A and TPMT*3C, account for most intermediate or low activity cases, with allele frequencies of approximately $0.5 \%, 5 \%$ and $0.5 \%$, respectively, in Caucasians. The main drawbacks of genotypic TPMT testing are lack of standardized testing and lack of knowledge of the phenotypic correlates of some of the rare TPMT mutations, in particular among nonCaucasians for whom less knowledge about the TPMT polymorphism is available. TPMT enzyme activity in the population is highly variable. Ninety per cent of individuals have high/normal activity of more than $10 \mathrm{U} / \mathrm{mL}$ blood (reflecting two active alleles) and $10 \%$ have intermediate TPMT activity of between $5 \mathrm{U} / \mathrm{mL}$ and $10 \mathrm{U} / \mathrm{mL}$ blood (reflecting only one active allele); $0.3 \%$ (approximately one person in 300) have low/absent activity due to two inactive alleles. TPMT testing in leukocytes is technically difficult and, as such, erythrocyte TPMT activity is used as a surrogate for leukocyte TPMT activity. Many drugs such as methotrexate, furosemide and sulfasalazine can affect TPMT activity. TPMT enzyme levels may be increased in the case of blood transfusions from a homozygous wild-type person before the blood sample is taken for TPMT assay.

In the case of homozygous polymorphisms, the recommendation is not to give thiopurine or to reduce to $10 \%$ of standard starting dose. Dose is reduced to $50 \%$ of standard dose in heterozygotes, with some authors recommending an even safer initial dose reduction to $33 \%$. If you start low and plan to increase, how long do you wait to reassess? The American College of Rheumatology guidelines, last updated in 1996 (6) recommend blood counts every two weeks until dosage is stable, then every one to three months.

TPMT testing, as sensitive and as cheap as it might become in the future, will never be able to identify in advance all patients who might suffer severe AZA-related adverse drug reactions, including severe 
leukopenia. For these reasons, among others, TPMT testing alone cannot assure maximal safety for AZA- or 6-mercaptopurine-prescribed patients, and regular monitoring of blood counts and liver functions must be continued, even in patients who are found to be normal TPMT metabolizers (5). It is important to bear in mind that AZArelated adverse events are not necessarily the result of TMPT deficiency and may reflect drug interactions or variants of other metabolic enzymes that affect AZA metabolism.

In conclusion, heritable deficiency of TPMT activity increases risk for adverse events from thiopurines, most notably myelosuppression, but to levels not correlated with hepatotoxicity. It appears preferable to have phenotype testing and dose reduction in patients with heterozygous deficiency and intermediate activity. One should avoid thiopurines in patients with a homozygous deficient genotype and low activity.

\section{REFERENCES}

1. Gurwitz D, Rodríguez-Antona C, Payne K, et al. Improving pharmacovigilance in Europe: TPMT genotyping and phenotyping in the UK and Spain. Eur J Hum Genet 2009;17:991-8.

2. Connell WR, Kamm MA, Ritchie JK, Lennard-Jones JE. Bone marrow toxicity caused by azathioprine in inflammatory bowel disease: 27 years of experience. Gut 1993;34:1081-5.

3. Gisbert JP, Luna M, González-Lama Y, et al. Liver injury in inflammatory bowel disease: Long-term follow-up study of 786 patients. Inflamm Bowel Dis 2007;13:1106-14.

4. Shaye OA, Yadegari M, Abreu MT, et al. Hepatotoxicity of 6-mercaptopurine (6-MP) and azathioprine (AZA) in adult IBD patients. Am J Gastroenterol 2007;102:2488-94.

5. Wang L, Weinshilboum R. Thiopurine S-methyltransferase pharmacogenetics: Insights, challenges and future directions. Oncogene 2006;25:1629-38

6. American College of Rheumatology Ad Hoc Committee on Clinical Guidelines. Guidelines for monitoring drug therapy in rheumatoid arthritis. Arthritis Rheum 1996;39:723-31

\section{Lung cancer in women}

\author{
Stephen Lam MD FRCPC \\ British Columbia Cancer Agency and the University of British \\ Columbia, Vancouver, British Columbia \\ Slam2@bccancer.bc.ca
}

\section{EPIDEMIOLOGY}

In Canada and the United States, lung cancer has superseded breast cancer as the most common cause of cancer death in women. Women tend to have an earlier onset of lung cancer and have significantly higher risk for adenocarcinoma. While some studies suggest women may be more susceptible to lung cancer from smoking, the greater risk is thought to be related to misunderstandings about relative versus absolute risk. When incidence rates are compared, there is usually no significant difference between men and women smokers. However, self-reported smoking may not reflect the actual exposure. Women reporting smoking 20 cigarettes per day were found to have a serum cotinine level equivalent to men smoking 13 cigarettes per day (1). Whether the difference is due to over-reporting of cigarette consumption in women, under-reporting in men, or increased metabolism of nicotine due to over-expression of cytochrome P450 genes (which would also lead to production of more tobacco smoke carcinogens), the observation would imply women may sustain more damage from smoking the same or lower quantity of tobacco.

In never smokers, the National Institutes of Health AARP cohort study found 1.3 times as many women as men to have lung cancer (2). In Asia, $60 \%$ to $80 \%$ of lung cancers in never smokers are women (3). The gross gender imbalance could not be accounted for by exposure to known carcinogens such as environmental tobacco smoke, heated cooking oil, fumes from coal/wood burners/stoves or human papillomavirus infection.

\section{BIOLOGICAL BASIS OF GENDER DIFFERENCES}

Exposure to cigarette smoke in teenagers reduces lung function growth more severely in girls than in boys (4). This reduction in lung growth may have an impact in adult life. For the same decrease in forced expiratory volume in $1 \mathrm{~s}$, adult women were found to be 2.6 times as likely to develop lung cancer as men (5). A recent study showed that early onset of chronic obstructive pulmonary disease in women is associated with an early onset of lung cancer (6). Female hormones such as $17 \beta$-estradiol up-regulate cytochrome P450 activity. Activation of estrogen receptors leads to increased cellular proliferation and tumour growth. In a xenograft model of adenocarcinoma, treatment with an estrogen receptor antagonist was found to reduce tumour growth (7).

Genetic alterations in tumours such as epidermal growth factor receptor mutations occur more often in women, especially never smokers of Asian origin (3). Polymorphism in the nicotinic acetylcholine receptor gene in chromosome $15 \mathrm{q} 24-25.1$ was found to be associated with relative risks for lung cancer of 2.5 in women and 1.37 in men (8). Nicotine and tobacco carcinogens such as NNK can activate the nicotinic acetylcholine receptor resulting in activation of a number of signalling pathways such as Akt, mitogen-activated protein kinase, cyclooxygenase-2 and epidermal growth factor receptor that can in turn lead to increase in cell proliferation, angiogenesis, inflammation and decrease apoptosis.

\section{IMPLICATION OF GENDER DIFFERENCES}

Gender differences have important implications in prevention and treatment of lung cancer. Removal of active and second-hand tobacco smoke exposure, modification of cooking practices and proper home ventilation can reduce lung cancer risk in women. In areas where human papillomavirus infection is prevalent, vaccination to prevent cervical cancer may have an added benefit of preventing lung cancer. Choice of systemic therapy needs to take gender into account in addition to histological cell type, smoking status and ethnicity. For example, response to erlotinib or gefitinib is better in women never smokers with adenocarcinoma.

\section{SUMMARY}

There is evidence suggesting that women may be more susceptible to lung cancer from exposure to tobacco smoke and other inhaled carcinogens. Lung cancer appears to be a different disease in women with predominant adenocarcinoma and a different molecular biology profile. Further prospective studies are needed to confirm whether the incidence rate is higher in women versus men never smokers, especially those in the premenopausal age group.

\section{REFERENCES}

1. Gan WQ, Cohen SB-Z, Man SFP, Sin DD. Sex-related differences in serum cotinine concentrations in daily cigarette smokers. Nicotine Tob Res 2008;8:1293-300.

2. Freedman ND, Leitzmann MF, Hollenbeck AR, Schatzkin A, Abnet CC. Cigarette smoking and subsequent risk of lung cancer in men and women: Analysis of a prospective cohort study. Lancet Oncol 2008:9:649-56.

3. Sun S, Schiller JH, Gazdar AF. Lung cancer in never smokers - a different disease. Nature 2007;7:778-90.

4. Gold DR, Wang X, Wypij D, Speizer FE, Ware JH, Dockery DW. Effects of cigarette smoking on lung function in adolescent boys and girls. N Engl J Med 1996;335:931-7.

5. Wasswa-Kintu S, Gan WQ, Man SF, Pare P, Sin DD. Relationship between forced expiratory volume in one second and the risk of lung cancer: A systematic review and meta-analysis. Thorax 2005;60:570-5.

6. Schwartz AG, Cote ML, Wenzlaff AS, et al. Chronic obstructive lung diseases and risk of non-small cell lung cancer in women. J Thorac Oncol 2009;4:291-9.

7. Stabile LP, Lyker JS, Gubish CT, Zhang W, Grandis JR, Siegfried $\mathrm{JM}$. Combined targeting of the estrogen receptor and the epidermal growth receptor in non-small call lung cancer shows enhanced antiproliferative effects. Cancer Res 2005;65:1459-70.

8. Spitz MR, Amos CI, Dong Q, Lin J, Wu X. The CHRNA5-A3 region on chromosome $15 \mathrm{q} 24-25.1$ is a risk factor for both nicotine dependence and for lung cancer. J Natl Cancer Inst 2008;100:1552-6. 


\section{Cystic fibrosis care as a model for general respiratory care}

\author{
Larry C Lands MD PhD \\ Department of Pediatrics, McGill University, Montreal, Quebec \\ larry.lands@muhc.mcgill.ca
}

$\mathrm{T}$ he classical model of patient care has used a pyramidal structure, with instructions emanating from the doctor to nursing and allied health. Furthermore, the patient is viewed as an individual, out of context to their social situation. In reality, the patient lives in a complex social network involving spouses, parents, siblings, dependents and others, including work or education responsibilities. This network will impact the patient's ability to cope with illness and manage symptoms and treatments. It is also important to differentiate disability or physiological impairment from handicap, or the consequences of this disability. Limited respiratory ability may result in a patient's curtailment of pleasant or important social interactions or being unable to comfortably perform activities of daily living.

A more comprehensive approach can be achieved through patientand family-centred care, with the patient and their family being the hub of a wheel, with the health care providers interacting with the patient, as well as interacting and supporting team members. A way to envision this management is a cilium seen in cross-section, with the patient and family at the centre, the team members circled around them connected by the radial spokes, and the dynein arms helping the other team members.

The team consists of various members, but is led by a tandem team of a respirologist and nurse-coordinator. In fact, the nurse-coordinator typically serves as a port of entry and coordinator of all needed services. Physiotherapists are important for instruction both in the clinic and at home to work on enhancing endurance, strength and mobility, as well as breath control. Respiratory therapists guarantee appropriate use of inhalation devices as well as performing pulmonary function and exercise testing. Nurses, social workers, psychologists and educators work to support the patient and family around the identification of barriers, gaps in education and stressors, including financial, that affect progress toward self-management. Motivational interviewing, discussed below, is now identified as a technique to help patients and families make sustained changes in behaviour by developing strategies that support short- and long-term attainment of personal goals.

Nutritionists are important team members providing both macroand micronutrient advice, and help with the choice of adjuvant therapies, such as oral herbal supplements. As the mix of medications and other therapies becomes more complex, pharmacists can be very helpful in patient education, assisting with scheduling of therapies, avoiding interactions between medications and foods, and limiting the risk for adverse events.

Other physicians are also important team members. This can involve other subspecialists to deal with such problems as cardiovascular disease, diabetes and gastrointestinal disease impacting lung function or nutrition. The community physician is also an integral team member, allowing for continuity of care and maintaining the patient at home.

It is obvious that good communication is required among the team members and that a common approach to the patient is provided. Motivational interviewing is a "directive, client-centered counselling style for eliciting behaviour change by helping clients to explore and resolve ambivalence" (www.advancmed.org/839mi). In this process, change is elicited within the patient, where the patient identifies and resolves the barriers and ambivalence toward achieving goals set by the patient. The therapist's and team's role is to counsel and partner with the patient through this process. Readiness to change is dependent on the patient/team partnership, and will fluctuate over time.

Work completed through the United States Cystic Fibrosis Foundation has identified factors that can improve team function and outcome (availableatwww.cff.org/LivingWithCF/QualityImprovement).
This includes involving patients and families in the organization and provision of care, anticipatory care, with attention to optimizing nutrition and preventing exacerbations, and early intervention when symptoms are worsening. The team also provides support and guidance surrounding transplantation and end-of-life decisions.

In summary, the team approach involves multiple medical, nursing, and allied health disciplines. The team requires good communication between members, respect of competencies, and living with shared responsibilities. This combined approach enhances results for patients and their families.

\section{Is my ICU safe?}

\author{
Denny P Laporta MD \\ Department of Adult Critical Care, Jewish General Hospital, \\ McGill University, Montreal, Quebec \\ dlaporta@jgh.mcgill.ca
}

W hat would we say to our patients if they asked us how well we adhere to best accepted standards of practice in our intensive care unit (ICU)? Or, how often do patients experience harm during their ICU stay? Better stated, how often do we do what we should? Have we adequate documentation of our practices and outcomes to respond? The sooner we acknowledge that our ultimate goal of care is better patient outcomes and less harm, the sooner we realize that the issue is not "Is my ICU safe?", but rather, how are we making our ICU safer? It is about improvement.

The best starting point is the ICU staff. Ask them what are they most and least proud of and satisfied with in the care delivered; what is working and what is not; what could be done to improve care; and how they think the next patient will be harmed - and listen. Through their observations, perceptions and ideas, you will sense the overall climate of safety and identify common goals for improving it. This proactive approach shows ICU staff that they are supported in helping to improve safety, while cultivating individual accountability. It also promotes group interest and buy-in to improvement initiatives.

Physician engagement in safety improvement is as important as the care they provide. It starts with sharing common goals: improving patient outcomes as well as physicians' personal sense of professional excellence. Simply ask, how can we save you time and make you safer? (1).

\section{CREATE THE TEAM}

The ICU safety improvement team should be mandated and supported by the hospital. Membership should include a chair, quality and safety manager, information technology, multidisciplinary clinical and secretarial support. The practice items chosen should be based on published evidence that will satisfy practitioners to change with an eye to expected outcomes. Regarding standardization, decide on what can be, should be and will be standardized. There are enough tasks in the ICU that would best be done without variation, that one need not attempt to standardize controversial practices. Start off by standardizing all aspects of simple high-volume practices (eg, heparin protocol, stress ulcer and venous thromboembolism prophylaxis). After successful change, consider moving to standardizing elements of more complex practices (eg, physiological goals in resuscitation, mechanical ventilation for hypoxemic respiratory failure).

\section{MEASURE AND MONITOR}

Safety improvement can only be evaluated by measuring its effect on patient care. Define the practice to be improved in terms of what you are trying to accomplish, how you will know that improvement has occurred, and what changes can be made that will result in improvement (2).

\section{A few tips on measurement}

Do not use the data until the improvement process is reliable. Remember that measurement is for improvement, not judgment. The primary concern being self-improvement, between-unit comparisons 
should only be undertaken if associated with an improvement goal. Ask physicians and other team members what data they would like collected and that they would trust. ICU scorecards (3) are an example of a tool for aggregating a number of measurements that relate to domains of care: structure (how care is organized, eg, multidisciplinary clinical team with specific expertise, interest and time dedicated to the care of ICU patients), process (what is done by caregivers), outcome (the health care results achieved), and context and culture (collective attitudes and beliefs of local caregivers). There should be agreement among staff on what each measurement reflects, and how changes in the measurement could indicate an improvement. This can be gradually introduced during staff encounters (eg, morbidity and mortality rounds, service meetings) by regularly presenting a patient case with a safety issue, discussing ICU readmissions, unplanned extubations, reintubations, line infections, etc.

\section{IMPLEMENTING CHANGE}

Start with standard safety practices such as hand hygiene, respiratory etiquette and best practice bundles (prevention of nosocomial infections [4], nutritional support, etc). If adherence to the improvement process is problematic, the problem is more likely to be the process than the people. Fix it before attempting to improve compliance. Make the right thing easier to do than the status quo. Addressing barriers to change requires uncompromising commitment to honest interpersonal communication and willingness to improve patient care.

Is my ICU safe? Yes, if ICU leaders and staff demonstrate an unrelenting commitment to improving the care of patients through individual and system competency and performance. "Engaging is not 'their' problem , but 'our' problem: it starts with us" (1). "The obstacles (to safe care)... are no longer technical ...(but) lie in beliefs, intentions, cultures and choices... All of those can change... we will not become safe until we choose to become safe" (5).

\section{REFERENCES}

1. Engaging physicians in a shared quality agenda. IHI white paper. <www.ihi.org/IHI/Results/WhitePapers/ EngagingPhysiciansWhitePaper.htm>

2. Safer Healthcare Now! The Canadian ICU Collaborative < www. saferhealthcarenow.ca/EN/about/WhoWeAre/clinicalSupports/Pages/ icu.aspx>

3. Berenholtz SM, Pustavoitau A, Schwartz SJ, Pronovost PJ. How safe is my intensive care unit? Methods for monitoring and measurement. Cur Opin Crit Care 2007;13:703-8.

4. Safer Healthcare Now! Interventions < www.saferhealthcarenow.ca/ EN/Interventions/Pages/default.aspx $>$

5. Leape LL, Berwick DM. Five years after To Err is Human - what have we learned? JAMA 2005;293:2384-90.

\section{Knowledge translation: Barriers and facilitators to implementation}

\author{
France Légaré MD PhD \\ Department of Family and Emergency Medicine, \\ Université Laval, Montreal, Québec \\ France.legare@mfa.ulaval.ca
}

$\mathrm{T}$ he effective transfer and exchange of knowledge in clinical practice is essential to ensure that Canadians have access to high-quality and safe care procedures. However, to date, there is a consensus among the implementation research community that most efforts in the translation and exchange of knowledge at the clinical level have met with very little success (1). Although each phase of the knowledge-to-action cycle is important for ensuring the effective translation and exchange of knowledge in clinical practice, the assessment of barriers and facilitators to knowledge use is a key stage for adapting knowledge to the target users' context (2). In a recently published systematic review of 78 studies (3), factors most consistently associated with prediction of behaviour change in health care professionals were beliefs about capabilities; in other words, barriers and facilitators to knowledge use (3).
One of the most often cited conceptual frameworks regarding barriers to knowledge use in health care is the Clinical Practice Guidelines (CPG) Framework for Improvement (4). This framework was based on an extensive search of the literature regarding barriers to physician adherence to CPG and was organized according to knowledge, attitudes or behaviour of physicians (5). It proposes a well-defined taxonomy of barriers that can be used by those involved in transfer and exchange of knowledge in clinical practice. A total of 76 studies describing at least one barrier to adherence to CPG were included in this review. Taken together, the included studies reported on a total of 293 potential barriers to physician guideline adherence, including awareness of the existence of the guideline (ie, the ability to correctly acknowledge the existence of shared decision-making) $(n=46)$, familiarity with the guideline recommendations (ie, the ability to correctly answer questions about the guideline content) $(n=31)$, agreement with the recommendations (ie, consenting to the recommendations) $(n=33)$, self-efficacy (ie, feeling one is able to carry out the recommendations) $(n=19)$, outcome expectancy (ie, perception that one's performance following the use of the recommendations will lead to improved patient outcome or process outcome) $(n=8)$, ability to overcome the inertia of previous practice (ie, feeling one is able to modify his/her routine) $(n=14)$ and absence of external barriers to following recommendations (ie, perception of factors external to oneself that would impede the use of the recommendations) $(n=34)(4)$. In recent years, this framework has been used successfully in diverse clinical contexts and expanded to include new barriers as well as facilitators to knowledge use $(6,7)$.

Based on the CPG Framework for Improvement, a tool to assess barriers to adherence to hand hygiene guidelines was developed and tested on a group of 21 infectious disease clinicians (8). The tool uses a six-point Likert scale and has two sections: attitudinal statements about practice guidelines in general, and specific statements regarding the Hand Hygiene Guideline. The survey was administered twice, at twoweek intervals. The Attitudes Regarding Practice Guideline tool was found to have a test-retest reliability coefficient of 0.86 and a standardized Cronbach alpha of 0.80 (8). However, the authors concluded that their tool needed to undergo further testing and adaptation as a measure of potential barriers to adherence to CPG in general (8).

In summary, there is a need to standardize the reporting of barriers and facilitators to knowledge use for the effective transfer and exchange of knowledge in clinical practice. Those responsible for this important activity may want to consider using existing models and their taxonomy, such as the CPG Framework for Improvement, to conduct barriers and facilitators assessment studies (4). However, there remains a need for more research on how to choose the right intervention to address a specific barrier and/ or a facilitator. Only then will the gap between research and practice be adequately addressed.

ACKNOWLEDGEMENTS: Dr Légare holds the Canada Research Chair in Implementation of Shared Decision Making in Primary Care.

\section{REFERENCES}

1. Grimshaw JM, Thomas RE, MacLennan G, , et al. Effectiveness and efficiency of guideline dissemination and implementation strategies. Health Technol Assess 2004;8:iii-iv, 1-72.

2. Graham ID, Logan J, Harrison MB, et al. Lost in knowledge translation: Time for a map? J Contin Educ Health Prof 2006;26:13-24.

3. Godin G, Belanger-Gravel A, Eccles M, Grimshaw J. Healthcare professionals' intentions and behaviours: A systematic review of studies based on social cognitive theories. Implement Sci 2008;3:36.

4. Cabana M, Rand C, Powe N, et al. Why don't physicians follow clinical practice guidelines? A framework for improvement. JAMA 1999;282:1458-65.

5. Ajzen I. Attitudes, Personality and Behavior. Keynes M, ed. Open University Press; 1988.

6. Espeland AA, Baerheim AA. Factors affecting general practitioners' decisions about plain radiography for back pain: Implications for classification of guideline barriers - a qualitative study. BMC Health Serv Res 2003;3:8. 
7. Légaré F, Ratté S, Gravel K, Graham ID. Barriers and facilitators to implementing shared decision-making in clinical practice: Update of a systematic review of health professionals' perceptions. Patient Educ Couns 2008;73:526-35.

8. Larson E. A tool to assess barriers to adherence to hand hygiene guideline. Am J Infect Control 2004;32:48-51.

\section{Managing childhood asthma: New insights into the September epidemic}

Piush J Mandhane MD PhD ${ }^{1}$, Neil W Johnston $\mathrm{MSc}^{2}$, Malcolm R Sears MB ChB ${ }^{2}$

${ }^{1}$ Department of Pediatrics, University of Alberta, Edmonton, Alberta;

${ }^{2}$ Division of Respirology, McMaster University, Hamilton, Ontario mandhane@ualberta.ca

\section{RELATIONSHIP BETWEEN ASTHMA EXACERBATIONS AND SCHOOL RETURN}

Epidemics of asthma exacerbations requiring hospital treatment occur annually following school return after the summer vacation (1). In Canada, the peak of the epidemic in school-age children occurs consistently 18 days after Labour Day (week 38; Figure 1A) (1), with slightly later and attenuated peaks seen in preschool-aged children and adults. Between 20\% and 25\% of hospital admissions for asthma of children in Canada occur in the month of September.

POTENTIAL ETIOLOGY OF THE SEPTEMBER EPIDEMIC

The September epidemic is likely the result of a number of factors, including children not being on regular asthma controller therapy such as inhaled corticosteroids (ICS) over the summer (Figure 1B) (2); rhinovirus-associated respiratory tract infections (3); exposure to increased car pollution and allergens in the school (4); and increased stress associated with school return (5).

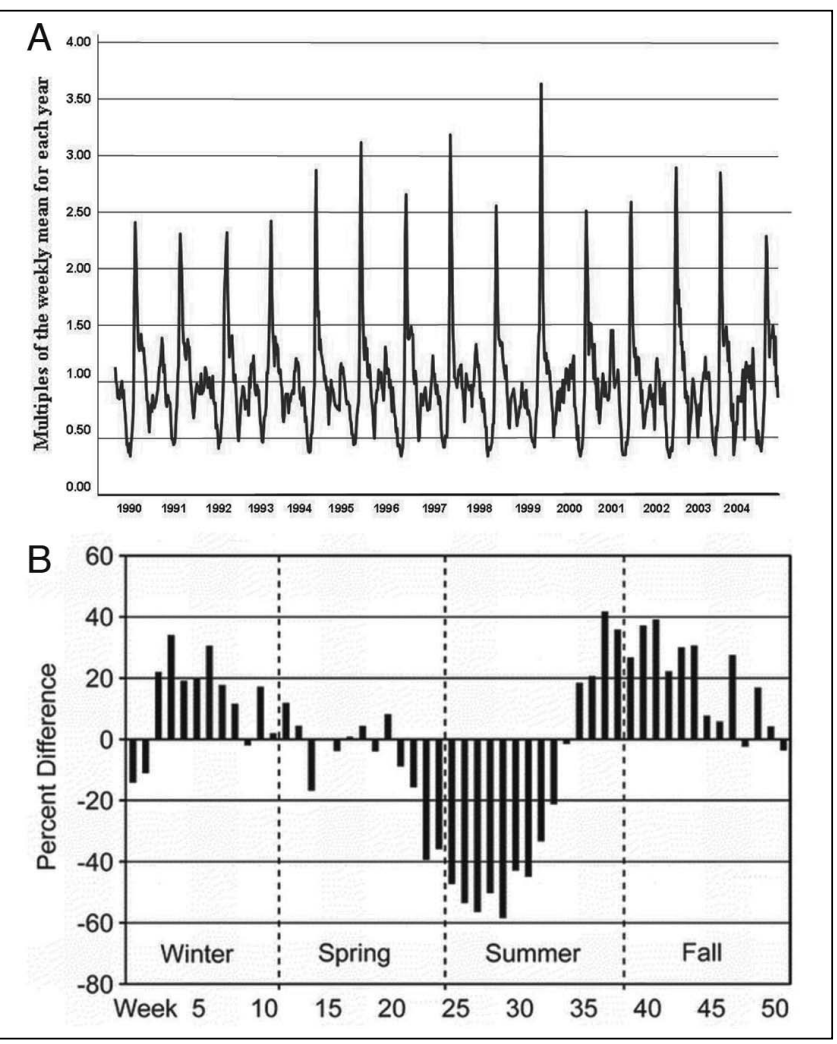

Figure 1) A Asthma admission rates for two-to 15-year-old children in Canada between 1990 and 2004 (1). Asthma admission rates are three times higher during September compared with the baseline weekly rate. B Prescription refills for inhaled corticosteroid by week of the year (2). Refills are lowest during the summer, just before the onset of the September epidemic
MANAGEMENT OF THE SEPTEMBER EPIDEMIC

Management of the September epidemic includes emphasizing that there are no holidays from asthma controller. Translation of this recommendation into practice may be difficult due to chaotic summer schedules for patients and practitioners in addition to challenges in providing timely asthma education programs effectively (6).

Pharmaceutical management has focused on adding asthma medication to the child's usual therapy during or before the onset of the September epidemic. We recently demonstrated that children who started montelukast (a leukotriene-receptor antagonist) on September 1st for six weeks experienced over a $50 \%$ reduction in days with worse asthma symptoms compared with placebo $(\mathrm{P}<0.02)$ and a $78 \%$ reduction in unscheduled physician visits for asthma $(\mathrm{P}=0.011)(7)$. The benefit of montelukast was seen both in those using and not using regular ICS, and among those reporting and not reporting colds during the trial.

\section{CONCLUSION}

The September epidemic of asthma exacerbations is closely related to school return. Rhinovirus infection is common in September and an important reason for the epidemic. Lack of adequate controller medication may also fuel the epidemic. Short-term addition of effective asthma controller therapy provides the opportunity to attenuate the epidemic. Future research may include evaluating the utility of targeted asthma education around the September epidemic with strategies to improve compliance with ICS over the summer.

\section{REFERENCES}

1. Sears MR, Johnston NW. Understanding the September asthma epidemic. J Allergy Clin Immunol 2007;120:526-9.

2. Van Dole KB, Swern AS, Newcomb K, Nelsen L. Seasonal patterns in health care use and pharmaceutical claims for asthma prescriptions for preschool- and school-aged children. Ann Allergy Asthma Immunol 2009;102:198-204.

3. Johnston NW, Johnston SL, Duncan JM, et al. The September epidemic of asthma exacerbations in children: A search for etiology. J Allergy Clin Immunol 2005;115:132-8.

4. Almqvist C, Larsson PH, Egmar AC, Hedren M, Malmberg P, Wickman M. School as a risk environment for children allergic to cats and a site for transfer of cat allergen to homes. J Allergy Clin Immunol 1999;103:1012-7.

5. Sandberg S, Paton JY, Ahola S, et al. The role of acute and chronic stress in asthma attacks in children. Lancet 2000;356:982-7.

6. McGhan SL, Cicutto LC, Befus AD. Advances in development and evaluation of asthma education programs. Curr Opin Pulm Med 2005;11:61-8.

7. Johnston NW, Mandhane PJ, Dai J, et al. Attenuation of the September epidemic of asthma exacerbations in children: A randomized, controlled trial of montelukast added to usual therapy. Pediatrics 2007;120:e702-12.

\section{What's next for the National Lung Health Framework?}

Darcy D Marciniuk MD FRCPC FCCP ${ }^{1}$, Nora Sobolov ${ }^{2}$

${ }^{1}$ Division of Respirology, Critical Care and Sleep Medicine, Royal University Hospital, University of Saskatchewan, Saskatoon, Saskatchewan;

2President and CEO, Canadian Lung Association, Ottawa, Ontario darcy.marciniuk@usask.ca

$T^{\text {he }}$ he National Lung Health Framework took a leap forward toward implementation with the welcome announcement by Health Minister Leona Aglukkaq on April 24, 2009, of 10 million dollars in initial funding over the next three years. The Framework was developed to address the growing and under-recognized burden of respiratory illness and disease in Canada. A coordinated plan and approach was required to enhance research intensiveness, to raise awareness of the benefits of improved respiratory health and the adverse consequences of disease, to focus attention both nationally and provincially on priority areas for action, and to enhance sharing 
and implementation of best practices and existing knowledge.

The history of the National Lung Framework began in 2006 with an initial meeting of 40 interested stakeholders, including representatives of the Canadian Thoracic Society, the Canadian Respiratory Health Professionals and the Canadian Lung Association. Initial funding for the project was provided by the Public Health Agency of Canada and the Canadian Lung Association, which have continued to strongly support this important endeavor. An Interim Steering Committee was formed, and helped to plan a larger national forum held in April 2007, attended by more than 200 stakeholders and personally attended by Minister of Health Tony Clement, and Minister of the Environment John Baird. Following that successful meeting, forums were held in every province and territory in 2008, together with a number of expert advisory panel meetings. In total, more than 500 individuals participated in this process. In May 2008, an initial draft Framework document was presented to the Minister of Health, and received very strong support. The final document was released in fall 2008, and work then began on an action plan for implementation, priority- and goal-setting, monitoring and evaluation. To assist with this important task, an expanded Steering Committee was formed with the intent of guiding the process forward for the next five years.

The continuum of lung health as developed by the Framework is depicted in Figure 1. It recognizes that all individuals are at risk of lung disease, and the magnitude of that risk is dependent on a number of factors, including genetic, environmental, and other determinants of lung health. The Framework emphasizes the importance of:

1. Health promotion, awareness and disease prevention;

2. Disease detection and management;

3. Policy partnerships, and community/systems support; and

4. Research, surveillance and knowledge translation in the prevention, awareness, early detection, and optimal management of lung symptoms, disorders and diseases.

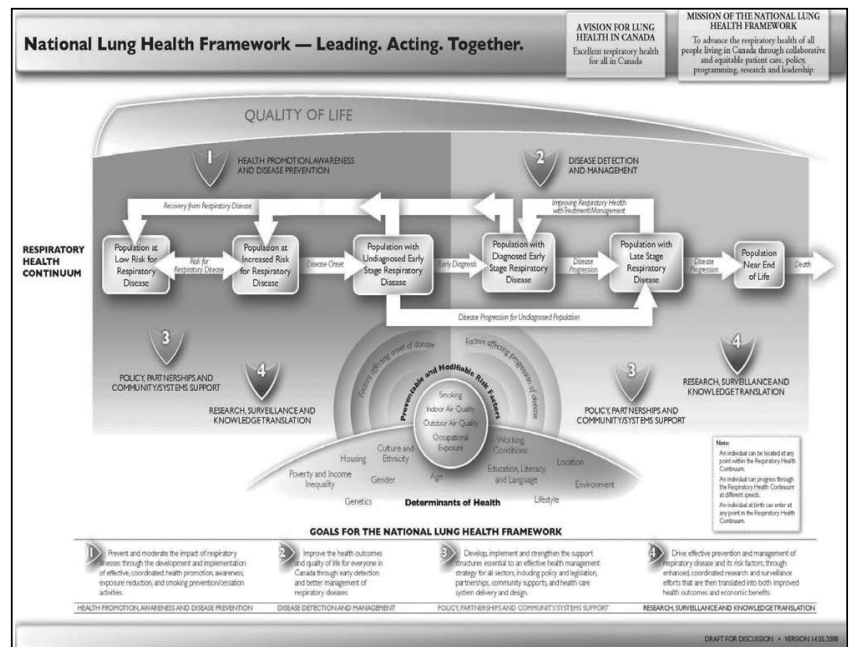

Figure 1) The Respiratory Health Continuum

The goal of the National Lung Health Framework is excellent respiratory health for all in Canada. As the first ever health strategy that appreciates the close relationship between the environment and health, the starting point of the Framework was to develop a common strategic action plan for the respiratory health community, stakeholders and governments, so that we best use resources to improve the lung health of Canadians.

The announcement by Health Minister Aglukkaq represented an important leap in the process. Until now, we have taken a number of steps forward including markedly increasing awareness and profile of the problem with governments, increasing coordination and collaboration among partners, particularly the Public Health Agency of
Canada. In addition, initial development of an online Knowledge Hub proceeded, and general consensus on the importance of priorities such as research funding, knowledge transfer, inadequate human resources, and the unique problems and needs of at-risk segments of the Canadian population was achieved.

While much has already been accomplished, there is more to be done. There is an opportunity for everyone to participate in the process, to share learnings and best practices with colleagues, and to listen to the successes of others. There is an opening to work with your member organizations to help with implementation and evaluation, and encourage those around you to do the same. The strong support of the federal government is both welcome and paramount, but that is only one piece to a very large puzzle. Without the engaged participation of all of us, we will not make progress. So much of what we need to do involves ensuring that we break down silos of excellence, share our knowledge and resources, and ensure that we continue to raise awareness of the impact of respiratory disease in Canada. To meet our goals and vision for our patients, we can do nothing less.

ACKNOWLEDGEMENTS: Dr Marciniuk is a Lung Association of Saskatchewan COPD Professor, and University of Saskatchewan/ Saskatchewan Health Research Foundation Airway Research Group Member.

\section{Twenty-four hour noninvasive ventilation in neuromuscular disease: The Ottawa experience}

Douglas A McKim MD FRCPC FCCP DABSM

Ottawa Hospital Sleep Centre and Respiratory Rehabilitation Services, University of Ottawa, Ottawa, Ontario dmckim@ottawahospital.on.ca

$\mathrm{N}$ oninvasive ventilation (NIV) has become a well established treatment in the management and survival of patients with neuromuscular diseases (NMD) (1-6). The benefits of NIV demonstrated in some populations include improved diurnal gas exchange, better sleep quality, better quality of life and increased survival. While NIV has been provided for more than 50 years with negative pressure ventilation, current devices are positive pressure, predominantly pressure-targeted bilevel ventilators with noninvasive mask interfaces. These are generally used overnight when gas exchange tends to be the most affected. As NMD progresses, the number of hours of required ventilatory support will also increase. In spite of a number of publications and extensive clinical experience $(7,8)$, patients who require more than an arbitrary number of hours of NIV are often advised to undergo tracheostomy ventilation, the default means of provision of $24 \mathrm{~h}$ ventilatory support.

Since 1993, it has been common practice in Ottawa, as recommended by experts and international consensus (Bach [7], ATS DMD [9]), to offer all NMD patients with diurnal respiratory failure and sufficient bulbar function the opportunity to use $24 \mathrm{~h}$ NIV. As a result, not one permanent tracheostomy has been required or requested in any of our patients with Duchenne muscular dystrophy in 16 years (10). The benefits of $24 \mathrm{~h}$ NIV have also been applied to those with amyotrophic lateral sclerosis (ALS), kyphoscoliosis, Becker's muscular dystrophy, high-level spinal cord injury and others. Some patients with no measurable spontaneous lung function (maximal inspiratory and expiratory pressures $=0$, vital capacity $=0$ ) have managed adequate ventilation and survival for months without a tracheostomy and without hospitalization or intensive care unit admission.

Since well before 1953 (11), it has been recognized that polio patients, unable to breathe on their own, could achieve adequate ventilation outside their iron lungs with use of a pressurized mouth piece. Twenty-four hour NIV involves the use of a mouth piece which is attached to the end of a single-limb volume-targeted ventilator 
(eg, LP10 $10^{\mathrm{TM}}$, Legendaire ${ }^{\mathrm{TM}}$, Newport $50^{\mathrm{TM}}$ ) (12) or less commonly a double-limb portable ventilator (LTV $850^{\mathrm{TM}}$ ). The general principle is to allow an open system by providing sufficient airway (tubing) pressure to prevent initiation of the low-pressure alarm, providing an appropriate tidal volume and frequency for comfort and ventilation, and sufficient maximal pressures to permit the performance of lung volume recruitment (LVR) $(13,14)$. This is achieved in a single-limb circuit by using a mouthpiece with adequate resistance or an in-line resistor, setting the low-pressure alarm to its lowest value (usually $2 \mathrm{cmH}_{2} \mathrm{O}$ ) and determining appropriate tidal volumes, rate and inspiratory time. High-pressure alarms are usually set at $60 \mathrm{cmH}_{2} \mathrm{O}$ to $70 \mathrm{cmH}_{2} \mathrm{O}$.

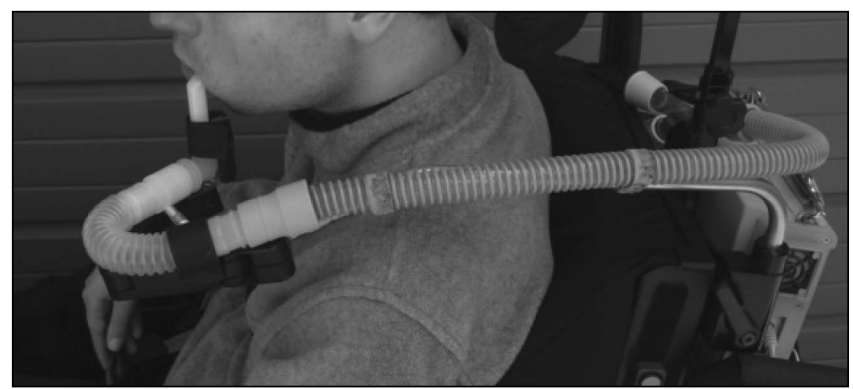

Figure 1) A patient with Duchenne muscular dystrophy with no ventilatorfree breathing time using a chair-mounted, volume-targeted ventilator for mouthpiece ventilation

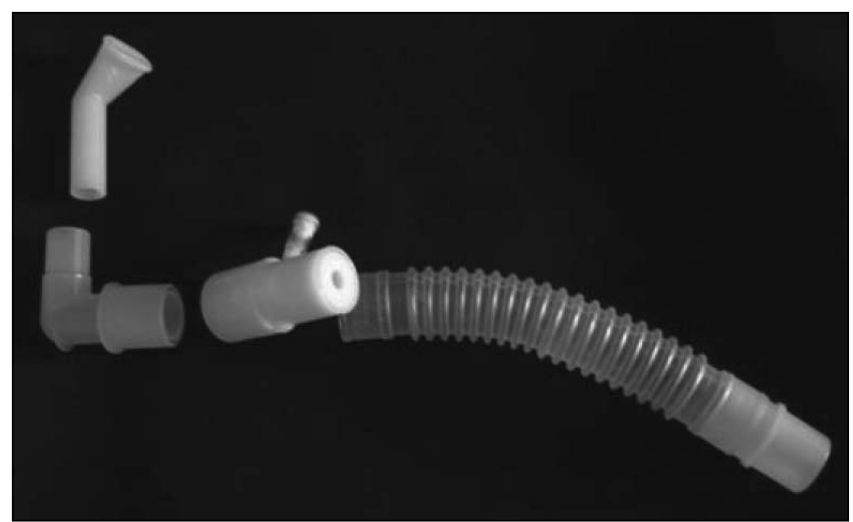

Figure 2) Basic components of a mouthpiece circuit: angled pediatric mouthpiece, elbow, in-line resistor and corrugated tubing

Most patients who are in a position of benefiting from mouthpiece ventilation (MPV) are power-wheelchair assisted. The ventilator can be mounted to the frame on the back of the chair to allow mobile ventilation. Volume-targeted ventilators with internal piston systems use little power and can last for hours with both internal and marine batteries. The ventilator tubing is provided to the patient through the mouth piece and fixed to the frame of the chair by a goose-neck clamp of similar fixation. It is critical that the individual be able to easily access the mouth piece for each required breath. Patients with limited or no ventilator-free breathing time must be accompanied because asphyxiation could occur if they were unable to access their mouth piece. Patients who chose this method, some for well over 10 years, understand and accept this unlikely risk rather than accept the risk and cost of a tracheostomy, particularly when a tracheostomy will likely prevent them from returning home.

A minimal degree of oropharyngeal (bulbar) function is required to manage MPV, and those who cannot speak, swallow and protect their airway are not likely to be good candidates for this alternative. Patients with ALS, for example, tend to have difficulty with LVR and MPV if their bulbar component of the ALS Functional Rating Scale score (15) is less than 8 out of the total of 12 . Such individuals who have elected not to pursue invasive tracheostomy ventilation (TV) would tend to use NIV via a mask for as long as tolerable while receiving palliation. Those who have chosen TV and cannot manage MPV and are requiring increasing hours of diurnal mask support will require elective tracheostomy. To date, we have found that approximately $25 \%$ of our patients with ALS who use NIV can subsequently utilize $24 \mathrm{~h}$ NIV/MPV. Almost all of our patients with Duchenne muscular dystrophy have been successful with MPV when required.

Most patients in our clinic at the Ottawa Hospital Rehabilitation Centre are trained to perform LVR effectively before any ventilatory requirement. These and other preventive airway clearance strategies can be continued during NIV and may contribute to the long-term success of NIV (16). Those individuals using MPV are encouraged to perform regular LVR, which they can do easily by stacking as many ventilatordelivered breaths as they can hold with their glottis. The MPV enables them to do this as often as they like, similar to a full sigh, which the able-bodied take for granted. The highest volume achieved with LVR is referred to as the maximum insufflation capacity (17). This can be more than a $400 \%$ increase over spontaneous vital capacity.

MPV can be an extremely valuable addition to the ventilatory care of patients with NMD who have sufficient bulbar function and a need for more than just nocturnal ventilation. It can safely provide support to patients with little or no respiratory function for extended periods of time. Essentially all of our (more than 40) patients have been managed entirely as outpatients. The arbitrary application of TV for such patients should be discouraged. In appropriate individuals, a trial of MPV is strongly recommended before committing patients and families to a potentially unnecessary, complex and costly tracheostomy.

\section{REFERENCES}

1. Gomez-Merino E, Bach JR. Duchenne muscular dystrophy: Prolongation of life by noninvasive respiratory muscle aids. Am J Phys Med Rehabil 2002;81:411-5.

2. Baydur A, Layne E, Aral H, et al. Long term non-invasive ventilation in the community for patients with musculoskeletal disorders: 46 year experience and review Thorax 2000;55:4-11.

3. Hill NS, Ambrosio C, Ozsancak A. Nocturnal noninvasive ventilation. Chest 2008;133:1275-86.

4. Bourke, SC, Bullock, RE, Williams, TL, et al Noninvasive ventilation in ALS: Indications and effect on quality of life. Neurology 2003;61:171-7.

5. Kleopa, KA, Sherman, M, Neal, B, et al Bipap improves survival and rate of pulmonary function decline in patients with ALS. J Neurol Sci $1999 ; 164: 82-8$

6. Bourke SC, Tomlinson M, Williams TL, et al. Effects of noninvasive ventilation on survival and quality of life in patients with amyotrophic lateral sclerosis: A randomised controlled trial. Lancet Neurol 2006;5:140-7.

7. Bach JR, Alba AS, Saporito LR. Intermittent positive pressure ventilation via the mouth as an alternative to tracheotomy for 257 ventilator users. Chest 1993;103:174-82.

8. Toussaint M, Steens M, Wasteels G, et al. Diurnal ventilation via mouthpiece: Survival in end-stage Duchenne patients. Eur Respir J 2006;28:549-55.

9. Respiratory Care of the Patient with Duchenne Muscular Dystrophy; ATS Consensus Statement. Am J Respir Crit Care Med 2004;170:456-65.

10. Griller N, McKim DA, LeBlanc C. 24 hour noninvasive ventilation in Duchenne muscular dystrophy. Chest 2008. Abst AS2336.

11. Affeldt JE. Roundtable conference on poliomyelitis equipment. 1953. National Foundation for Infantile Paralysis-March of Dimes. White Plains, New York.

12. Boitano LJ, Benditt JO. An evaluation of home ventilators that support open circuit mouthpiece ventilation. Respir Care 2005:50:1457-61.

13. McKim DA. Keeping ventilated and at-risk patients out of the ICU. Can Respir J 2008;15(Suppl C):9C-10C.

14. McKim DA, Rocha JA. Tracheostomy weaning from long term ventilation. In: N Ambrosino, R Goldstein, eds. Ventilatory Support in Chronic Respiratory Failure. Informa Healthcare, 2008. 
15. The ALS CNTF Treatment Study (ACTS) Phase I-II Study Group. The Amyotrophic Lateral Sclerosis Functional Rating Scale: Assessment of activities of daily living in patients with amyotrophic lateral sclerosis. Arch Neurol 1996;53:141-7.

16. Servera E, Sancho J, Zafra MJ, et al. Secretion management must be considered when reporting success or failure of noninvasive ventilation. Chest 2003;123:1773-4

17. Kang, SW, Bach, JR Maximum insufflation capacity. Chest 2000;118:61-5.

\section{Chronic respiratory disease surveillance in Canada}

\author{
Louise McRae \\ Public Health Agency of Canada, Chronic Disease Surveillance \\ Division, Ottawa, Ontario \\ Louise_mcrae@phac-aspc.gc.ca
}

\section{PUBLIC HEALTH SURVEILLANCE}

The Public Health Agency of Canada's Chronic Disease Surveillance Division defines public health surveillance as the tracking or forecasting of health events or health determinants through the regular collection of the best available data; the integration, analysis and interpretation of the data into surveillance products; and the dissemination of these data to those who need it, for a public health purpose or a policy objective (1).

\section{COLLABORATION AND DEVELOPMENT FUNCTIONS}

Within the Chronic Disease Surveillance Division, the work of the Collaboration and Development section includes four key functions.

\section{Analysis, interpretation and use of existing data sources}

Routine surveillance: Burden of respiratory disease in Canada: Existing data such as hospital morbidity, mortality and population survey databases are analyzed on an ongoing basis. Some highlights include:

- More than three million Canadians are affected by one of five serious respiratory diseases: asthma, chronic obstructive pulmonary disease (COPD), lung cancer, tuberculosis and cystic fibrosis (2).

- According to self-reported estimates from the Canadian Community Health Survey, COPD is now being reported more in women than in men younger than 75 years of age (2).

- Prevalence of self-reported asthma among children continues to increase; however, asthma prevalence among Canadians 12 years of age and over has stabilized (2).

Canadian Health Measures Survey (3): The Canadian Health Measures Survey is a new survey being conducted by Statistics Canada with both physical measures and questionnaire survey components. Data collection continues to Spring 2009 on a sample of approximately 5000 Canadians between the ages of six to 79 years, and data release is expected in Spring 2010. The variables of interest to respiratory disease surveillance are measured spirometry, self-reported diagnosed chronic conditions including asthma and COPD (including chronic bronchitis and emphysema), medications, and self reported respiratory symptoms such as cough, phlegm, shortness of breath and persistent colds.

\section{Reporting to key stakeholders}

Life and Breath: Respiratory Disease in Canada (2): A surveillance report describing the burden of major respiratory diseases and their risk factors was released November 22, 2007, and has been widely disseminated.

Chronic Disease Infobase (4): Infobase is a free online data dissemination tool providing access to high-quality and up-to-date health data easily and quickly. Data available include demographics, hospital morbidity, length of stay, mortality, chronic disease risk factors and self-reported prevalence of selected chronic diseases. It is accessible through a web browser, allows one to develop custom queries of aggregated data and can provide data in map, graph or data table format with detailed sources and notes.

\section{Expanding data sources}

Canadian Community Health Survey (CCHS) (5) - Chronic Disease Prevention Theme: The prevention theme was conducted in 2007/2008, and data will be released in June 2009. The content focussed on screening, prevention and awareness. PHAC was successful in adding a question on spirometry administered by a health professional.

Sleep Apnea Rapid Response Survey: The Public Health Agency of Canada developed and sponsored a 2 min supplement survey to Statistics Canada's CCHS. Rapid response surveys collect data on a two-month survey sample of the main CCHS (approximately 10,000 respondents 12 years of age and over). In the case of sleep apnea, data collection was conducted from January to February 2009. The data will provide national level estimates of self-reported sleep apnea prevalence and prevalence of those at high risk for developing sleep apnea. Data are anticipated to be received at the Public Health Agency in the fall of 2009.

Provincial and Territorial Administrative Data: The Public Health Agency of Canada is expanding the National Diabetes Surveillance System (NDSS) (5) provincial/territorial administrative data platform to other chronic diseases. This platform uses three types of databases linked using a unique lifetime identifier: Physician Claims Files, Hospital Files, Health Insurance Registries. Preliminary pilot test results demonstrated the feasibility to generate comparable estimates of treated asthma and treated chronic obstructive pulmonary disease prevalence across provinces. Additional feasibility work is currently underway on revised case definitions and incidence. Recommendations will be presented to the NDSS Steering Committee in the winter of 2009/10.

Survey on Living with Chronic Disease in Canada (SLCDC) (6): The Public Health Agency of Canada has developed the SLCDC with Statistics Canada. The survey consists of a 20 min follow-up survey to the main CCHS survey focussing on specific chronic diseases. Survey content focuses on the following themes: symptoms/severity, selfmanagement, clinical management, patient education, adherence, quality of life and risk factors. The first SLCDC was conducted in 2008/09 and consisted of surveys on hypertension and arthritis. In 2010/11 a survey on respiratory diseases will be conducted concurrently with a survey on diabetes. The respiratory survey will follow-up individuals who reported having asthma or chronic obstructive pulmonary disease (including chronic bronchitis and emphysema) in the main CCHS survey.

\section{Coordination, planning and evaluation}

Chronic Respiratory Disease Surveillance work at the Public Health Agency of Canada is not conducted in isolation. The input of our Chronic Respiratory Disease Surveillance Advisory Committee members and other project-specific working groups is instrumental to the success of this work.

\section{REFERENCES}

1. Public Health Agency of Canada. 2008-09 Report on Plans and Priorities. http://www.tbs-sct.gc.ca/rpp/2008-2009/inst/AHS/ahseng.pdf

2. Public Health Agency of Canada. Life and Breath: Respiratory Disease in Canada. www.phac-aspc.gc.ca/publicat/2007/lbrdc-vsmrc/ index-eng.php

3. Statistics Canada. Canadian Health Measures Survey. http://www. statcan.gc.ca/cgi-bin/imdb/p2SV.pl?Function=getSurvey\&SDDS=50 $71 \&$ lang $=$ en $\& d b=i m d b \& a d m=8 \&$ dis $=2$ infobase phac-aspc.gc.ca

4. Statistics Canada. Canadian Community Health Survey. http://www. statcan.gc.ca/cgi-bin/imdb/p2SV.pl?Function=getSurvey\&SDDS=32 26\&lang $=e n \& d b=i m d b \& a d m=8 \&$ dis $=2$

5. Public Health Agency of Canada. National Diabetes Surveillance System. http://www.phac-aspc.gc.ca/ccdpc-cpcmc/ndss-snsd/english/ ndss_description/index-eng.php

6. Public Health Agency of Canada and Statistics Canada. Survey on Living with Chronic Diseases in Canada. http://www.statcan.gc.ca/ cgi-bin/imdb/p2SV.pl?Function=getSurvey\&SDDS=5160\&lang=en $\& d b=i m d b \& a d m=8 \&$ dis $=2$ 


\section{State-of-the-art management of pulmonary hypertension}

Sanjay Mehta MD FRCPC FCCP

SW Ontario Pulmonary Hypertension Clinic, London Health Sciences Centre, University of Western Ontario, London, Ontario

Sanjay.mehta@lhsc.on.ca

P lmonary hypertension $(\mathrm{PH})$ is a serious and often fatal disease that is increasingly being recognized as neither rare nor uncommon. $\mathrm{PH}$ is defined hemodynamically by persistent elevation in mean pulmonary arterial pressure exceeding $25 \mathrm{mmHg}$ at rest. Patients commonly experience dyspnea, and quickly become incapacitated due to progressive right ventricle (RV) failure. Untreated, the mean survival time in many $\mathrm{PH}$ patients is less than three years. There have been tremendous therapeutic advances over the past decade, as seven effective $\mathrm{PH}$-specific medications are now approved and available for use. Appropriate use of novel $\mathrm{PH}$ medications depends on clinical recognition of $\mathrm{PH}$, prompt and accurate diagnosis of the cause of $\mathrm{PH}$, and institution of therapy in selected $\mathrm{PH}$ patients.

\section{DIAGNOSIS OF PH}

Patients with $\mathrm{PH}$ are usually diagnosed based on the clinical features of their disease (Figure 1). Dyspnea and exertion intolerance are common presenting complaints. Other symptoms include edema, chest pain, dizziness and syncope. Physical findings may be helpful in the identification of $\mathrm{PH}$ patients. The most sensitive sign is an accentuated pulmonic component (P2) of the second heart sound, best heard in the left second intercostal space. Other signs of $\mathrm{PH}$ include increased jugular venous pressure, pedal edema, palpable left parasternal right-ventricular heave, and a pansystolic murmur of tricuspid insufficiency. Many medical conditions are associated with a greater risk of $\mathrm{PH}$, including cardiac disorders (eg, congenital heart disease), pulmonary disorders (eg, pulmonary fibrosis), pulmonary thromboembolic disease, connective tissue disorders, portal hypertension and HIV infection. In such patients, clinicians should be vigilant for any clinical or laboratory features that may suggest $\mathrm{PH}$.

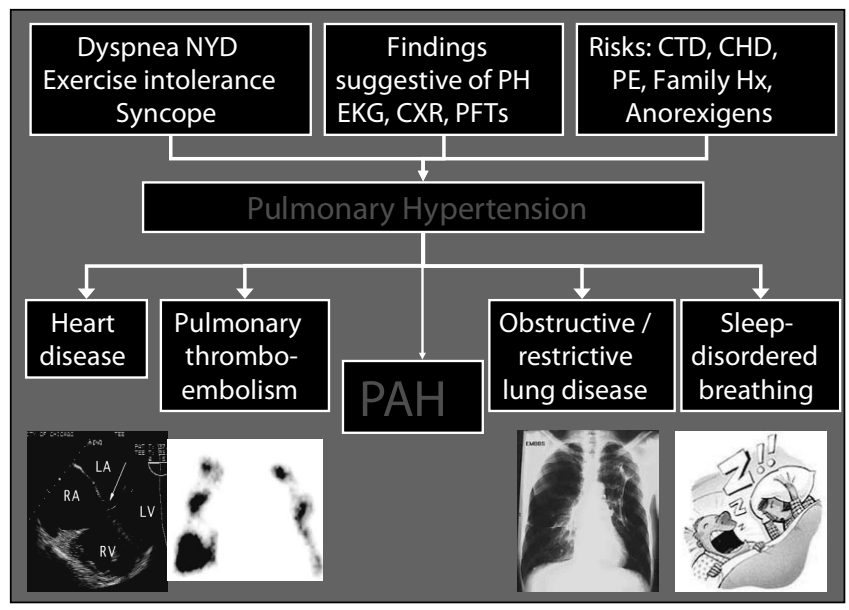

Figure 1) Clinical and diagnostic approach to pulmonary hypertension. CHD Congenital heart diseases; CTD Connective tissue disorders; $\mathrm{Hx}$ History; NYD Not yet diagnosed; PAH Pulmonary arterial hypertension; PE Pulmonary embolism

Abnormalities on commonly used imaging and laboratory tests can sometimes suggest a diagnosis of $\mathrm{PH}$. A chest $\mathrm{x}$-ray can reveal enlarged hilar pulmonary arteries, or an enlarged right ventricle. Electrocardiogram abnormalities that suggest $\mathrm{PH}$ include right axis deviation and RV hypertrophy. Pulmonary function tests often reveal an isolated reduction in diffusing capacity in $\mathrm{PH}$.

In patients suspected to have $\mathrm{PH}$, an appropriate first test would be echocardiography. Echocardiography can measure the RV systolic pressure (approximate systolic pulmonary arterial pressure), but more importantly, can assess the severity of $\mathrm{PH}$ through measurement of abnormal RV size and function. Echocardiography can also detect underlying left-sided or congenital heart disease as a cause of PH. In patients with clinically significant $\mathrm{PH}$, subsequent investigations are focused on detection of underlying pulmonary or pulmonary thromboembolic disease that may be the cause of PH (Figure 1). As such, pulmonary function tests are indicated to detect significant obstructive or restrictive lung disease. Computed tomography imaging is recommended to assess for the presence of underlying interstitial lung disease. A V/Q nuclear lung scan can effectively assess for the presence of pulmonary thromboembolism as a cause of PH. In selected $\mathrm{PH}$ patients, assessment for sleep-disordered breathing would be indicated.

In the absence of significant cardiopulmonary disease associated with $\mathrm{PH}$, patients are diagnosed with pulmonary arterial hypertension (PAH). PAH is a disease of obliteration of small pulmonary arteries due to proliferation and growth of both endothelial and vascular smooth muscle cells.

\section{TREATMENT OF PH}

In the many patients with $\mathrm{PH}$ due to underlying cardiopulmonary disease, there is no specific medical treatment for the PH. The cardiac (eg, heart failure) or pulmonary condition (eg, chronic obstructive pulmonary disease) needs to be aggressively managed, which is often associated with improvement in the degree of PH. In patients with chronic thromboembolic $\mathrm{PH}$, life-long anticoagulation is strongly recommended, but is often insufficient to reverse PH. In appropriate patients, major pulmonary thromboendarterectomy surgery can effectively reverse $\mathrm{PH}$ and greatly improve quality of life and survival.

In patients with PAH, clinical use of the novel PAH-specific medications is recommended. Many of these novel drugs are associated with improved quality of life, better functional capacity, improved cardiac function and, often, better survival.

\section{CONCLUSIONS}

$\mathrm{PH}$ is a common and important clinical condition for clinicians to be familiar with. A clear diagnostic algorithm will help define the cause of $\mathrm{PH}$ in the majority of patients. In specific patients with $\mathrm{PH}$ due to thromboembolic disease or $\mathrm{PAH}$, specific surgical or medical therapy offers improved quality and life and survival.

\section{REFERENCES}

1. D'Alonzo GE, Barst RJ, Ayres SM, et al. Survival in patients with primary pulmonary hypertension. Results from a national prospective registry. Ann Intern Med 1991;115:343-9.

2. McGoon M, Gutterman D, Steen V, et al; American College of Chest Physicians. Screening, early detection, and diagnosis of pulmonary arterial hypertension: ACCP evidence-based clinical practice guidelines. Chest 2004;126:14S-34S.

3. Badesch DB, Abman SH, Ahearn GS, et al. Medical therapy for pulmonary arterial hypertension: ACCP evidence-based clinical practice guidelines. Chest 2004;126:35S-62S.

4. Doyle RL, McCrory D, Channick RN, et al. Surgical treatments/ interventions for pulmonary arterial hypertension: ACCP evidencebased clinical practice guidelines. Chest 2004;126:63S-71S.

5. McLaughlin VV, Presberg KW, Doyle RL, et al; American College of Chest Physicians. Prognosis of pulmonary arterial hypertension: ACCP evidence-based clinical practice guidelines. Chest 2004;126:78S-92S

6. Langleben D, Archer S, Granton J, et al. Canadian Cardiovascular Society and Canadian Thoracic Society position statement on pulmonary arterial hypertension. Can Resp J 2005;12:303-8.

7. Mehta S, Shoemaker GJ. Improving survival in idiopathic pulmonary arterial hypertension: Revisiting the "kingdom of the near-dead". Thorax 2005;60:981-3.

8. Badesch DB, Abman SH, Simonneau G, Rubin LJ, McLaughlin VV. Medical therapy for pulmonary arterial hypertension: Updated ACCP evidence-based clinical practice guidelines. Chest 2007;131:1917-28. 
9. McLaughlin VV, Archer SL, Badesch DB, et al. ACCF/AHA 2009 expert consensus document on pulmonary hypertension: A report of the American College of Cardiology Foundation Task Force on Expert Consensus Documents and the American Heart Association: developed in collaboration with the American College of Chest Physicians, American Thoracic Society, Inc., and the Pulmonary Hypertension Association. Circulation 2009;119:2250-94.

\section{New trials in COPD management: How to translate these into clinical practice}

\author{
Marc Miravitlles MD \\ Fundació Clínic, Institut d'Investigacions Mèdiques August Pi i Sunyer \\ (IDIBAPS), Hospital Clínic, Barcelona, Spain. \\ marcm@separ.es
}

$\mathrm{T}$ he treatment traditionally recommended to patients with chronic obstructive pulmonary disease (COPD) has been based on drugs that were initially developed for the treatment of bronchial asthma. This anomalous situation was due to two causes. On one hand, investigations into the physiopathology and pharmacology of COPD were scarce; on the other hand, there was an erroneous impression that all obstructive bronchial diseases followed the same pathogenic mechanisms. Fortunately, in recent years drugs have been developed according to the specific pathogenic mechanisms of COPD. Similarly, the Global Initiative for Obstructive Lung Disease (GOLD) (1) guidelines adopted a stepwise approach for pharmacological treatment of COPD, similar to the approach in the Global Initiative for Asthma (GINA) guidelines for treatment of asthma.

One proposal for treatment of COPD according to the characteristics of the patients has recently been published (2). The following is a synthesis of these concepts.

1. The initial treatment of all patients with symptomatic COPD is based on the administration of a long-acting bronchodilator. Today, it is difficult to justify treatment with short-acting bronchodilators as the first option in symptomatic patients, even in mild cases.

2. Given that both the combination of salmeterol or formoterol with ipratropium has additive effects on lung function (3), if the initial response is not considered satisfactory, it seems reasonable to assume that the combination of tiotropium with any of these long-acting beta agonists (LABAs) may provide additive benefits similar to that observed with the combination of short-acting bronchodilators.

3. Theophylline is the next drug to add in the bronchodilator treatment of COPD. Theophylline has been shown to have additive effects on treatment with salmeterol (4). However, it is important to point out that the long-term effectiveness and, perhaps more important, the safety of this combination remain unknown.

4. In the most severe patients, the use of tioptropium plus the combination of inhaled corticosteroid (ICS) and LABA may be tested. A recent study (5) demonstrated that the addition of fluticasone/salmeterol to tiotropium treatment in severe patients was able to reduce all-cause and COPD-related hospital admissions, and also improved lung function and quality of life.

5. In patients who do not present with frequent exacerbations and do not have a significant bronchodilator response, despite the severity of their lung function (forced expiratory volume in $1 \mathrm{~s}$ less than $50 \%$ predicted), treatment with tiotropium plus salmeterol or formoterol may be sufficient. The last step of the treatment is the combination of all the therapeutic groups.

6. In any severity of disease, even in patients with mild to moderate COPD (forced expiratory volume in $1 \mathrm{~s}$ greater than $50 \%$ predicted) but with frequent exacerbations or characteristics similar to asthma, the use of ICS should be indicated (6-8), always in combination with a long-acting bronchodilator. The proportion of COPD patients that may benefit from treatment with ICS is not known. New studies such as Evaluation of COPD Longitudinally to Identify Predictive Surrogate Endpoints (ECLIPSE) (9), aimed at identifying different subtypes and phenotypes of COPD, will provide new clues for selecting the most appropriate treatment for each patient with COPD.

The future trend in the treatment of COPD will undoubtedly be to use drugs in a single daily administration to ensure maximum compliance. It should be taken into account that most patients are elderly with multiple medications, and the treatment is indefinite in length. Long-acting bronchodilators alone or in different combinations will be the basis of the treatment (10), and the ICS are useful in the group of patients with welldefined characteristics. The latest studies indicate that the benefits of the ICS are limited in COPD and the risks are not insignificant. Therefore their use should remain limited to 'responder' patients and should always be administered in conjunction with LABA. There is no longer one treatment for COPD; rather, similar to other chronic diseases such as hypertension or diabetes, the different therapeutic options should be individualized based on the characteristics of each patient.

ACKNOWLEDGEMENTS: Boehringer Ingleheim and Pfizer Canada provided funding for Dr Miravitlles' participation in the conference.

\section{REFERENCES}

1. Rabe KF, Hurd S, Anzueto A, et al. Global strategy for the diagnosis, management, and prevention of chronic obstructive pulmonary disease: GOLD executive summary. Am J Respir Crit Care Med 2007:176:532-55.

2. Miravitlles M. Tratamiento de la enfermedad pulmonar obstructiva crónica. Med Clin 2005;125:65-74.

3. D'Urzo AD, De Salvo MC, Ramirez-Rivera A, et al. In patients with COPD, treatment with a combination of formoterol and ipratropium is more effective than a combination of salbutamol and ipratropium. Chest 2001;119:1347-56.

4. ZuWallack RL, Mahler DA, Reilly D, et al. Salmeterol plus theophylline combination therapy in the treatment of COPD. Chest 2001;119:1661-70.

5. Aaron SD, Vandemheen KL. Fergusson D, et al. Tiotropium in combination with placebo, salmeterol, or fluticasone-salmeterol for treatment of chronic obstructive pulmonary disease. Ann Intern Med 2007;146:545-55.

6. Kerstjens HAM, Overbeek SE, Schouten JP, Brand PLP, Postma DS. Airways hyperresponsiveness, bronchodilator response, allergy and smoking predict improvement in $\mathrm{FEV}_{1}$ during long-term inhaled corticosteroid treatment. Eur Respir J 1993;6:868-76.

7. Siva R, Green RH, Brightling CE, et al. Eosinophilic airway inflammation and exacerbations of COPD: A randomised controlled trial. Eur Respir J 2007;29:906-13.

8. O'Donnell DE, Aaron S, Bourbeau J, et al. Canadian Thoracic Society recommendations for management of chronic obstructive pulmonary disease - 2007 update. Can Respir J 2007;14(Suppl B):5B-32B.

9. Vestbo J, Anderson W, Coxson HO, et al. Evaluation of COPD longitudinally to identify predictive surrogate endpoints (ECLIPSE). Eur Respir J 2008;31:1-5.

10. Tashkin DP, Celli B, Senn S, et al. A 4-year trial of tiotropium in chronic obstructive pulmonary disease. N Engl J Med 2008;359:1543-54.

\section{The pharmacoeconomic evaluation of exacerbation of COPD}

\author{
Marc Miravitlles MD \\ Fundació Clínic, Institut d'Investigacions Mèdiques August Pi i Sunyer \\ (IDIBAPS), Hospital Clínic, Barcelona, Spain \\ marcm@separ.es
}

bstructive lung diseases, particularly chronic obstructive pulmonary disease (COPD), are among the main causes of morbidity and mortality in developed countries. It is estimated that more than 15 million persons in the United States suffer from COPD, and more than 12 million from chronic bronchitis (1). In Spain, the prevalence 
of COPD is $9 \%$ in adults between 40 and 70 years of age, although only $22 \%$ are diagnosed (2).

Considering its high prevalence and the chronic and progressive course of COPD, it is easy to understand that this disease will represent a high societal and economic burden. Exacerbations, particularly the most severe that require hospital admission, are the main cause of the high use of resources generated by these patients $(3,4)$.

A study performed in the United States based on national statistics estimated that the total burden of exacerbations was $\$ 1,592$ million (for 1995) (3). The mean cost of an exacerbation managed in an outpatient clinic was $\$ 159$, and interestingly, drug costs represented only $11.2 \%$ of the costs in inpatients and $15 \%$ in outpatients (3). The average cost of hospitalization for COPD in a cohort of severe patients in the United States was estimated to be $\$ 7,100$ (5). Some studies have determined that hospitalization costs represent between $40 \%$ and $57 \%$ of total direct costs generated by patients with COPD. However, only a small proportion of exacerbations require hospitalization. A recent observational study performed in a cohort of COPD patients followed by primary care physicians observed that $22 \%$ were admitted over one year (6). The mean total cost of an acute exacerbation of COPD was estimated to be $\$ 159$ in a recent study in primary care in Spain, the main part being due to hospitalizations that represented $58 \%$ of the total cost, followed by the total drug acquisition cost of $32.2 \%$ (4). Interestingly, this was exactly the same estimate obtained by Niederman et al (3) in the United States in 1995 using a different methodology. Treatment failure implies a cost that is three times higher than that of exacerbation management, particularly due to the high cost of hospitalization. If the proportion of relapse could be reduced, especially in severe cases, or if switching a patient from parenteral to oral therapy could reduce the length of hospital stay, valuable resources could be saved. As an example, of the total mean cost of $\$ 159$ seen in the large community study, $\$ 100.30$ are derived from the cost of relapse. Ideally, if relapse in the global population could be avoided completely, the mean cost of an exacerbation would be reduced to only $\$ 58.70$; if the relapse rate could be halved, costs would be reduced to $\$ 107$ (4). Based on these results, it can be speculated that a new treatment that is able to reduce failure rate, particularly in severe patients with high risk of hospitalization, may easily be a cost-effective strategy.

Acquisition cost alone is inadequate for completing a comprehensive cost-effectiveness analysis of a drug. Incremental cost is a method for helping the healthcare payers decide between two or more therapeutic options (7). It is based one the cost-effectiveness ratio according to the following formula:

\section{Incremental cost $=$ Difference in cost $/$ Difference in efficacy}

Cost-effectiveness analysis is increasingly important in the evaluation of new treatments for chronic diseases. Although there is no threshold for an acceptable incremental cost for decision makers, the results of evaluation of interventions by regulatory agencies can provide some guidance. If a new intervention demonstrates an incremental cost of less than $\$ 20,000$ per quality-adjusted life-year gained, there is a strong likelihood of it being accepted; an incremental cost of more than $\$ 100,000$ is very likely to be unacceptable (8). Interventions with incremental costs between these values may have different considerations depending on a variety of factors: economic, medical, societal and others (9). Unfortunately, there is no such guideline for acceptable incremental cost in exacerbations of COPD in terms of willingness to pay for any increase in clinical efficacy or exacerbation avoided.

Economic evaluation of the new treatments is increasingly recognized as an important part of the evaluation of a new drug, not only by the healthcare payers, but also by clinicians. Researchers must provide the data necessary for these analyses to be adequately performed.

\section{REFERENCES}

1. Celli BR, MacNee W and committee members. Standards for the diagnosis and treatment of patients with COPD: A summary of the ATS/ERS position paper. Eur Respir J 2004;23:932-46.
2. Sobradillo V, Miravitlles M, Gabriel R, et al. Geographical variations in prevalence and underdiagnosis of COPD. Results of the IBERPOC multicentre epidemiological study. Chest 2000;118:981-9.

3. Niederman MS, McCombs JS, Unger AN, Kumar A, Popovian R. Treatment cost of acute exacerbations of chronic bronchitis. Clin Ther 1999;21:576-91.

4. Miravitlles M, Murio C, Guerrero T, Gisbert R; on behalf of the DAFNE study group. Pharmacoeconomic evaluation of acute exacerbations of chronic bronchitis and COPD. Chest 2002;121:1449-55.

5. Connors jr AF, Dawson NV, Thomas C, et al. Outcomes following acute exacerbation of severe chronic obstructive pulmonary disease. Am J Respir Crit Care Med 1996;154:959-67.

6. Miravitlles M, Mayordomo C, Artés M, Sánchez-Agudo L, Nicolau F, Segú JL; on Behalf of the EOLO Group. Treatment of chronic obstructive pulmonary disease and its exacerbations in general practice. Respir Med 1999;93:173-9.

7. Davey PG, Malek MM, Parker SE. Pharmacoeconomics of antibacterial treatment. PharmacoEconomics 1992;1:409-37.

8. Laupacis A, Feeny D, Detsky AS, Tugwell PX. How attractive does a new technology have to be to warrant adoption and utilization? Tentative guidelines for using clinical and economic evaluations. Can Med Assoc J 1992;146:473-81.

9. Laska EM, Meisner M, Siegel C, et al. Ratio-based and net benefit based approaches to health care resource allocation: Proofs of optimality and equivalence. Health Economics 1999;8:171-4.

\section{The impact of obesity on dynamic respiratory mechanics, dyspnea and exercise tolerance in COPD}

Denis E O'Donnell MD FRCP(I) FRCP(C), Josuel Ora MD Respiratory Investigation Unit, Department of Medicine, Queen's University and Kingston General Hospital, Kingston, Ontario odonnell@queensu.ca

$\mathrm{T}$

he prevalence of both chronic obstructive pulmonary disease (COPD) and obesity is increasing dramatically throughout the western world (1). Obesity is common in patients with COPD and population studies indicate that, paradoxically, its presence appears to convey a survival advantage (2). Although both of these common health problems have been studied extensively in isolation, the impact of their combination on respiratory pathophysiology and symptom intensity during activity is largely unknown.

\section{RESPIRATORY CONSEQUENCES OF OBESITY}

The mechanical derangements of simple obesity are well established and include reductions in chest wall, lung and total respiratory system compliance $(3,4)$. Pulmonary function tests in obesity (excluding morbid obesity) show the following: little or no change in forced expiratory volume in $1 \mathrm{~s}\left(\mathrm{FEV}_{1}\right)$ and forced vital capacity (FVC) with preserved or increased $\mathrm{FEV}_{1} / \mathrm{FVC}$ ratio; reduction in expiratory reserve volume and functional residual capacity (FRC), with little or no change in total lung capacity (TLC), vital capacity and residual volume; increase in resting inspiratory capacity (IC); and increase in airway resistance $(5,6)$. Respiratory muscle strength and endurance have been reported as either normal or reduced.

During activity, oxygen uptake $\left(\mathrm{V}^{\prime} \mathrm{O}_{2}\right)$, carbon dioxide production $\left(\mathrm{V}^{\prime} \mathrm{CO}_{2}\right)$ and ventilation $\left(\mathrm{V}_{\mathrm{E}}^{\prime}\right)$ are consistently higher at any given power output in obese people compared with normal weight subjects (7). Peak $\mathrm{V}^{\prime} \mathrm{O}_{2}$ is usually well preserved (adjusted for ideal body weight), but peak work rate is lower (8). Breathing pattern is more rapid and shallow, which is likely a compensatory strategy to minimize the increase in the elastic work of breathing.

Activity-related breathlessness is a common symptom in obesity, and dyspnea perception is higher during submaximal work loads in obese subjects compared with lean individuals. However, a recent study in obese adult women showed that during weight-supported cycle exercise, dyspnea/ $\mathrm{V}_{\mathrm{E}}^{\prime}$ slopes were similar to those of normal 
weight controls (8). This was explained, at least in part, by the advantages of a reduced FRC and by recruitment of resting IC in the setting of a preserved TLC in obese individuals.

\section{EFFECTS OF OBESITY ON STATIC AND DYNAMIC LUNG MECHANICS IN COPD}

Despite the high prevalence of these two conditions, there are no studies to show the effects of obesity on respiratory system mechanics in COPD. Preliminary data from a population study $(n=2267)$ in our laboratory indicated that among patients with similar $\mathrm{FEV}_{1}$ (across Global Initiative for Obstructive Lung Disease [GOLD] stages I to IV), the $\mathrm{FEV}_{1} / \mathrm{FVC}$ ratio was higher in the obese COPD group. Furthermore, indices of resting lung hyperinflation (FRC, TLC and residual volume) varied inversely with body mass index (BMI) (9).

To evaluate the consequences of these lower lung volumes in obese COPD patients, we compared dyspnea intensity ratings and ventilatory responses (breathing pattern and operating lung volumes) during symptom-limited incremental cycle exercise in well characterized groups of 18 obese (mean $[ \pm \mathrm{SD}] \mathrm{BMI}=35 \pm 4 \mathrm{~kg} / \mathrm{m}^{2}$ ) and 18 normalweight $(\mathrm{NW})\left(\mathrm{BMI}=22 \pm 2 \mathrm{~kg} / \mathrm{m}^{2}\right)$ patients with moderate to severe COPD (10). The obese COPD group had a significantly smaller FRC, expiratory reserve volume and TLC (expressed as \% predicted) and the IC/TLC ratio was significantly larger compared with NW COPD. The dynamic end-expiratory and end-inspiratory lung volumes were lower at rest and throughout exercise in obese compared with NW COPD. Nevertheless, the magnitude of dynamic pulmonary hyperinflation during exercise was similar in both groups.

\section{IMPACT OF OBESITY ON DYSPNEA AND EXERCISE TOLERANCE}

At first glance, it would be reasonable to anticipate that when the derangements of dynamic ventilatory mechanics of COPD are coupled with the increased metabolic demands and mass loading effects of obesity, dyspnea and exercise intolerance should increase. In our study, obese COPD participants had a significantly greater $\mathrm{V}_{\mathrm{E}}^{\prime}$ and $\mathrm{V}^{\prime} \mathrm{O}_{2}$ at rest and throughout exercise compared with NW COPD controls. Despite these effects, the combination of obesity and COPD was not associated with diminished exercise capacity or greater dyspnea at any work rate compared with NW COPD. Moreover, in obese COPD, dyspnea intensity ratings were reduced at any given $\mathrm{V}_{\mathrm{E}}^{\prime}$ and $\mathrm{V}^{\prime} \mathrm{O}_{2}$ compared with $\mathrm{NW}$ COPD. We found a strong correlation $(\mathrm{r}=0.67, \mathrm{P}<0.00001)$ between ratings of dyspnea intensity at a standardized ventilation and resting and dynamic end-expiratory lung volumes/TLC ratio in the whole group $(n=36)$. We reasoned that the relatively reduced operating lung volumes at rest and throughout exercise (and the attendant advantages with respect to inspiratory muscle function), were the most likely contributory factors to reduced dyspnea intensity in obese COPD.

\section{SUMMARY}

In western countries, 'the obese COPD patient' has emerged as an increasingly common clinical phenotype. Obesity certainly has consistent effects on static and dynamic respiratory mechanics in COPD and this has important physiological and clinical implications. We were intrigued to find that the relatively reduced lung hyperinflation in obese COPD patients (compared with lean COPD patients matched for $\mathrm{FEV}_{1}$ ) appeared to convey a mechanical advantage during cycle exercise. Of course, this does not mean that we should advocate excessive weight gain as the lung volume reduction intervention of choice in COPD! However, our results do justify further exploration of the impact of obesity on respiratory muscle function during rest and activity in patients with COPD.

ACKNOWLEDGEMENTS: This work was supported by the Ontario Ministry of Health and the Ontario Thoracic Society.

\section{REFERENCES}

1. Franssen FM, O'Donnell DE, Goossens GH, Blaak EE, Schols AM. Obesity and the lung: 5. Obesity and COPD. Thorax 2008;63:1110-7.
2. Landbo C, Prescott E, Lange P, Vestbo J, Almdal TP. Prognostic value of nutritional status in chronic obstructive pulmonary disease. Am J Respir Crit Care Med 1999;160:1856-61.

3. Pelosi P, Croci M, Ravagnan I, et al. The effects of body mass on lung volumes, respiratory mechanics, and gas exchange during general anesthesia. Anesth Analg 1998;87:654-60.

4. Naimark A, Cherniack RM. Compliance of the respiratory system and its components in health and obesity. J Appl Physiol 1960;15:377-82.

5. Jones RL, Nzekwu MM. The effects of body mass index on lung volumes. Chest 2006;130:827-33.

6. Jensen D, Ofir D, O'Donnell DE. Effects of pregnancy, obesity and aging on the intensity of perceived breathlessness during exercise in healthy humans. Respir Physiol Neurobiol 2009;167:87-100.

7. Babb TG, Ranasinghe KG, Comeau LA, Semon TL, Schwartz B. Dyspnea on exertion in obese women: Association with an increased oxygen cost of breathing. Am J Respir Crit Care Med 2008;178:116-23.

8. Ofir D, Laveneziana P, Webb KA, O'Donnell DE. Ventilatory and perceptual responses to cycle exercise in obese women. J Appl Physiol 2007;102:2217-26.

9. Deesomchok A, Ora J, Webb KA, et al. The impact of obesity on pulmonary function measurements in patients with COPD across GOLD stages. Am J Respir Crit Care Med 2009;179:A1460.

10. Ora J, Laveneziana P, Ofir D, Deesomchok A, Webb K, O'Donnell DE. Combined effects of obesity and COPD on dyspnea and exercise tolerance. Am J Respir Crit Care Med 2009 (in press).

\section{Assessment and treatment of pulmonary hypertension in COPD and other lung diseases}

\author{
Steeve Provencher MD MSc \\ Centre de recherche de I'Institut Universitaire de Cardiologie et de \\ Pneumologie de Québec, Université Laval, Montreal, Québec \\ Steve.Provencher@criucpq.ulaval.ca
}

$\mathrm{P}$ ulmonary hypertension $(\mathrm{PH})$ is a frequent complication of chronic lung diseases (CLD), occurring in $15 \%$ to $90 \%$ of patients with severe chronic obstructive pulmonary disease (COPD) and idiopathic pulmonary fibrosis $(1,2)$. CLD also subsumes other interstitial lung diseases and diffuse parenchymal disorders that are often associated with clinically relevant $\mathrm{PH}$. Nevertheless, the precise epidemiology of CLD-related PH remains unknown, because its prevalence depends on the population under study, the underlying disease severity, the definition applied (mean pulmonary artery [PA] pressure greater than $20 \mathrm{mmHg}$ versus $25 \mathrm{mmHg}$ ), and the tools used to evaluate patients (echocardiography versus right heart catheterization).

The hemodynamic features of CLD-related PH significantly differ from those seen in pulmonary arterial hypertension (PAH). Although $\mathrm{PH}$ may markedly worsen during exacerbations, the degree of $\mathrm{PH}$ is generally low to moderate in magnitude in stable CLD patients (mean PA pressure less than $35 \mathrm{mmHg})$, is slowly progressing $(0.4 \mathrm{mmHg}$ to $0.7 \mathrm{mmHg}$ per year in COPD), and cardiac output is usually preserved $(1,2)$. Nonetheless, a small proportion of patients display severe $\mathrm{PH}$ with mean PA pressure greater than $40 \mathrm{mmHg}$. Because these patients are frequently characterized by only moderate obstructive/restrictive disorders, severe hypoxemia, hyperventilation and a very low diffusing capacity (DLCO), it has been proposed that a subset of CLD patients with 'out of proportion' $\mathrm{PH}$ shares some clinical features with $\mathrm{PAH}$. Disproportionate $\mathrm{PH}$ is also increasingly reported in patients with sarcoidosis (3), pulmonary Langerhans cell histiocytosis (4) and a combination of emphysema in the upper lung zones and pulmonary fibrosis in the lower lobes (5).

CLD-related $\mathrm{PH}$ has been traditionally attributed to pulmonary vasoconstriction related to alveolar hypoxia, vascular bed destruction and, less importantly, hypercapnia and hyperviscosity. There is, however, limited correlation between $\mathrm{PH}$ severity and markers of CLD severity (pulmonary function tests, blood gas analyses), suggesting that other mechanistic factors are involved in its pathophysiology $(1,2)$. 
PA pressure represents the sum of the driving pressure across the pulmonary circulation and of the pulmonary wedge pressure, both influenced by intrathoracic and left heart pressures. More recently, pulmonary vascular remodelling and inflammatory changes, as well as endothelial dysfunction and genetic predisposition have also been shown to be involved in the pathophysiology of CLD-related PH. Pulmonary vascular infiltration by Langerhans cells (4) and sarcoid granulomas (3) have also been reported. $\mathrm{PH}$ thus results from the complex interactions among the pulmonary vasculature, intrathoracic pressures and left ventricular diastolic dysfunction commonly observed in CLD patients $(6,7)$.

Numerous studies have confirmed the clinical relevance of even mild $\mathrm{PH}$ being one of the strongest predictors of mortality in many CLD including COPD, idiopathic pulmonary fibrosis, sarcoidosis and pulmonary Langerhans cell histiocytosis $(1,2)$. PH is also independently related to exercise capacity in COPD (7). Whether PH influences prognosis and exercise capacity because it represents a surrogate marker of the CLD severity or because it relates to concomitant left heart abnormalities and intrinsic pulmonary vascular disorder remains unknown.

Dyspnea and fatigue are symptoms of both CLD and PH. Concomitant PH should be suspected when the symptoms or gas exchange abnormalities are more severe than one would expect from lung function data. Suspicion of PH should also be high if DLCO is disproportionally decreased, clinical deterioration is not matched by a decline in pulmonary function, or when signs of right heart failure develop. Echocardiography remains the screening tool of choice. PA pressure, however, is less likely to be measurable and is often inaccurate in CLD patients (8). Biomarkers such as brain natriuretic peptides lack specificity and sensitivity (8). Thus, right heart catheterization remains the standard for the diagnosis of $\mathrm{PH}$, and is currently recommended when the presence of PH will likely affect patients' management (8). Furthermore, an underlying CLD does not preclude a complete diagnostic work-up to exclude others causes of $\mathrm{PH}$ such as chronic thromboembolic $\mathrm{PH}$, left heart diseases or a condition (eg, scleroderma) predisposing to PAH.

There is currently no specific therapy for CLD-related PH. The underlying CLD should be optimally treated according to relevant guidelines. Although $\mathrm{PH}$ was not an outcome of the pivotal trials on oxygen therapy in hypoxemic COPD, long-term oxygen therapy was associated with either a stabilization (9) or a decrease in PA pressure (10). Long-term oxygen therapy is thus a logical treatment for hypoxemic CLD patients. Nonspecific pulmonary vasodilators such as calcium channel blockers, uradipil and angiotensin-converting enzyme inhibitors were found to have no or even deleterious effects on pulmonary gas exchange.

Drugs with proven efficacy in PAH such as endothelin receptor antagonists, phosphodiesterase type 5 inhibitors and prostanoids are being increasingly used in CLD-related $\mathrm{PH}$, despite the virtual absence of clinical trials supporting this approach. The only placebo-controlled randomized trials, evaluating bosentan in COPD with mild $\mathrm{PH}$, resulted in no functional benefit and an increased pulmonary shunt. The few open-label trials also reported discordant results, suggesting that any pulmonary vasodilator has the potential to worsen gas exchange in patients with CLD. Whether patients with disproportionate $\mathrm{PH}$, in which intrinsic vasculopathy may be a prominent pathophysiological feature, may benefit from these therapies remains unknown. It is noteworthy, however, that histological analysis of severe PH related to sarcoidosis (3), pulmonary Langerhans cell histiocytosis (4) and idiopathic pulmonary fibrosis (11) documented frequent pulmonary veno-occlusive-like lesions. Therefore, there is a theoretical risk of treatment-induced pulmonary edema with these therapies. All in all, much more evidence is needed before the use of $\mathrm{PH}$-targeted therapy can be recommended for certain subpopulations of CLD. These patients should ideally be referred to specialized $\mathrm{PH}$ centres for inclusion in clinical trials (8).
PH is clearly a prevalent and clinically relevant complication of CLD. Its pathophysiology remains incompletely understood. The use of drugs approved for PAH is currently not recommended for the treatment of CLD-related PH until their safety and efficacy is clearly demonstrated. Patients with disproportionate $\mathrm{PH}$ should be ideally referred to specialized PH clinics for further evaluation and potential inclusion in clinical trials.

ACKNOWLEDGEMENTS: Dr Provencher is a clinical scientist of the Fonds de Recherche en Santé du Québec. He has received lecture fees from Actelion Pharmaceuticals Canada Inc, Encysive Canada Inc, Pfizer Canada Inc, and received consultant fees from Actelion Pharmaceuticals Canada Inc, Eli Lilly Canada Inc, Encysive Canada Inc, Glaxo-Smith-Kline Canada Inc and Pfizer Canada Inc.

\section{REFERENCES}

1. Chaouat A, Kraemer JP, Canuet M, et al. [Pulmonary hypertension associated with disorders of the respiratory system]. Presse Med 2005;34:1465-74.

2. Behr J, Ryu JH. Pulmonary hypertension in interstitial lung disease. Eur Respir J 2008;31:1357-67.

3. Nunes H, Humbert M, Capron F, et al. Pulmonary hypertension associated with sarcoidosis: Mechanisms, haemodynamics and prognosis. Thorax 2006;61:68-74.

4. Fartoukh M, Humbert M, Capron F, et al. Severe pulmonary hypertension in histiocytosis X. Am J Respir Crit Care Med 2000;161:216-23.

5. Cottin V, Le Pavec J, Prevot G, et al. Pulmonary hypertension in patients with combined pulmonary fibrosis and emphysema syndrome. Eur Respir J 2010;35:105-11.

6. Funk GC, Lang I, Schenk P, Valipour A, Hartl S, Burghuber OC. Left ventricular diastolic dysfunction in patients with COPD in the presence and absence of elevated pulmonary arterial pressure. Chest 2008; 133:1354-9.

7. Sims MW, Margolis DJ, Localio AR, Panettieri RA, Kawut SM, Christie JD. Impact of pulmonary artery pressure on exercise function in severe COPD. Chest 2009;136:412-9.

8. Hoeper MM, Barbera JA, Channick RN, et al. Diagnosis, assessment, and treatment of non-pulmonary arterial hypertension pulmonary hypertension. J Am Coll Cardiol 2009;54:S85-S96.

9. Report of the Medical Research Council Working Party. Long term domiciliary oxygen therapy in chronic hypoxic cor pulmonale complicating chronic bronchitis and emphysema. Lancet 1981;1:681-6.

10. Nocturnal Oxygen Therapy Trial Group. Continuous or nocturnal oxygen therapy in hypoxemic chronic obstructive lung disease: A clinical trial. Ann Intern Med 1980;93:391-8.

11. Colombat M, Mal H, Groussard O, et al. Pulmonary vascular lesions in end-stage idiopathic pulmonary fibrosis: Histopathologic study on lung explant specimens and correlations with pulmonary hemodynamics. Hum Pathol 2007;38:60-5.

\section{Controversies in pediatric ventilator- associated pneumonia}

Pramod S Puligandla MD MSc FRCSC FACS

Divisions of Paediatric Surgery and Paediatric Critical Care Medicine, Montreal Children's Hospital, McGill University Health Centre, Montreal, Quebec pramod.puligandla@mcgill.ca

Ventilator-associated pneumonia (VAP) is a pulmonary infection occurring in ventilated patients that is not present at the time of intubation. The true pathogenetic mechanisms for the development of VAP are unknown. It is postulated that oropharyngeal colonization with noncommensal bacteria and distal spread to the airways represents a central event leading to VAP.

\section{DIAGNOSTIC CRITERIA FOR VAP}

The diagnostic criteria for VAP have been created by the National Nosocomial Infection Surveillance (NNIS) System (1). Furthermore, 
age-specific criteria have also been created to specifically address paediatric patients (2). These criteria comprise both clinical and radiological findings. Interestingly, the NNIS does not require microbiological confirmation of the diagnosis of VAP. However, several laboratory criteria have been described to support the clinical diagnosis of VAP (2).

\section{THE MANAGEMENT AND IMPACT OF VAP}

The treatment of VAP includes supportive measures as well as the early and judicious use of antibiotics. Empirical antibiotic regimens should cover all organisms associated with VAP, such as Staphylococcus aureus, Pseudomonas, and other Gram-negative species (Hemophilus, Enterobacter). Clinicians involved in the care of these patients must be aware of the local resistance patterns within their pediatric intensive care unit, hospital and community to provide effective treatment. Once an organism has been identified, therapy should be promptly de-escalated. The rates of pediatric VAP, as reported by the NNIS and National Healthcare Safety Network (NHSN), are 2.9 and 2.1 infections/1000 ventilator days, respectively (3). These rates represent a significant decrease from previously reported data (4), and may be the result of the use of a more stringent definition of VAP. However, one may question if VAP was previously over-diagnosed or that it is presently under-diagnosed.

The economic impact of VAP cannot be understated. Indeed, in adults, the cost of treatment of VAP in Ontario has been estimated at $\$ 11,450$ per patient, with an overall excess cost approaching $\$ 46$ million (5). Similar figures for pediatric intensive care units in Canada are more difficult to ascertain. However, in the United States, costs of over $\$ 30,000$ per patient have been estimated for paediatric patients with VAP after controlling for age, illness severity, underlying disease and ventilator days (6).

\section{CONTROVERSIES IN PEDIATRIC VAP}

The controversies in paediatric VAP simply represent areas where further evaluation or study are required in paediatric patients. For instance, we currently lack a gold standard for the diagnosis of VAP. This has major implications because it makes evaluation of the literature difficult. Furthermore, the clinical and radiological criteria used by the NNIS and the NHSN are open to interpretation. For example, there are no objective indices for "worsening gas exchange", (eg, increasing oxygenation index or decreasing $\mathrm{PaO}_{2} /$ $\mathrm{FiO}_{2}$ ), or a "change in the character of secretions". The latter is important because purulent tracheal secretions occur frequently in ventilated pediatric patients in the absence of pneumonia. Moreover, the discrimination of 'atelectasis' from 'consolidation' on chest radiographs may be plagued with significant interobserver variability (sensitivity $50 \%$ to $78 \%$ [7]). Indeed, focal persistent atelectasis is also a frequent finding in ventilated paediatric patients. What is really required is a determination of age-specific clinical and radiological criteria against a histopathological gold standard of VAP.

A second controversy relates to the use of invasive testing in children for the diagnosis of VAP (8). This is important because adult techniques such as bronchoalveolar lavage (BAL) or protected brush specimens (PBS) that have been shown to lead to faster de-escalation therapy for antibiotics, may not be applicable to pediatric patients. Only two studies evaluating these techniques have been performed in children. Gauvin et al (9) found that a bacterial index (sum of log of all bacterial species identified on BAL) was the best indicator of VAP. Labenne et al, using nonbronchoscopic (NB)-BAL and PBS found that the presence of intracellular bacteria on Gram stain as well as the use of both NB-BAL and NB-PBS were the most sensitive indicators. $\mathrm{NB}$ techniques have been shown to provide equivalent accuracy (9-11) as more invasive techniques, but a comparison of age-specific definitions of VAP with and without invasive testing against a diagnostic gold standard is likely warranted to definitively answer this question.
The pediatric VAP bundle is a collection of 'evidence-based' interventions that are meant to reduce the incidence of VAP (12). These interventions as a whole have led to some dramatic reductions in adult VAP in some institutional reports $(12,13)$. Interestingly, an evaluation of the evidence behind the use of the specific elements of the bundle shows only a handful of studies that have been performed in children. For example, only two studies have evaluated the routine use of stress ulcer prophylaxis. Both studies failed to reveal any benefit to this practice with respect to the incidence of VAP $(14,15)$. It seems evident that further pediatric-specific studies are required to ratify the individual elements of the bundle.

One of the most important aspects of VAP that is still unknown is its pathogenesis. Although oral colonization plays a central role in the development of VAP, a better understanding of those patients who do and do not develop VAP would certainly aid the development and implementation of both preventive and treatment strategies in these patients.

\section{CONCLUSION}

Paediatric VAP is an important problem with significant medical and economic implications. Better pediatric definitions for VAP, as well as the tests required to confirm its diagnosis, are required. Prevention seems to be a key element in the management of VAP but further pediatric-specific research is required to better understand its pathogenesis and treatment options.

\section{REFERENCES}

1. Jarvis WR, Edwards JR, Culver DH, et al. Nosocomial infection rates in adult and paediatric intensive care units in the United States. National Nosocomial Infections Surveillance System. Am J Med 1991;91:185S-191S.

2. Wall RJ, Ely EW, Talbot TR, et al. Evidence-based algorithms for diagnosing and treating ventilator-associated pneumonia. J Hosp Med 2008;3:409-22

3. Rotstein C, Evans G, Born A, et al. Clinical practice guidelines for hospital-acquired pneumonia and ventilator-associated pneumonia in adults. Can J Infect Dis Med Microbiol 2008;19:19-53.

4. Principi N, Esposito S. Ventilator-associated pneumonia (VAP) in paediatric intensive care units. Pediatr Infect Dis J 2007;26:841-3.

6. Muscedere JG, Martin CM, Heyland DK. The impact of ventilatorassociated pneumonia on the Canadian health care system. J Crit Care 2008;23:5-10.

7. Foglia E, Meier MD, Elward A. Ventilator-associated pneumonia in neonatal and paediatric intensive care unit patients. Clin Microbiol Rev 2007;20:409-25.

8. Wright ML, Romano MJ. Ventilator-associated pneumonia in children. Semin Pediatr Infect Dis 2006;17:58-64.

9. Gauvin F, Lacroix J, Guertin MC, et al. Reproducibility of blind protected bronchoalveolar lavage in mechanically ventilated children. Am J Respir Crit Care Med 2002;165:1618-23.

10. Flanagan PG, Jackson SK, Findlay G. Diagnosis of gram negative, ventilator associated pneumonia by assaying endotoxin in bronchial lavage fluid. J Clin Pathol 2001;54:107-10.

11. Flanagan PG, Findlay GP, Magee JT, et al. The diagnosis of ventilator-associated pneumonia using non-bronchoscopic, nondirected lung lavages. Intensive Care Med 2000;26:20-30.

12. Burmester M , Mok Q. How safe is non-bronchoscopic bronchoalveolar lavage in critically ill mechanically ventilated children? Intensive Care Med 2001;27:716-21.

13. Bigham MT, Amato R, Bondurrant P, et al. Ventilator-associated pneumonia in the paediatric intensive care unit: Characterizing the problem and implementing a sustainable solution. J Pediatr 2009; 154:582-7.

14. Resar R, Pronovost P, Haraden C, et al. Using a bundle approach to improve ventilator care processes and reduce ventilatorassociated pneumonia. Jt Comm J Qual Patient Saf 2005;31:243-8.

15. Lopriore E, Markhorst DG, Gemke RJ. Ventilator-associated pneumonia and upper airway colonisation with Gram negative bacilli: The role of stress ulcer prophylaxis in children. Intensive Care Med 2002;28:763-7.

16. Yildizdas D, Yapicioglu H, Yilmaz HL. Occurrence of ventilatorassociated pneumonia in mechanically ventilated paediatric intensive care patients during stress ulcer prophylaxis with sucralfate, ranitidine, and omeprazole. J Crit Care 2002;17:240-5. 


\section{Cystic fibrosis: Pathophysiology and early intervention strategies}

\author{
Felix Ratjen MD PhD FRCP(C) \\ Division of Respiratory Medicine, The Hospital for Sick Children, \\ Toronto, Ontario \\ felix.ratjen@sickkids.ca
}

\section{PATHOPHYSIOLOGY}

The cystic fibrosis (CF) gene defect leads to an absent or malfunctioning CF transmembrane regulator (CFTR) protein, which results in abnormal chloride conductance on the apical membrane of epithelial cells. More than 1500 different mutations have been described, but the majority of these mutations are rare: less than 10 mutations occur in a frequency of more than $1 \%$ (1). CFTR mutations are grouped into different classes based on their functional consequences on CFTR within the cell. Until recently, the prognostic knowledge of the genetic mutation has been of limited clinical value, but new treatment approaches that address specific CFTR mutations are currently being tested. For instance, the most common mutation worldwide (DF508 CFTR) leads to a misfolded protein that is degraded intracellulary before reaching the plasma membrane. However, DF508 CFTR has functional activity and drugs that potentially correct the intracellular trafficking defect of DF508 CFTR are currently in development.

CFTR acts as a chloride channel in apical membranes, but possesses other important functions (2). CFTR has been described as a regulator of other membrane channels, to transport or regulate bicarbonate transport and to act as a channel for other proteins such as glutathione. In addition, interactions with many other intracellular proteins have been described. This may potentially be important for therapeutic interventions, because drugs that induce chloride secretion, but do not affect other CFTR functions may not address all relevant aspects of CF pathophysiology.

Lack of CFTR activity causes less chloride secretion and, because ion transport also creates an osmotic gradient, less water transport into the epithelial surface layer. This results in airway surface liquid (ASL) depletion, and, because ASL is essential to support ciliary stability and function, ciliary collapse and breakdown of mucociliary transport (3). The consequence of this is perpetuating a vicious cycle of mucus retention, infection and inflammation. However, mucociliary transport is not completely absent in CF and local mediators secreted into the ASL can induce both CFTR-dependent and -independent chloride secretion (4). For example, ATP mediates chloride secretion independently of CFTR by binding to P2Y receptors. Respiratory syncytial virus (RSV) has been shown to increase ATPase activity resulting in breakdown of ATP and loss of this compensatory mechanism, which may explain its negative impact on airway clearance in CF. ATP analogues are currently being tested as a treatment option for CF patients (5).

Lung infections with bacterial pathogens such as Pseudomonas aeruginosa and Staphylococcus aureus are a typical feature of CF lung disease. These bacteria are not unique for CF as other patient groups with poor mucociliary clearance show infections with these organisms. Most evidence would suggest that inhaled bacteria are trapped in the viscous mucus layer on respiratory epithelial cells that is not cleared effectively from the lower airways. It has also been shown that CF mucus lacks oxygen and these anaerobic conditions may be important to trigger a switch of $P$ aeruginosa from nonmucoid to mucoid cell types, the predominant phenotype in CF lungs. These mucoid strains form biofilms in CF airways, which are resistant to killing by the host defence system, resulting in chronic infection (3).

The cycle of mucus retention, infection and inflammation perpetuates itself, since inflammatory products released by neutrophils, such as elastase, stimulate mucus secretion. Whether inflammation is directly related to the CFTR defect is still disputed, but an exaggerated, sustained and prolonged inflammatory response to bacterial and viral pathogens is an accepted feature of CF lung disease (6).

\section{EARLY INTERVENTION STRATEGIES}

Airway rehydration

Because lack of airway surface liquid is an important step in the development of CF lung disease, increasing the airway fluid by inhalation of an osmotically active agent can potentially address the underlying abnormality in CF. Hypertonic saline was initially tested as an irritant to obtain sputum samples in patients with airway diseases, but smaller studies had also shown positive effects on mucociliary transport, and recent evidence suggests that hypertonic saline has a prolonged effect on ASL height in CF. Clinical efficacy of hypertonic saline was demonstrated in a multi-centre trial conducted in Australia that demonstrated a relatively modest improvement in lung function, but a more remarkable reduction in pulmonary exacerbations in treated patients (7). Studies in infants have shown tolerability in this age group as well, and a large trial in infants and young children is being conducted in North America (8). Mannitol is currently being tested as an alternative to hypertonic saline, but tolerability of this treatment varies among patients.

\section{$P$ aeruginosa eradication}

$P$ aeruginosa continues to be the major pathogen in CF lung disease. Most patients will eventually develop chronic infection with mucoid strains of $P$ aeruginosa, which cannot be eradicated even with intensive antibiotic therapy. However, there is increasing evidence that antibiotic therapy initiated early after the onset of infection has a much higher success rate (9). A recent, large, multicentre trial has demonstrated that a one-month course of inhaled tobramycin has both a high short- and long-term efficacy in clearing $P$ aeruginosa infection (10).

\section{REFERENCES}

1. The Cystic Fibrosis Genetic Analysis Consortium. Available at http://www.genet.sickkids.on.ca/cftr/

2. Bear $\mathrm{CE}, \mathrm{Li} \mathrm{CH}$, Kartner N, et al. Purification and functional reconstitution of the cystic fibrosis transmembrane conductance regulator (CFTR). Cell 1992;68:809-18.

3. Ratjen F, Döring G. Cystic fibrosis. Lancet 2003;361:681-9.

4. Tarran R, Button B, Picher M, et al. Normal and cystic fibrosis airway surface liquid homeostasis. The effects of phasic shear stress and viral infections. J Biol Chem 2005;280:35751-9.

5. Deterding RR, Lavange LM, Engels JM, et al. Phase 2 randomized safety and efficacy trial of nebulized denufosol tetrasodium in cystic fibrosis. Am J Respir Crit Care Med 2007;176:362-9.

6. Ratjen F. What's new in CF airway inflammation: An update. Paediatr Respir Rev 2006;7:S70-2.

7. Elkins M, Robinson M, Rose B, et al. National Hypertonic Saline in Cystic Fibrosis (NHSCF) Study Group. A controlled trial of longterm inhaled hypertonic saline in patients with cystic fibrosis. N Engl J Med 2006;354:229-40.

8. Subbarao P, Balkovec S, Solomon M, Ratjen F. Pilot study of safety and tolerability of inhaled hypertonic saline in infants with cystic fibrosis. Pediatr Pulmonol 2007:42:471-6.

9. Ratjen F. Treatment of early Pseudomonas aeruginosa infection in patients with cystic fibrosis. Curr Opin Pulm Med 2006;12:428-32.

10. Ratjen F, Munck A, Kho P. Short and long-term efficacy of inhaled tobramycin in early P. aerug inosa infection: The Elite Study. Pediatric Pulmonol 2008;(Suppl 31):334A. (Abst)

\section{The current state of diaphragm pacing in spinal cord injured patients}

\author{
Jeremy Road $M D^{1}$, John Yee $M D^{2}$ \\ ${ }^{1}$ Division of Respiratory Medicine; ${ }^{2}$ Division of Thoracic Surgery, \\ University of British Columbia, Vancouver, British Columbia \\ jeremy.road@vch.ca
}

The he diaphragm is considered to be the major muscle of inspiration. By contracting, force is exerted by the so-called insertional and appositional components of the diaphragm leading to expansion of the chest wall and, hence, lung inflation. Diaphragm shortening and function is very dependent on diaphragm length. When subjects with 
quadriplegia are tipped from the horizontal toward the upright position, diaphragmatic shortening and, hence, tidal volume decreases. Another aspect of diaphragm physiology is the implication of its continuous use. Recent data suggest that immobilization on mechanical ventilators can lead to quite rapid diaphragmatic atrophy and a change from slow-twitch oxidative to fast-twitch glycolytic fibres. The latter fibres are much more susceptible to fatigue.

Recently, the technique of stimulation of the diaphragm has been expanded to include placement of intramuscular electrodes within the diaphragm itself. Previously the diaphragm had been stimulated in patients with high-level quadriplegia via electrodes placed on the phrenic nerves. Placement of these electrodes is somewhat more problematic, as a thoracotomy has been traditionally used to place these electrodes and there is always concern regarding phrenic nerve injury. Diaphragm pacing stimulation (DPS) uses electrodes placed endoscopically at key points within the diaphragm. These points are determined by mapping areas of maximal activation of the diaphragm that lie close to the entrance of the phrenic nerve to the muscle. Thus the diaphragm is stimulated by activating the phrenic nerves within the muscle. Muscle stimulation without intact phrenic nerves requires excessive current and is not practical. Potential advantages of diaphragmatic stimulation as compared to mechanical ventilation are severalfold, including the fact that spontaneous breathing is more closely simulated and, hence, there is less impact on cardiac output and less potential for barotrauma. The bases of the lungs are ventilated whereas when mechanical ventilation is used, the nondependent parts of the lung tend to be ventilated. Ventilators are also bulky, impeding mobility. Finally, there is improved taste and smell as well as speech with DPS.

The worldwide experience now is that 50 spinal cord injury patients have been instrumented with the DPS system (1). The average age is 36 years (range 18 to 74 years). The time since injury has varied from three months to 27 years. The average times the individuals were on mechanical ventilation before the DPS placement was 5.6 years. Needless to say, once the pacemaker is in place, the diaphragm has to be conditioned to sustain tidal volume potentially for $24 \mathrm{~h}$ a day, seven days a week. Initial attempts at stimulation reveal rapid fatigue. However, the diaphragm is readily conditioned. Control options on the pacing system include amplitude, frequency, rate, pulse, width and pulse modulation. The latter component allows a slow ramping stimulation that prevents aspiration while eating. The time for conditioning depends on the time from injury and the amount of training done per day.

Follow-up has been on average for two years (range 0.5 to eight years). There has been a $98 \%$ success rate in providing adequate tidal volumes and allowing patients to be removed from mechanical ventilators. Ninety-six per cent can use the pacer for more than $4 \mathrm{~h}$. Ten patients have had cardiac pacemakers and there have been no device interactions. The main complication is capnothorax, which occurred in $42 \%$ of patients and resolved without treatment. This complication occurs as a result of the $\mathrm{CO}_{2}$ insufflation into the peritoneal cavity during the laparoscopic surgery and small leaks through the diaphragm into the pleural space. Wound infections occurred in two individuals. There have been five deaths, none of them related to pacemaker failures. Stimulated tidal volumes average $860 \mathrm{~mL}$ for men (range $540 \mathrm{~mL}$ to $1.5 \mathrm{~L}$ ) and $528 \mathrm{~mL}$ for women (range $350 \mathrm{~mL}$ to $680 \mathrm{~mL}$ ). These volumes were more than adequate to sustain the basal metabolic requirements. Patient questionnaires to evaluate efficacy have found $60 \%$ of individuals report a decrease in secretions and suctioning requirements. One hundred per cent reported improved speech and improved independence.

Food and Drug Administration (United States) approval for the DPS system was obtained in June 2008. In Canada, Health Protection Branch approval has been applied for and is pending.

The DPS system is safe and effective. There have been no significant device-related adverse events. All patients have been able to utilize DPS for ventilation. No patients have stopped pacing and all would recommend it.

\section{REFERENCES}

1. Onders, RP, Elmo M, Khansarina S, et al. Complete worldwide operative experience in laparoscopic diaphragm pacing: Results and differences in spinal cord injured patients and amyotrophic lateral sclerosis patients. Surg Endosc 2009;23:1433-40.

\section{The role of portable monitoring in the management of obstructive sleep apnea}

\author{
C Frank Ryan MD \\ Division of Respiratory Medicine, University of British Columbia, \\ Vancouver, British Columbia \\ fryan@interchange.ubc.ca
}

\section{BACKGROUND}

Polysomnography (PSG) is currently recommended for both the diagnosis of obstructive sleep apnea and the titration of optimal continuous positive airway pressure (CPAP) therapy (1-3). This approach to a common medical problem (approximately $5 \%$ of the adult population) inevitably leads to delays in diagnosis and treatment. Major disparities in the availability of PSG in Canada and internationally were recently highlighted (4). In 2006, the Institute of Medicine of the National Academies found that most American communities did not have adequate health care resources to meet the clinical demands to provide adequate prevention and management of sleep disorders (5). To increase diagnostic and therapeutic capacity, the report recognized the need to validate and develop existing and new technologies, especially portable technology.

\section{THE EVIDENCE FOR PORTABLE MONITORING}

In 2007, the Centre for Medicare and Medicaid Services undertook a critical appraisal of the evidence for portable monitoring, including an external technology assessment carried out by the Agency for Health Care Research and Quality (6). The main question addressed was whether there was adequate evidence to determine that diagnostic strategies other than facility-based PSG could accurately identify patients with obstructive sleep apnea who would benefit from CPAP treatment. The review found that facility-based PSG was not an errorfree gold standard. The apnea-hypopnea index (AHI) or respiratory disturbance index measurements from portable monitors and facilitybased PSG are not interchangeable, especially at the higher end of the AHI spectrum. Baseline AHI is only modestly associated with response to CPAP therapy or CPAP use among patients with a high probability of obstructive sleep apnea-hypopnea syndrome (OSAHS). Nevertheless, portable monitors may be able to predict an AHI suggestive of OSAHS with high positive likelihood ratios and low negative likelihood ratios. Limited evidence indicates that for high probability patients, PSG does not result in better outcomes compared with an ambulatory approach using portable monitoring (7). The increased accuracy in AHI estimation with facility-based PSG compared with a portable monitor did not translate into more accurate prediction of response to CPAP with respect to a quality of life outcome (7).

\section{MODELLING DIFFERENT MANAGEMENT STRATEGIES}

Because of the positive health outcomes associated with treating OSAHS, the optimal management strategy should maximize true positive diagnoses and reduce the time to diagnosis and treatment, while at the same time minimizing false positive diagnoses. The Agency for Health Care Research and Quality systematic review conducted a Markov process to model different simulated strategies among people with symptoms and signs suggestive of OSAHS (8). Polysomnography for both diagnosis and CPAP titration resulted in all patients with OSAHS being identified and offered CPAP therapy, whereas no patients without OSAHS were treated. The time to diagnosis was 13.6 weeks and the time to treatment was 27.3 weeks. Portable monitoring for diagnosis followed by home auto-CPAP titration for test- 
positive patients and split night PSG for test-negative patients identified and offered CPAP to $99 \%$ of patients with OSAHS, but also $20 \%$ of patients without OSAHS. The ambulatory approach resulted in marked reductions in time to diagnosis ( 3.8 weeks), and treatment ( 6.2 weeks). The systematic review found no documented adverse health events in patients without OSAHS who received CPAP. Furthermore, patients without OSAHS were unlikely to improve with and adhere to CPAP. Nevertheless, false-positive diagnoses represent symptomatic patients who require further investigation and treatment. The Centers for Medicare and Medicaid Services (CMS) coverage decision published in March 2009 concluded that there was sufficient evidence to determine that portable monitoring tests could be used to diagnose OSAHS. Their use demonstrated improved health outcomes in patients who received appropriate treatment, and were reasonable and necessary tests. The recommendation excluded portable devices with less than three channels, such as oximetry. However, two recent randomized controlled trials that compared an ambulatory strategy using oximetry versus PSG showed at least equivalent outcomes in terms of CPAP adherence, sleepiness and quality of life $(7,9)$.

\section{IMPLICATIONS}

These recent data and policy decisions recognize the limitations of both PSG and portable monitoring in predicting treatment outcomes. They place less emphasis on diagnostic accuracy and more emphasis on predicting favourable outcomes from treatment with CPAP. They also encourage a chronic disease management model for OSAHS. A simplified management strategy for OSAHS should include: knowledge of the pre-test probability of OSAHS; awareness of the limitations and pitfalls that can confound the diagnosis and treatment of OSAHS; and a back-up strategy for dealing with uncertainty. Strategies with high positive and low negative likelihood ratios for the diagnosis of OSAHS can be developed using baseline prevalence together with a clinical prediction rule and a suitable portable monitoring device. Factors that may confound diagnosis and treatment include co-morbid medical conditions and sleep disorders, technical limitations of portable monitors and auto-CPAP devices, and limited expertise among personnel using these strategies. A back-up strategy requires the expertise of a tertiary sleep program and the availability of polysomnography to deal with patients who do not meet the criteria of the ambulatory strategy, or who do not respond appropriately to treatment. Education, training and research may enable dissemination of these skills beyond the tertiary sleep program to include other physicians and health care workers, including those practicing in remote communities. Telehealth holds additional promise for the provision of timely care to patients with limited access to PSG.

\section{REFERENCES}

1. Practice parameters for the indications for polysomnography and related procedures. Polysomnography Task Force, American Sleep Disorders Association Standards of Practice Committee. Sleep 1997;20:406-22.

2. Chesson AL Jr, Berry RB, Pack A. Practice parameters for the use of portable monitoring devices in the investigation of suspected obstructive sleep apnea in adults. Sleep 2003;26:907-13.

3. Fleetham J, Ayas N, Bradley D, et al. Canadian Thoracic Society guidelines: Diagnosis and treatment of sleep disordered breathing in adults. Can Respir J 2006;13:387-92.

4. Flemons WW, Douglas NJ, Kuna ST, et al. Access to diagnosis and treatment of patients with suspected sleep apnea. Am J Respir Crit Care Med 2004;169:668-72.

5. Colten HR AF, Block GD, Boat TF, Litt IF. Sleep disorders and sleep deprivation: An unmet public health problem: Institutes of Medicine of the National Academies, 2006.

6. Trikalinos T, Ip S, Raman G, et al. Home diagnosis of obstructive sleep apnea hypopnea syndrome: Agency for Healthcare Research and Quality, Department of Health and Human Services, USA, 2007.

7. Mulgrew AT, Fox N, Ayas NT, Ryan CF. Diagnosis and initial management of obstructive sleep apnea without polysomnography: A validation study. Ann Int Med 2007;146:157-66.
8. Trikalinos TA, Lau J. Obstructive sleep apnea hypopnea syndrome: Modeling different diagnostic strategies: Agency for Healthcare Research and Quality, Department of Health and Human Services, USA, 2007.

9. Antic NA, Buchan C, Esterman A, et al. A randomized controlled trial of nurse-led care for symptomatic moderate-severe obstructive sleep apnea. Am J Respir Crit Care Med 2009;179:501-8.

\section{The Canadian Healthy Infant Longitudinal Development (CHILD) study}

\author{
Malcolm R Sears MB ChB \\ Division of Respirology, McMaster University, Hamilton, Ontario \\ searsm@mcmaster.ca
}

I ongitudinal studies of childhood asthma reveal considerable Lheterogeneity, but most cases of persistent asthma have their first symptoms in early life. Domestic animal exposure reduces risk of allergy (1), but breastfeeding may increase later childhood risks (2). Viral infections may be major pathogenetic factors (3). Patterns of asthma track from childhood into adult life, and loss of lung function may be established early. In the Dunedin Multidisciplinary Child Development Study, independent risk factors for persistence of childhood asthma included female sex, methacholine airway responsiveness, house dust mite allergy and personal smoking (4). Longitudinal assessment of lung function in those with persistent asthma indicated that lung function had tracked substantially lower than normal from age 9 , suggesting the damage occurred in early childhood.

Many questions remain unanswered. What influences lung growth and development in infancy and early childhood? Is the development of asthma related primarily to nature or nurture? What role does environment play in the development of allergy and asthma? Do early childhood infections decrease or increase the risk of allergy and asthma? How do gene-environment interactions impact allergy and asthma?

To address these questions, a new longitudinal birth cohort study has been developed in conjunction with several interested groups, the Canadian Healthy Infant Longitudinal Development (CHILD) study. Researchers at McMaster University and the University of Toronto questioned whether children with persistent asthma are born with small airways, or whether the early environment (pollutants, infections, allergens) damages the airway. The Allergy, Genes and Environment (AllerGen) Network of Centres of Excellence (NCE) is seeking to determine the underlying causes of the major increase in allergic diseases, including asthma. The Canadian Institutes of Health Research (CIHR) expressed strong interest in the impact of the built environment on the health of the growing child, especially allergies and asthma. These groups came together to develop a proposal for a new longitudinal birth cohort study, funded jointly by AllerGen NCE and CIHR.

The primary hypothesis of CHILD is that exposure to indoor pollutants including chemical agents and microbiological agents, by interaction with host genetics, hormonal, metabolic, psychosocial, physiological, nutritional and immunological factors, increases the risk of allergy and asthma in infancy and early childhood. The study will recruit 5000 pregnant mothers in four major centres across Canada in 2009-2010, and follow the children until five years of age. The study will assess the home environment by questionnaire in pregnancy and at one, three and five years, and by direct inspection and sampling at three months; collect DNA at birth and five years; document infections in the first year of life; examine immune and inflammatory responses to pathogens and allergens; and correlate outcomes with markers of innate immune function. Lung function will be measured in infancy and at one, three and five years. Family data will be obtained by questionnaires, skin tests and lung function tests, together with parental genetics. The psychosocial environment will also be assessed, together with nutritional intake. Children will be seen at one, three 
and five years, with telephone contacts between visits. At five years, detailed questionnaires, clinical assessment, skin allergy tests, lung function tests and a final physician assessment will be undertaken.

The CHILD study team of more than 40 highly motivated skilled investigators has achieved CIHR and AllerGen funding after rigorous CIHR peer review, and has built excellent study teams at recruitment sites. Ethics approval has been obtained at all sites, and protocols and questionnaires developed and tested, using a multi-functional database built using HealthDiary. A pilot study was launched in late 2008, and the main study will commence in mid-2009.

Challenges facing the study include recruitment of a representative Canadian population avoiding biases in age, education, and socioeconomic status (to ensure diversity of environmental exposure), maintaining standardization of operational procedures within and across centres, quality assurance and control, administrative organization and communication, database management, long-term storage of biological samples, retention of the study families and ensuring sufficient funding.

Prospective studies such as CHILD, with multiple exposures carefully documented before outcome assessments, may allow determination of fundamental causes of diseases. Childhood studies may also become the base for lifelong studies of development of chronic diseases. Over the next six years, the CHILD study will gather a vast amount of data from Canadian children and their families, which will provide insights into the pathogenesis of allergy and asthma, and lead to improved health outcomes through appropriate interventions.

ACKNOWLEDGEMENTS: This work is supported by the CIHR and the AllerGen Network of Centres of Excellence.

\section{REFERENCES}

1 Takkouche B, Gonalez-Barcala F-J, Etminan M, FitzGerald M. Exposure to furry pets and the risk of asthma and allergic rhinitis: A meta-analysis. Allergy 2008;63:857-64.

2. Duncan JM, Sears MR. Breastfeeding and allergies: Time for a change in paradigm? Curr Opin Allergy Clin Immunol 2008;8:398-405.

3. Jartti T, Lee W-M, Pappas T, et al. Serial viral infections in infants with recurrent respiratory illnesses. Eur Respir J 2008;32:314-20.

4. Sears MR, Greene JM, Willan AR, et al. A longitudinal, populationbased, cohort study of childhood asthma followed to adulthood. N Engl J Med 2003:1414-22.

5. Subbarao P, Becker A, Brook JR, et al. Epidemiology of asthma: Risk factors for development. Expert Rev Clin Immunol 2009;5:77-95.

\section{A sexual revolution in COPD}

Don D Sin MD
The Providence Heart and Lung Institute \& The James Hogg iCAPTURE
Center for Cardiovascular and Pulmonary Research, St Paul's Hospital,
Vancouver, British Columbia
dsin@mrl.ubc.ca

$\mathrm{O}$ ver the past 30 years, the age-adjusted mortality rate of chronic obstructive pulmonary disease (COPD) has more than doubled, whereas total mortality has decreased by one-third during the same period of time (1). The future looks even bleaker for COPD mortality, which is expected to increase by $50 \%$ over the next 15 years (2). Whereas the COPD mortality rates in men have plateaued in most western countries, the rates in women continue to increase (3). The exact reasons belying these gender differences are unknown. However, emerging epidemiological and animal studies are beginning to shed light on plausible mechanisms.

There is increasing evidence that female smokers are at increased risk of developing COPD compared with men. Kohansal et al (4) have shown that women smokers experience an accelerated decline in lung function compared with male smokers over an average follow-up of 23 years. In contrast, the rate of decline in lung function is similar between male and female never-smokers (4). This risk is modified by the number of cigarettes smoked per day and by the menopausal status of women. In the peri- and post-menopausal period, the risk of COPD is amplified among female smokers (5). Moreover, female smokers, in a dose-dependent manner, are at increased risk of total and COPD mortality compared with never smokers (6). The good news for female smokers is that if they stop smoking, they will recover more lung function than male smokers who quit smoking (7). The increased susceptibility of female smokers to COPD may be related to their smaller lung volumes, increased particle deposition of toxins in the airways, and enhanced generation of toxic metabolites of cigarette smoke from increased activity of cytochrome P450 enzymes (8).

While cigarette smoking is the leading risk factor for COPD in both men and women, it is notable that more women die from COPD than men despite the fact that there are fewer female than male smokers, suggesting that other factors are involved in the epidemic of COPD in women. This was well illustrated by a recent publication from China. Gu et al (6) found that the population attributable risk (ie, the percentage of deaths that can be avoided by eliminating the risk factor from society) of cigarette smoking for COPD mortality in women was only $5.6 \%$, whereas it was $12.1 \%$ for men. Similarly, the population attributable risk of smoking for lung cancer mortality, another disorder clearly linked with cigarette smoking, in women was only $14.8 \%$, whereas it was $50.6 \%$ in men (6). These data raise the possibility that other risk factors such as gender differences in genetic susceptibility or exposure to other known environmental lung toxins (eg, biomass fuel, coal smoke and infections), may also play salient roles in enhancing the risk of COPD in women.

The role of sex hormones in COPD pathogenesis has not been fully elucidated. Animal models suggest that estrogens and progesterone may have proinflammatory effects in the lungs in response to aeroallergens, whereas they may have a protective effect against acute bacterial infections and acute lung injury by downregulating neutrophil accumulation in the lungs following acute injury (9). Interestingly, although in the premenopausal period estrogen and progesterone levels are markedly elevated in women than in men, postmenopausally, these female hormone levels may drop precipitously, and in some cases, below those levels in men. It is possible then that the withdrawal of the female hormonal milieu in the postmenopausal period may enhance the susceptibility of women toward lung injury from exposure to cigarette smoke and other environmental toxins. This theory will need to be tested in the future.

ACKNOWLEDGEMENTS: Dr Sin is supported by funding from ICEBERGS (Interdisciplinary Capacity Enhancement: Bridging Excellence in Respiratory disease and Gender Studies), which is funded by The Canadian Institutes of Health Research.

\section{REFERENCES}

1. Jemal A, Ward E, Hao Y, Thun M. Trends in the leading causes of death in the United States, 1970-2002. JAMA 2005;294:1255-9.

2. Murray CJ, Lopez AD. Alternative projections of mortality and disability by cause 1990-2020: Global Burden of Disease Study. Lancet 1997;349:1498-504.

3. Deaths from chronic obstructive pulmonary disease - United States, 2000-2005. MMWR Morb Mortal Wkly Rep 2008;57:1229-32.

4. Kohansal R, Martinez-Camblor P, Agusti A, Buist AS, Mannino DM, Soriano JB. The natural history of chronic airflow obstruction revisited: An analysis of the Framingham Offspring Cohort. Am J Respir Crit Care Med 2009;180:3-10.

5. Gan WQ, Man SF, Postma DS, Camp P, Sin DD. Female smokers beyond the perimenopausal period are at increased risk of chronic obstructive pulmonary disease: a systematic review and meta-analysis. Respir Res 2006;7:52.

6. Gu D, Kelly TN, Wu X, et al. Mortality attributable to smoking in China. N Engl J Med 2009;360:150-9.

7. Connett JE, Murray RP, Buist AS, et al. Changes in smoking status affect women more than men: results of the Lung Health Study. Am J Epidemiol 2003;157:973-9. 
8. Ben-Zaken Cohen S, Pare PD, Man SF, Sin DD. The growing burden of chronic obstructive pulmonary disease and lung cancer in women: Examining sex differences in cigarette smoke metabolism. Am J Respir Crit Care Med 2007;176:113-20.

9. Carey MA, Card JW, Voltz JW, Germolec DR, Korach KS, Zeldin DC. The impact of sex and sex hormones on lung physiology and disease: Lessons from animal studies. Am J Physiol Lung Cell Mol Physiol 2007;293:L272-8.

\section{Physical activity behaviour in COPD: Implications for self-management interventions}

\author{
Judith Soicher PhD \\ Respiratory Epidemiology and Clinical Research Unit, McGill University \\ Health Centre, Montreal, Quebec \\ judith.soicher@mcgill.ca
}

PHYSICAL ACTIVITY IN CHRONIC DISEASE AND COPD Physical activity is a self-management behaviour with beneficial effects on survival (1) and quality of life (2). In a recent study of individuals meeting the diagnostic criteria for COPD $(n=2386)$, those performing any level of physical activity had significantly lower risk of hospital admissions and all-cause mortality (3).

Exercise is a type of physical activity, defined as planned and structured movement where the goal is to maintain or improve physical fitness (4). Pulmonary rehabilitation is the setting in which many patients with COPD adopt exercise; however, little is known about behavioural aspects of exercise. We undertook a longitudinal study to examine behavioural and disease-related aspects of exercise among individuals with COPD enrolled in rehabilitation.

\section{LONGITUDINAL STUDY OF PHYSICAL ACTIVITY IN COPD}

The longitudinal study was embedded within a randomized trial comparing the effectiveness of home-based versus outpatient hospitalbased pulmonary rehabilitation (5). Subjects participated in four weeks of self-management education and eight weeks of either homeor hospital-based exercise training, comprising a three-month rehabilitation program.

In phase 1 of the longitudinal study ( $n=215)$, significant pre- to postrehabilitation improvements $(\mathrm{P}<0.05)$ were observed in exercise habits, self-efficacy for (confidence in ability to carry out) endurance and strength exercise, and barriers to exercise. There were no substantial pre- to postrehabilitation changes in the proportion of individuals reporting barriers related to time, schedule, cost or family.

In phase $2(n=206)$, adherence to exercise was assessed at four, six, eight and 12 months using a one-week recall questionnaire, which uses the past week as a sample of an individual's exercise over the past months. Adherence was operationally defined according to guidelines for older adults and individuals with chronic disease (6). At four months (one month after completing rehabilitation), $61 \%$ of subjects were adherent to endurance exercise (three or more days/week) and $54 \%$ to strength exercise (two or more days/week). These proportions declined to $46 \%$ and $37 \%$, respectively, at 12 months. Longitudinal statistical modelling showed that adherence to endurance exercise from four to 12 months was significantly better in spring/summer $(\mathrm{P}=0.009)$ and among people who did any exercise before rehabilitation $(\mathrm{P}=0.018)$; adherence was worse among those with lower forced expiratory volume at $1 \mathrm{~s}\left(\mathrm{FEV}_{1}\right)$ at baseline $(\mathrm{P}=0.007)$ and who had a moderate or severe disease exacerbation during rehabilitation $(\mathrm{P}=0.045)$. Higher baseline self-efficacy for strength exercise significantly predicted better adherence to this type of exercise from four to 12 months $(\mathrm{P}=0.048)$. Exercise setting (home versus outpatient hospital) was not a significant predictor of subsequent adherence to either endurance or strength exercise.

\section{IMPLICATIONS FOR SELF-MANAGEMENT INTERVENTIONS}

To optimize longer-term adherence to exercise, variables that changed following rehabilitation (phase 1) or that predicted adherence (phase 2) should be targeted through educational and self-management interventions. In pulmonary rehabilitation, barriers to exercise should be identified with individual participants, and strategies to overcome or minimize barriers can then be developed jointly by the participant and health professionals. Group sessions can be used to discuss common barriers among participants and to share successful strategies.

Predictors of adherence to endurance exercise included diseaserelated variables $\left(\mathrm{FEV}_{1}\right.$ at baseline, exacerbation during rehabilitation) and season. Although $\mathrm{FEV}_{1}$ is not modifiable, it can serve as an indicator to identify and monitor individuals who may have difficulty with exercise adherence. Exacerbations can be addressed through implementation of an action plan to recognize and treat early symptoms, and by highlighting to patients the detrimental effect of exacerbations and the need to resume exercise as soon as possible after the acute exacerbation has resolved. The finding that adherence was better in the spring and summer points to the need for patients to develop maintenance strategies, such as purchasing equipment for home use and/or attending organized exercise classes during the fall and winter. Future work is needed to study the effect on adherence of contextual factors related to program delivery and follow-up, and to examine qualitatively patient perceptions of personal and environmental factors that facilitate or hinder exercise.

ACKOWLEDGEMENTS: Dr Soicher is supported by funding from the Canadian Institutes of Health Research, Fonds de la recherche en santé du Québec, and the Lung Association.

\section{REFERENCES}

1. Blair SN, Wells CL, Weathers RD, Paffenbarger RS. Chronic disease: The physical activity dose-response controversy. In: Dishman RK, ed. Advances in Exercise Adherence. Champaign: Human Kinetics, 1994;31-54.

2. Rejeski WJ, Brawley LR, Shumaker SA. Physical activity and health-related quality of life. Exerc Sport Sci Rev 1996;24:71-108.

3. Garcia-Aymerich J, Lange P, Benet M, Schnohr P, Anto JM. Regular physical activity reduces hospital admission and mortality in chronic obstructive pulmonary disease: A population based cohort study. Thorax 2006;61:772-8.

4. Franklin B, Whaley MH, Howley ET. ACSM's Guidelines for Exercise Testing and Prescription. Baltimore, MD: ACSM, 2000:1-368.

5. Maltais F, Bourbeau J, Shapiro S, et al. Effects of home-based pulmonary rehabilitation in patients with chronic obstructive pulmonary disease: A randomized clinical trial. Ann Intern Med 2008;149:869-78.

6. Nelson ME, Rejeski WJ, Blair SN, et al. Physical activity and public health in older adults: Recommendation from the American College of Sports Medicine and the American Heart Association. Circulation 2007;116:1094-105.

\section{The Canadian Obstructive Lung Disease (COLD) initiative}

Wan C Tan $\mathrm{MD}^{1}$, Jean Bourbeau MD MSc${ }^{2}$, Kenneth Chapman MD MSc ${ }^{3}$, Robert Cowie MB ChB MD MSc ${ }^{4}$, Paul Hernandez $M D^{5}$, Mark FitzGerald $M B M D^{1}$, Don Sin $M D^{1}$ ${ }^{1}$ University of British Columbia, Vancouver, British Columbia; ${ }^{2}$ McGill University, Montreal, Quebec; ${ }^{3}$ University of Toronto, Toronto, Ontario; ${ }^{4}$ University of Calgary, Calgary, Alberta; ${ }^{5}$ Dalhousie University, Halifax, Nova Scotia wtan@mrl.ubc.ca

The prevalence of chronic obstructive pulmonary disease (COPD) in Canada is currently based on self-reported physician-diagnosed COPD, and ranges from $2.9 \%$ to $4.7 \%$ (1). It is widely recognized that 
an accurate diagnosis of COPD requires spirometric confirmation of chronic airflow limitation (2). There is a need for a population-based lung health study of COPD prevalence based on spirometry measurements in Canada.

\section{KEY FEATURES OF THE COLD INITIATIVE}

The Canadian Obstructive Lung Disease (COLD) initiative is a crosssectional, multisite, nationwide, population-based, epidemiological study on lung health, initiated in Vancouver in August 2005. The initiative proposes to include nine study sites across the country and has been completed to date in five cities (Vancouver, Montreal, Toronto, Halifax and Calgary) in Canada. The primary aim of the initiative is to measure the prevalence of COPD and its risk factors in the Canadian population.

The COLD initiative is standardized by using the Burden of Obstructive Lung Disease (BOLD) protocol for all sites (3). The BOLD protocol includes standardized lung health questionnaires, standardized performance of spirometry and standardized conduct of the study. Details of the BOLD study protocol have been described in previous publications $(3,4)$.

\section{COLD STUDY POPULATION AND DESIGN}

The target population consisted of adults 40 years of age and older who resided in each of five sampling frames of at least 250,000 people. These geographic areas are the health service delivery area for Vancouver; census subdivisions for Toronto, Montreal, and Calgary; and the Federal Electoral Districts for Halifax. The approximate population sizes of these sampling frames are 0.6 million (M) in Vancouver, $1.6 \mathrm{M}$ in Montreal, 2.5M in Toronto, 0.3M in Halifax and $1 \mathrm{M}$ in Calgary.

The minimal sample size per site in the COLD study was a random sample of 600 participants who complete the clinic visit, assuming a prevalence of chronic airflow limitation of $15 \%$ (3). Sampling was conducted in two stages, starting with random-digit-dialling to identify and recruit a random sample of at least 1000 individuals (4), followed by an invitation to complete the full protocol at the clinic. This consisted of interviewer-administered standardized questionnaires that included demographic details and questions about respiratory health and symptoms; smoking history of tobacco and marijuana; quality of life; health care use; cardiovascular comorbidities and other respiratory diseases; and the performance of spirometry before and after administration of $200 \mu \mathrm{g}$ of albuterol/salbutamol, according to the American Thoracic Society acceptability and reproducibility criteria.

\section{DEFINITION OF COPD}

The presence of chronic airflow limitation in the COLD study is defined as postbronchodilator forced expiratory volume in $1 \mathrm{~s} /$ forced vital capacity of less than 0.70 , while its severity is defined according to the Global Initiative for Obstructive Lung Disease (GOLD) severity classification, grades I to IV. Other spirometric definitions of COPD such as the lower limits of normal and the European Respiratory Society criteria will be used for comparison against the primary definition.

\section{RESULTS TO DATE}

The study has been completed in five sites. Preliminary results show similar sample characteristics and rates of usable spirometry data for the Vancouver and Montreal sites (Table 1). To date, a total of 3002 subjects have completed the full protocol, with 878 in Vancouver, 557 in Montreal, 546 in Toronto, 454 in Halifax and 567 in Calgary. Minimal telephone interview data on age, sex, smoking status, respiratory disorders and comorbidites, obtained from the random-digitdialing recruitment process, are also available on 10,091 adults aged 40 years and older and on 3154 younger adults aged 18 to 39 years (Table 1).
TABLE 1

\begin{tabular}{|c|c|c|c|c|}
\hline & \multicolumn{2}{|c|}{ Minimal telephone data } & \multirow{2}{*}{$\begin{array}{c}\begin{array}{c}\text { BOLD/COLD } \\
\text { volunteers }\end{array} \\
\geq 40\end{array}$} & \multirow{2}{*}{$\begin{array}{c}\text { BOLD/COLD } \\
\text { data+spirometry } \\
\text { with } \\
\text { reversibility } \\
\geq 40\end{array}$} \\
\hline Age, years & 18 to 39 & $\geq 40$ & & \\
\hline \multicolumn{5}{|l|}{ Site } \\
\hline Vancouver & 648 & 1787 & 1034 & 878 \\
\hline Montreal & 798 & 1862 & 801 & 557 \\
\hline Toronto & 984 & 2735 & 875 & 546 \\
\hline Calgary & 328 & 1840 & 851 & 567 \\
\hline Halifax & 396 & 1867 & 913 & 454 \\
\hline Total & 3154 & 10,091 & 4474 & 3002 \\
\hline
\end{tabular}

BOLD/COLD Study Completers Summary

ACKNOWLEDGEMENTS: This work is supported by an unrestricted educational grant from AstraZeneca Canada, Boehringer Ingelheim Canada, GlaxoSmithKline Canada, and Pfizer Canada.

\section{REFERENCES}

1. The Canadian Community Health Survey. http://www.statcan.gc.ca/ concepts/health-sante/index-eng.htm

2. GOLD-Global Initiative for Chronic Obstructive Lung Disease. Global strategy for the diagnosis, management, and prevention of chronic obstructive pulmonary disease 2006. Available from: http:// goldcopd.org/Guidelineitem.asp?11 =2\&12=1\&intId=996

3. Buist AS, Vollmer WM, Sullivan SD, et al. The Burden of Obstructive Lung Disease Initiative (BOLD): Rationale and design. COPD 2005;2:277-8.

4. Tan W, Sin D, Balson D, et al. The burden of obstructive lung disease (BOLD) study in Vancouver, Canada - sampling and recruitment. Can Respir J 2007;14(Suppl A):7A-9A.

\section{The pattern of health services use in children with asthma - a 10-year review of population-based data from Ontario}

\author{
Teresa To PhD \\ The Hospital for Sick Children, Toronto, Ontario \\ teresa.to@sickkids.ca
}

\section{OBJECTIVE}

Asthma is the most common chronic childhood illness in North America. The purpose of the present study was to measure the burden of childhood asthma in Ontario from 1996 to 2005, by reviewing the patterns of asthma incidence, prevalence and health services use.

\section{METHODS}

An asthma algorithm with $84 \%$ sensitivity and $89 \%$ specificity was applied to the Ontario health administrative data to identify children with asthma (1). Children (younger than 20 years) were considered to have physician-diagnosed asthma if they had one or more hospitalization for asthma and/or two or more physician visits for asthma within a period of two years. Three major Ontario health administrative databases were used for measuring health services use. They include the hospital discharge abstract database (collected by the Canadian Institute for Health Information), physicians' billings (collected by the Ontario Health Insurance Plan) and the emergency room visit database (also collected by Canadian Institute for Health Information). Data were available from fiscal years 1996 to 2005. A fiscal year runs from April 1 to March 31 of the following year. From this 10-year period, the number of asthma prevalent cases in Ontario increased from slightly below 1 million to 1.67 million and $40 \%$ of them were in children aged 20 years or younger. 


\section{FINDINGS (TABLE 1)}

Hospitalizations for asthma

There was a dramatic decline in hospitalization rates for asthma from 1996 to 2005 for all children from 2.7 to 1.3 per 100 asthma individual, representing a $52 \%$ relative reduction. However, the decline was much smaller in preschoolers aged zero to four years (5.4 to 4.0 per $100,26 \%$ reduction).

\section{Emergency room visits for asthma}

Overall, in children younger than 20 years of age, there was a $37 \%$ decrease in emergency department (ED) visits for asthma (8.8 to 5.5 per 100) from 1996 to 2005 . However, the ED visit rate for asthma remained highest in preschoolers. In the 10-year period of study, there was practically no change in the ED visit rates in this youngest group in our population (14.3 to 14.1 per 100 ).

\section{Outpatient care for asthma}

In 2005, there were nearly 900,000 Ontario Health Insurance Plan claims for asthma. About $40 \%$ of them were for children younger than 20 years. Over the 10 -year observation period, there was a $40 \%$ decline in outpatient care for asthma in children from 1.0 to 0.6 asthma claims per individual with asthma. Again, in the very young, the rates showed a much smaller decline (1.6 to 1.4 claims per child with asthma, $12 \%$ decrease).

\begin{tabular}{|c|c|c|c|c|}
\hline \multirow{2}{*}{$\begin{array}{l}\text { Health services use for } \\
\text { asthma }\end{array}$} & \multirow[b]{2}{*}{ Year } & \multicolumn{2}{|c|}{ Age groups, years } & \multirow{2}{*}{$\begin{array}{c}\text { Total } \\
\text { Ontario }\end{array}$} \\
\hline & & 0 to 4 & 0 to 19 & \\
\hline \multirow[t]{3}{*}{ Hospitalization (per 100) } & 1996 & 5.4 & 2.7 & 3.7 \\
\hline & 2005 & 4.0 & 1.3 & 0.9 \\
\hline & $\%$ change & -26.3 & -52.2 & -75.3 \\
\hline \multirow[t]{3}{*}{ ED visits (per 100) } & 1996 & 14.3 & 8.8 & 7.4 \\
\hline & 2005 & 14.1 & 5.5 & 3.6 \\
\hline & $\%$ change & -1.5 & -37.4 & -51.4 \\
\hline Outpatient care & 1996 & 1.6 & 1.0 & 1.1 \\
\hline \multirow[t]{2}{*}{ (per individual) } & 2005 & 1.4 & 0.6 & 0.6 \\
\hline & $\%$ change & -12.2 & -37.6 & -50.0 \\
\hline
\end{tabular}

ED Emergency department

\section{SUMMARY}

While the 10-year review showed a stabilizing trend of asthma incidence in children, asthma still has a significant presence in children younger than 20 years of age, with $21.3 \%$ prevalence in 2005. The overall decrease in acute and primary health services for asthma is encouraging and may be explained by improvement in asthma control and management in the past decade. With proper management (use of appropriate medications, good control of symptoms, avoidance of triggers, etc), asthma exacerbations and the use of acute health services for that reason can be avoided. However, in children zero to four years of age, the use of both acute and primary health care for asthma remained substantial. While there is improvement in the level of use of health services for asthma, it is much less compared with older children and the rest of the population. Close monitoring of this most vulnerable age group is important to ensure their asthma is well managed and controlled.

ACKNOWLEDGEMENTS: Supported by funding from the Ontario Ministry of Health and Long-term Care and the Institute for Clinical Evaluative Sciences.

\section{REFERENCES}

1. To T, Dell S, Dick PT, et al. Case verification of children with asthma in Ontario. Pediatr Allergy Immunol 2006;17:69-76.

\section{Self-management: Motivational change to enhance behaviour modification}

\author{
Margot Underwood \\ Education Consultant, Calgary COPD \& Asthma Program, \\ University of Calgary, Calgary, Alberta \\ munderwo@ucalgary.ca
}

Self-management is an important strategy in chronic disease programs with the understanding that it can lead to improved health and quality of life. According to Lorig et al (1), self-management involves the person with the disease being actively involved in four key areas:

- engaging in activities that protect and promote health;

- monitoring and managing the symptoms and signs of illness;

- managing the impact of illness on functioning, emotions and interpersonal relationships; and

- adhering to treatment regimes.

Health care professionals such as respiratory physicians and Certified Respiratory Educators, who provide care and education in lung health programs, are interested in helping a person gain the confidence to more effectively self-manage their asthma or chronic obstructive pulmonary disease. Translating this knowledge into practice (regarding self-management and self-efficacy) often necessitates health team members developing higher-level communication skills.

A key communication skill is that of motivational interviewing (MI), a directive counselling intervention that can enhance communication with patients and facilitate positive behaviour changes (2). A central MI concept is that the patient is responsible for their behaviour change, therefore their expertise and experience is always honoured.

Gaining experience in the use of MI helps the health provider to listen attentively, think reflectively, then provide empathetic, nonjudgmental feedback. MI has been demonstrated to be especially useful in addressing ambivalence and resistance to change. Tools such as decisional balance worksheets can help an individual reflect on the pros and cons of a behaviour change and identify barriers that need to be addressed. Tracking cards and diaries will increase awareness of current behaviour or triggers in early stages and later will provide a means of tracking progress. Rating scales can be effectively integrated to help an individual identify their readiness to change, importance of the change and their personal confidence. It is also important to listen for change in language, such as, "I have been thinking about..." and consider how to integrate these statements when communicating back to the patient.

Listed below is a brief summary of the core MI strategies. Provided for each are examples of MI phrases that could be used in lung health education.

\section{Support self-efficacy}

Emphasize personal choice and control in behaviour change. Confidence and self-efficacy can be increased through incorporating past mastery experiences, integrating vicarious experiences and verbal persuasion (3).

- "What has worked for you in the past when you successfully quit smoking?"

- "You have identified, as have many others, that it helps to have a plan".

- "It's great that tracking your symptoms has helped you manage your asthma".

\section{Express empathy}

Learn to listen reflectively and then let the person know that their concerns have been heard.

- "It sounds like you are finding it difficult to believe that you have COPD". 
- "Dealing with this chronic cough seems to be really impacting your life".

- "You do not like having to sneak out for a smoke at home".

\section{Develop discrepancy}

In neutral tone and language, address the discrepancy between an individual's current behaviour and his/her stated values and interests. It can be helpful to listen for ambivalent statements such as "I want to, but..." and to provide reflective feedback to the individual.

- "So on one hand you find smoking pleasurable, but on the other hand you are worried about your increasing shortness of breath".

- "You want to have better asthma control, but are finding it hard to remember to use your inhaler".

- "Would you say that smoking is the only way for you to manage stress in your life?"

\section{Roll with resistance}

Avoid arguing and meet resistance with reflection. Reinforce that it is the patient's role to be the problem-solver.

- "I hear you. Right now you are not ready to quit smoking".

- "You don't like it when people pressure you to make changes".

- "It seems like this is a hard decision for you to make".

Motivational interviewing will help you to better understand a patient and their motives for changing a behaviour. Taking the time to attentively listen, use open-ended questions and provide thoughtful, empathetic reflections will help to build a bond with the individual. The information gained will then enable you to effectively assist the patient to develop and confidently use a tailored self-management plan.

More information on motivational interviewing and self-management can be found on these Web sites:

- Motivational Interviewing: www.motivationalinterviewing.org

- Stanford Patient Education Research Centre: www.patienteducation.stanford.edu

- Flinders Chronic Condition Management Program: www.flinders.edu.au

- Tobacco Reduction: www.smokingcessationrounds.ca

\section{REFERENCES}

1. Lorig KR, Sobel DS, Stewart AL, et al. Evidence suggesting that a chronic disease self-management program can improve health status while reducing utilization and costs: A randomized trial. Med Care 1999;37:5-14.

2. Rollnick S, Miller WR. What is motivational interviewing? Behav Cognitive Psychother 1995;23:325-34.

3. Bandura A. Self-efficacy: The Exercise of Control. New York: WH Freeman, 1997.

\section{Chronic ventilatory support in patients with chronic obstructive pulmonary disease}

\author{
Peter Jan Wijkstra MD PhD \\ Department of Home Mechanical Ventilation / Pulmonary Diseases, \\ University Medical Centre, Groningen, The Netherlands \\ p.j.wijkstra@int.umcg.nl
}

International guidelines have advocated that patients with COPD admitted to hospital with acute respiratory failure (ARF) due to an exacerbation, should receive non-invasive ventilatory support along with standard medical therapy. There is no such consensus on chronic noninvasive positive pressure ventilation (NIPPV) as findings of studies have been conflicting $(1,2)$. In the present short report we will discuss the various reasons why different outcomes might have been obtained.

\section{DISCUSSION}

Monitoring

One of the possible reasons for conflicting results is the lack of control of ventilation during the night. In contrast to many other negative studies, Meecham Jones et al (3) and Duiverman et al (4) did control ventilation by either transcutaneous partial pressure of arterial carbon dioxide $\left(\mathrm{PaCO}_{2}\right)$ or arterial blood gases, and found an improved gas exchange and health-related quality of life.

\section{Number of hours on NIPPV}

While use of NIPPV $2 \mathrm{~h}$ daily for five days a week (5), and for $3 \mathrm{~h}$ daily for five days a week for three consecutive weeks (6) both showed significant benefits in clinical parameters, Duiverman et al (4) showed that increased number of hours on bilevel positive airway pressure was related to a decrease in $\mathrm{PaCO}_{2}$. As the optimal duration of ventilatory support is still unknown, different approaches are still being used.

\section{Patient selection}

The three studies that showed improvements in arterial blood gases after NIPPV included patients with a higher level of hypercapnia $(3,6,7)$. Diaz et al $(6)$ and Clini et al $(7)$ selected only patients with a $\mathrm{PaCO}_{2}$ greater than $6.6 \mathrm{kPa}(50 \mathrm{mmHg})$. Even though Meecham Jones et al (3) allowed a lower cut-off point, the lowest baseline $\mathrm{PaCO}_{2}$ actually seen in patients included was $6.9 \mathrm{kPa}(52 \mathrm{mmHg})$. This suggests that the more hypercapnic patients benefit most.

\section{Mean inspiratory pressures}

When taking the levels of inspiratory pressure into account, it seems that the studies that targeted higher mean inspiratory pressure showed the greatest improvements in outcome measures, particularly in daytime blood gases $(3,4)$. These findings correspond to two uncontrolled studies by Windisch et al (8) and Budweiser et al (9), who both found significant reductions in daytime $\mathrm{PaCO}_{2}$ using high inspiratory pressures of $28 \mathrm{cmH}_{2} \mathrm{O}$ and $21 \mathrm{cmH}_{2} \mathrm{O}$, respectively.

\section{Survival}

The two long-term trials lasting one and two years, respectively, did not find any differences in survival between the long-term oxygen therapy group and the NIPPV group $(7,10)$. Because they used lower pressures of $12 / 4$ and 14/2, respectively, the lack of benefit could have been due to insufficient ventilation. An uncontrolled study by Budweiser et al (9) compared long-term survival of 140 patients with severe persistent hypercapnic chronic obstructive pulmonary disease with or without NIPPV (9). Mean inspiratory pressure was $21 \mathrm{cmH}_{2} \mathrm{O}$. Significantly higher survival rates were reported in patients with NIPPV $(87.7 \%$ and $71.8 \%$ ) after one and two years, compared with those without $(56.7 \%$ and $42.0 \%$ ). It should be noted, however, that the control group comprised patients who refused NIPPV or could not tolerate it.

\section{Compliance}

Meecham Jones et al (3) and Clini et al (7) both showed improvements in several outcome measures and had good compliance, with mean total hours spent on ventilation of $9 \mathrm{~h}$ and $7 \mathrm{~h}$ per night, respectively. Similar positive results were reported by Duiverman et al (4), for patients using the ventilator for more than $7.5 \mathrm{~h}$ per night. Good compliance can be obtained by giving the patient sufficient time to become familiarized with NIPPV in an in-hospital setting, where experienced staff can adjust ventilation to optimal standards.

In conclusion, evidence is insufficient to recommend chronic NIPPV on a routine basis to stable severe chronic obstructive pulmonary disease patients. We do believe that it could be of benefit to certain patient groups, such as hypercapnic patients. Effective monitoring during the night and giving the patient sufficient time to become familiarized with NIPPV are crucial issues in obtaining effective ventilation.

\section{REFERENCES}

1. Wijkstra PJ, Lacasse Y, Guyatt GH, et al. A meta-analysis of nocturnal noninvasive positive pressure ventilation in patients with stable COPD. Chest 2003;124:337-43.

2. Kolodziej MA, Jensen L, Rowe B, Sin D. Systematic review of noninvasive positive pressure ventilation in severe stable COPD. Eur Respir J 2007;30:293-306.

3. Meecham Jones DJ, Paul EA, Jones PW, Wedzicha JA. Nasal pressure support ventilation plus oxygen compared with oxygen 
therapy alone in hypercapnic COPD. Am J Respir Crit Care Med 1995; 152:538-44.

4. Duiverman ML, Bladder G, Wempe JB, Kerstjens HA, Zijlstra JG, Wijkstra PJ. Chronic ventilatory support improves the outcomes of rehabilitation in hypercapnic COPD patients. Thorax 2008;63:1052-7.

5. Renston JP, DiMarco AF, Supinski GS. Respiratory muscle rest using nasal BiPAP ventilation in patients with stable severe COPD. Chest 1994;105:1053-60.

6. Diaz O, Begin P, Torrealba B, Jover E, Lisboa C. Effects of noninvasive ventilation on lung hyperinflation in stable hypercapnic COPD. Eur Respir J 2002;20:1490-8.

7. Clini E, Sturani C, Rossi A, et al. The Italian multicentre study on noninvasive ventilation in chronic obstructive pulmonary disease patients. Eur Respir J 2002;20:529-38.

8. Windisch W, Kostic S, Dreher M, Virchow JC Jr, Sorichter S. Outcome of patients with stable COPD receiving controlled noninvasive positive pressure ventilation aimed at a maximal reduction of $\mathrm{Pa}(\mathrm{CO} 2)$. Chest 2005;128:657-62.

9. Budweiser S, Hitzl AP, Jorres RA, et al. Impact of noninvasive home ventilation on long-term survival in chronic hypercapnic COPD: A prospective observational study. Int J Clin Pract 2007;61:1516-22.

10. Casanova C, Celli BR, Tost L, et al. Long-term controlled trial of nocturnal nasal positive pressure ventilation in patients with severe COPD. Chest 2000;118:1582-90.

\section{Interstitial lung disease in scleroderma}

Pearce Wilcox MD

Respiratory Division, St Paul's Hospital, University of British Columbia, Vancouver, British Columbia

pwilcox@providencehealth.bc.ca

Interstitial lung disease (ILD) in systemic sclerosis (SSc) is highly prevalent, with clinically relevant disease occurring in $20 \%$ to $40 \%$ (1). Outcomes are worse in SSc patients who manifest ILD. Considerable pulmonary disease heterogeneity exists, however, and an ability to identify those most likely to progress would be valuable. Goh et al (2) have developed a relatively simple clinical staging system and found that those with extensive lung disease based on a high-resolution computed tomography (HRCT) disease activity score of greater than $20 \%$, or in indeterminate cases, forced vital capacity less than $70 \%$ predicted, are much more likely to progress. Earlier retrospective studies had suggested that an 'active alveolitis' based on bronchoalveolar lavage identified those more likely to worsen (3). However, in a recent large prospective SSc cohort, bronchoalveolar lavage parameters did not prove to be independent predictors of either disease progression or response to therapy (4).

Given this conflicting and limited information, we advocate incorporating composite measures including HRCT scores, lung function testing, serology, time from onset of diagnosis and, importantly, rate of progression when deciding whom to prioritize for therapy.

\section{THERAPY}

To date, the therapeutic literature for SSc has been most notable for the number of negative studies. Thus, the results of the Scleroderma Lung Study (SLS) (4), which sought to evaluate cyclophosphamide in a prospective placebo-controlled design, were anxiously awaited. In this study, there was a statistically significant difference in favour of the cyclophosphamide group in the primary outcome parameter (vital capacity [VC]) and also in other secondary outcomes of total lung capacity, dyspnea score, quality of life and skin thickness scores. The clinical significance, however, has been correctly questioned given the very small differences in VC, and the fact that diffusing capacity did not differ. A decision has to be made on an individual basis, which incorporates the appreciable potential toxicity of cyclophosphamide (marrow suppression, bladder toxicity, infection risk, malignancy potential and gonadal suppression). One means of potentially reducing these risks is to use pulse intravenous dosing of cyclophophamide (5).

Other data subsequently reported from the SLS help in understanding the longer term course of patients. In one further year of follow-up, in essence without therapy, there was a progressive improvement in VC seen in the former cyclophosphamide group up to 18 months; by 24 months, it had returned to the level of placebo patients (6). This has been interpreted as indicating that one year of cyclophosphamide does not modify the natural history of SSc ILD. If treatment is to be initiated, one year would seem insufficient in duration. Another interesting observation in this study was that the degree of ground glass HRCT changes had little predictive value, but that those with more fibrosis at baseline were more likely to respond to cyclophosphamide.

The very modest benefits of cyclophosphamide, when placed in the context of potential adverse effects, has driven the search for other therapies. Mycophenolate mofetil has biological plausibility, a reasonable safety profile, established efficacy in other disease states and a number of retrospective case series that have been promising in SSc ILD (7). Increased oxidant stress has been shown in SSc (8) and can drive disease progression in other ILD, providing rationale for further study in SSc ILD. Gastroesophageal reflux and aspiration is an almost invariable occurrence in SSc and can accelerate lung disease in idiopathic ILD. Treatment can be problematic but attempts to at least minimize this complication should be a routine part of therapy. A number of other agents are attracting attention in SSc ILD such as novel antifibrotics, biologics and even stem cell therapy, with a multicentre North American study already underway.

\section{ILD AND PULMONARY HYPERTENSION}

Pulmonary hypertension $(\mathrm{PH})$ is a well-recognized complication in SSc and one that has a high mortality (9). ILD itself can be a cause of PH; however, there exists a group of patients with ILD who have 'disproportionate' $\mathrm{PH}$. The management of these individuals remains controversial, but evaluation for PH in ILD should be routine. It is notable that some in vitro data suggest that therapies used in $\mathrm{PH}$, such as endothelin receptor antagonists, may have an antifibrotic effect.

\section{SUMMARY}

ILD in SSc is a common occurrence and an important cause of morbidity and mortality. The challenges remain not so much in its detection but in the decision of whom to treat with therapies that have limited potency and considerable potential adverse outcomes. Newer treatments are clearly required and a partnership among respiratory physicians, rheumatologists and $\mathrm{PH}$ specialists is necessary to properly evaluate and institute them.

\section{REFERENCES}

1. Ferri C, Valentini G, Cozzi F, et al. Systemic sclerosis: Demographic, clinical, and serologic features and survival in 1012 Italian patients. Medicine (Baltimore) 2002;81:139-53.

2. Goh NS, Desai SR, Veeraraghavan S, et al. Interstitial lung disease in systemic sclerosis: A simple staging system. Am J Resp Crit Care Med 2008;177:1248-54.

3. Behr J, Vogelmeirer C, Beinert T, et al. Bronchoalveolar lavage for evaluation and management of scleroderma disease of the lung. Am J Resp Crit Care Med 1996;154:400-6.

4. Tashkin DP, Elashoff R, Clements PJ, et al. Cyclophosphamide versus placebo in scleroderma lung disease. N Engl J Med 2006;354:2655-66.

5. Hoyles RK, Ellis RW, Wellsbury, et al. A multicenter prospective, double-blind, placebo-controlled trial of corticosteroids and intravenous cyclophosphamide followed by oral azathiaprine for the treatment of pulmonary fibrosis in scleroderma. Arthr Rheum 2006;54:3962-70.

6. Tashkin DP, Elashoff R, Clements PJ, et al. Effects of 1-year treatment with cyclophosphamide on outcomes at 2 years in scleroderma lung disease. Am J Resp Crit Care Med 2007;176:1026-34.

7. Gerbino AJ, Gross CH, Molitor JA. Effect of mychophenolate mofetil on pulmonary function in scleroderma-associated interstitial lung disease. Chest 2008;133:455-60.

8. Musellim B, Ikitimur H, Uzun H, Onegen G. The oxidantantioxidant balance in systemic sclerosis cases with interstitial lung involvement. Rheumatol Int 2006;27:163-7.

9. Condliffe R, Kiely DG, Peacock AG, et al. Connective tissue disease associated pulmonary arterial hypertension in the modern treatment era. Am J Resp Crit Care Med 2009;179:151-7. 


\section{CONFLICTS OF INTEREST}

Dr Shawn Aaron: is supported by funding from the Canadian Institutes of Health Research; Dr Darryl J Adamko, Dr Ramses Illaraza, Yingqi Wu: this work is supported by funding from the Canadian Institutes of Health Research and Merck-Frosst Canada; Dr Mark Anselmo: none to report; Dr Jane Batt: none to report; Donna Bleakney: none to report; Dr Louis-Philippe Boulet: none to report; Dr T Douglas Bradley: is supported by funding from the Canadian Institutes of Health Research; Dr Anna Day: none to report; Dr Neil D Eves: none to report; Dr Kathleen A Ferguson: none to report; Dr Richard J Finley: is supported by funding from the British Columbia Lung Association; Dr Ian D Graham, Jacqueline M Tetroe: none to report; Dr Hartmut Grasemann: none to report; Dr Samir Gupta: is supported by funding from the Li Ka Shing Knowledge Institute of St Michael's Hospital, Toronto, Ontario; Dr Kylie Hill: none to report; Dr Rick Hodder: none to report; Dr Nader Khalidi: none to report; Dr Stephen Lam: none to report; Dr Larry C Lands: none to report; Dr Denny P Laporta: none to report; Dr France Légaré: holds the Canada Research Chair in Implementation of Shared Decision Making in Primary Care; Dr Piush J Mandhane, Neil W Johnston, Malcolm R Sears: none to report; Dr Darcy D Marciniuk: is a Lung Association of Saskatchewan COPD Professor, and University of Saskatchewan/Saskatchewan Health Research Foundation Airway Research Group Member; Nora Sobolov: none to report; Dr Douglas A McKim: none to report; Louise McRae: none to report; Dr Sanjay Mehta: none to report; Dr Marc Miravitlles: Boehringer Ingleheim and Pfizer Canada provided funding for Dr Miravitlles' participation in the conference; Dr Denis E O’Donnell, Dr Josuel Ora: this work was supported by the Ontario Ministry of Health and the Ontario Thoracic Society; Dr Steeve Provencher: is a clinical scientist of the Fonds de Recherche en Santé du Québec. He has received lecture fees from Actelion Pharmaceuticals Canada Inc, Encysive Canada Inc, Pfizer Canada Inc, and received consultant fees from Actelion Pharmaceuticals Canada Inc, Eli Lilly Canada Inc, Encysive Canada Inc, Glaxo-Smith-Kline Canada Inc and Pfizer Canada Inc; Dr Pramod S Puligandla: none to report; Dr Felix Ratjen: none to report; Dr Jeremy Road, Dr John Yee: none to report; Dr C Frank Ryan: none to report; Dr Malcolm R Sears: this work is supported by the CIHR and the AllerGen Network of Centres of Excellence; Dr Don D Sin: is supported by funding from ICEBERGS (Interdisciplinary Capacity Enhancement: Bridging Excellence in Respiratory disease and Gender Studies), which is funded by The Canadian Institutes of Health Research; Dr Judith Soicher: is supported by funding from the Canadian Institutes of Health Research, Fonds de la recherche en santé du Québec, and the Lung Association; Dr Wan C Tan, Dr Jean Bourbeau, Dr Kenneth Chapman, Dr Robert Cowie, Dr Paul Hernandez, Dr Mark FitzGerald, Dr Don Sin: this work is supported by an unrestricted educational grant from AstraZeneca Canada, Boehringer Ingelheim Canada, GlaxoSmithKline Canada, and Pfizer Canada; Dr Teresa To: supported by funding from the Ontario Ministry of Health and Long-term Care and the Institute for Clinical Evaluative Sciences; Margot Underwood: none to report; Dr Peter Jan Wijkstra: none to report; Dr Pearce Wilcox: none to report. 


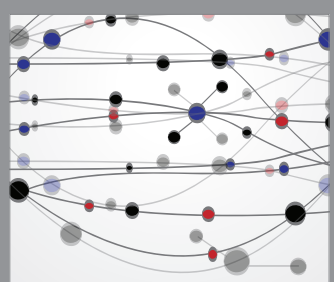

The Scientific World Journal
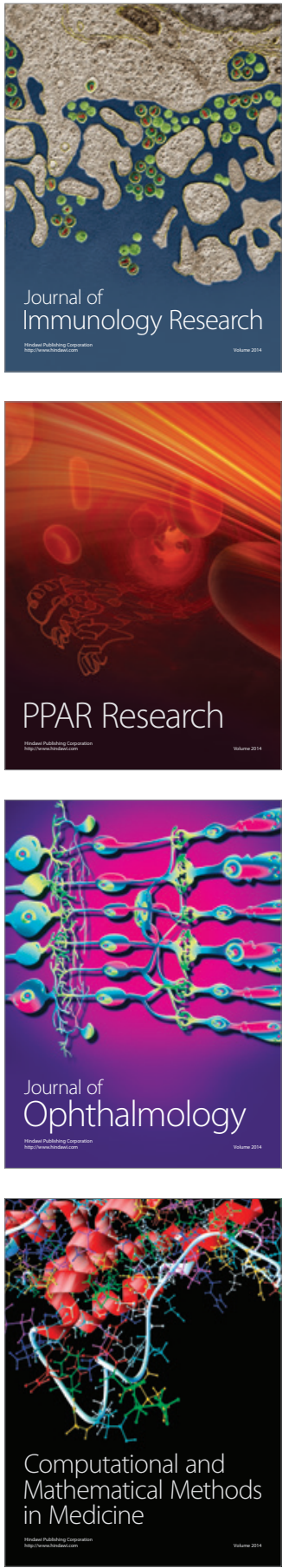

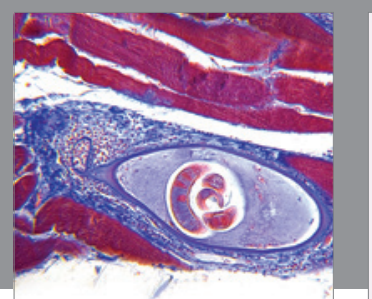

Gastroenterology Research and Practice

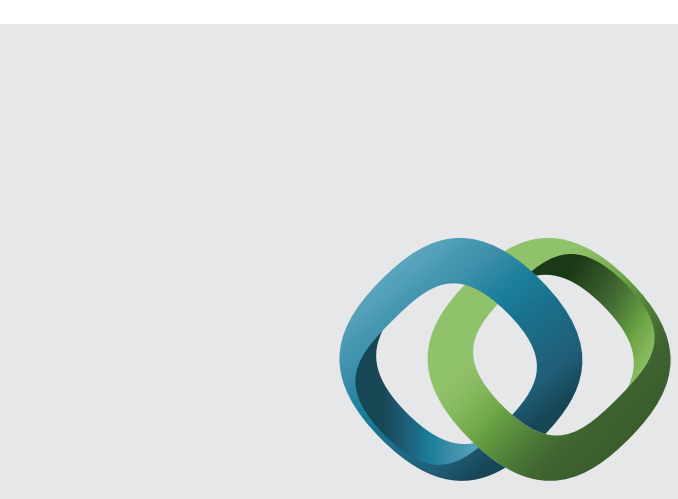

\section{Hindawi}

Submit your manuscripts at

http://www.hindawi.com
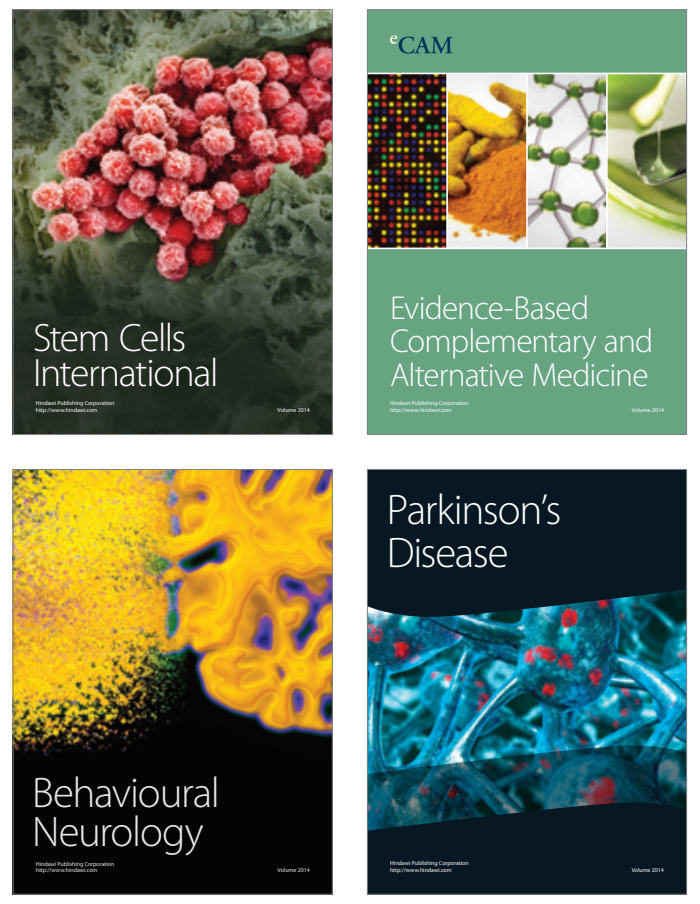
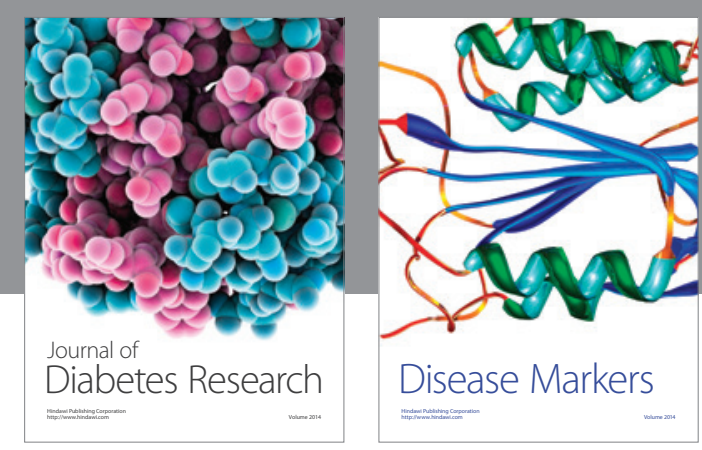

Disease Markers
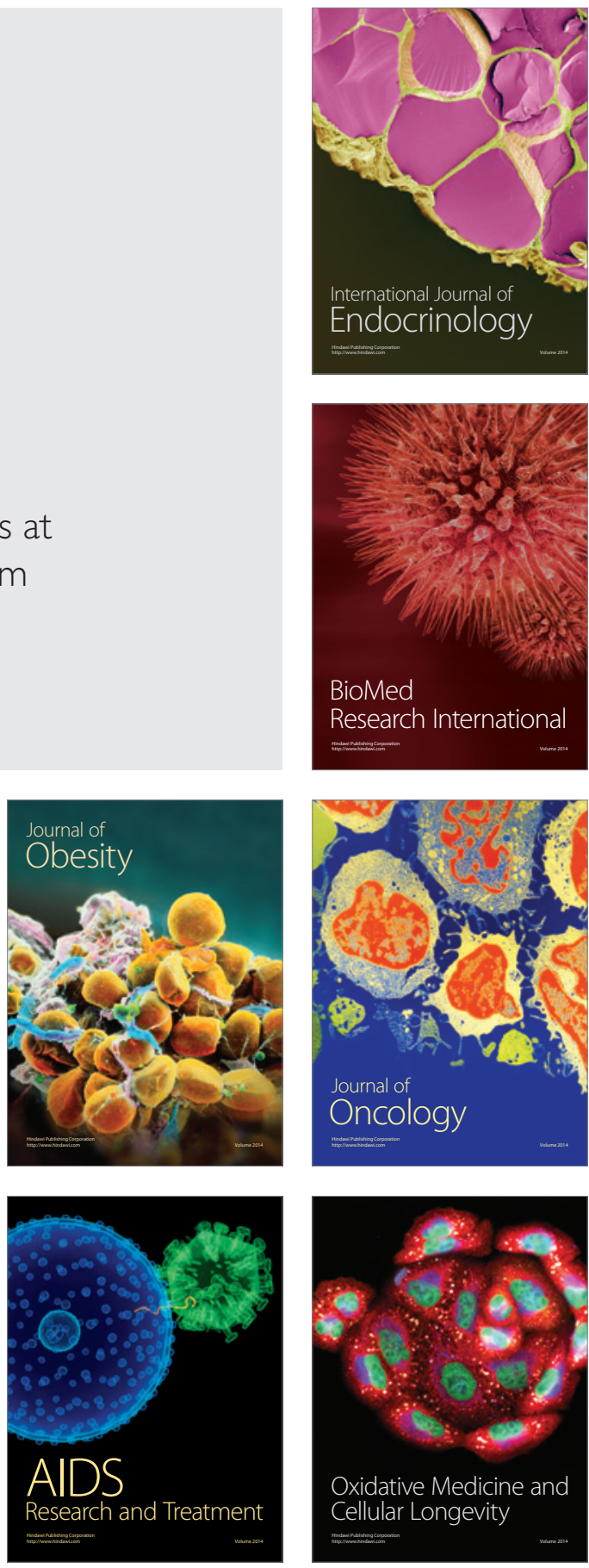